\title{
GLEANINGS IN OLD
}

\section{GARDEN LITERATURE}

IV. C. HAZLITT

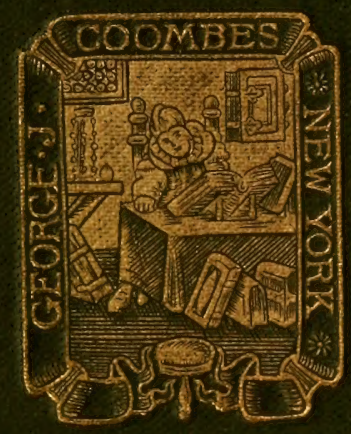




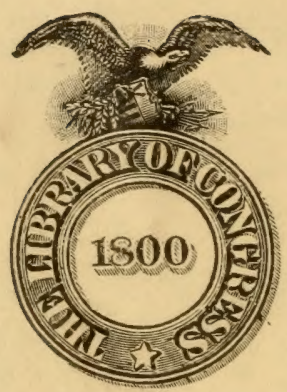

Olass $S B 455$

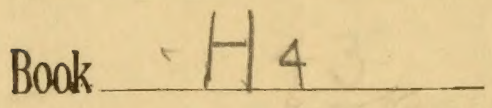

By bequest of copy William Lukens Shoemaker 



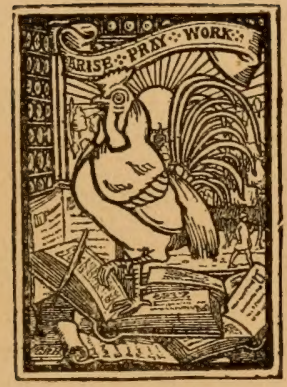




\title{
The Book-Lover's Library.
}

Edited by

\author{
Henry B. Wheatley, F.S.A.
}




\section{GLEANINGS IN}

\section{OLD GARDEN LITERATURE}

BY

W. CAREW HAZLITT

Author of "Old Cookery Books

\section{8}

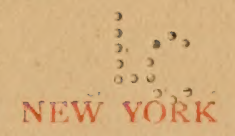

GEORGE J. COOMBES, 275, FIFTH AVENUE I 887 


$$
\int^{5} 3^{x^{5^{5}}} x^{x}
$$

Gift.

Hillian L. Shoemarer.

7 SEF 1906

$\because \vdots \vdots \vdots$ 


\section{CONTENTS.}

PAGE

I. Preliminaries - * • • - I

II. Literary Antiquities-The VocabuLARIES-THE FirST ENGLISH WORK ON GARDENING • • • • • II

III. Elizabethan Gardening-The EarLiest Gardener's Calendar BaCON AND Evelyn . . 22

IV. The French AND DutCh SchoolsEvelyn aNd THE "French GaRDENER" - His "SyLVA" - JOHN WORLIDGE-GARDENING IN SCOTLAND . . . . . . 34

V. Herbals, Physic-Gardens, and Bees 46

VI. The Kitchen-Garden - Alexander Neckam and JohanNes de GaRlandia - The Gardens at Sheen, Greenwich, and Somerset House - Sir William Temple's Garden at Sheen-Kew Gardens-GarDENS IN AND ABOUT LONDON IN I69I 
-Early Catalogues of Plants-

THE DUKE OF BedFord's Botanical

Publications • • • • 54

VII. The Ancient and Modern Arbour

-Grottoes-Garden Life • . 72

VIII. Window-GaRde NING-CotTAGE GAR-

DENS IN I677-INFLUENCE OF ASTROLOGY - WARMING APPARATUS -

VARIEgation OF Foliage • . 78

IX. Bacon as a Gardener • . . 90

$X$. Herbs and Vegetables - High

Price of Vegetables in Early

Times - The Suburbs of London Celebrated as a Growing-Ground

-Rarity and Estimation of the Potato - Asparagus - Sanitary

Value of Vegetables • • • II5

XI. Fruit-Trees - Home-Made WineBeEr - Bacon and Shakespeare on the Strawberry . . .

XII. Fruit-Trees (continued)-The Peach, the Quince, the Medlar, the Pine-Apple, and the Pomegranate-Introduction of the Black Mulberry - RHubarb - LemonsThe Tool-House-Espaliers and Pruning-Forest Trees-Ancient Survivals - Hooke's " MicroGRAPHIA " AND MOSSES . . . 142 
XiII. Flora-The Tulip, the Rose, the riGIS JESSAMINE-ABERCROMBIE'S Works, I6I XiV. Market Gardens in the Suburbs OF LONDON - TESTIMONY OF AN ITALIAN VISITOR IN I6I4--NURSERIES AND GROUNDS AT Ot.d BRoMP. TON, Fulham, Battersea, AND DEPTFORD . • • • . . 169

XV. Sir William Temple-Walpole and the Gakdeners of the Ejght. eenth Century • • . . i 82

XVI. Bibliography OF Gardening LiteratURE (1603-I800), AND OF Herbals and BeE Culture-William and Samuel Curtis - Janies and George Sowerby-The Lindleys ANDLOUDONS-CRYPTOGAMIC FLORA OF SCOTLAND-SIRWILLIAM JACKSON HOOKER . . . . . . 203

APPENDIX

INDEX 



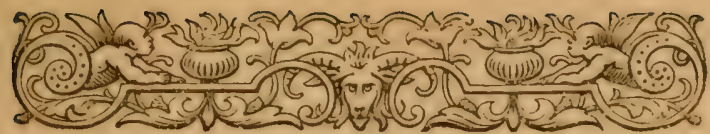

GLEANINGS

IN

OLD GARDEN LITERATURE.

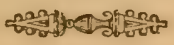

I.

PReLIMINARIES.

NG RS. MATTHEWS, in her Memoirs of her husband, 1839, mentions the gratification which it afforded Coleridge, when he came from the Gilmans', to visit them at Highgate Hill, to walk round the garden and gather a handful of flowers to take home with him.

We know how some of the wisest and best of mankind have delighted in gardens. Even such an inveterate Londoner as Charles Lamb, when he went down to live at Edmonton, took a pleasure in superintending the 


\section{Gleanings in Old Garden Literature.}

small plot of ground behind his house there, and watched with interest the progress toward maturity of his Windsor pears and jargonelles.

How affectionately attached to their gardens and the pursuits connected with the culture of trees, fruits, and flowers Bacon, Evelyn, Temple, Walpole, and other eminent Englishmen have been, it will form part of my duty in the following pages to demonstrate.

General Lambert, who was lord of the manor of Wimbledon in $165 \dot{6}$, was very fond of his garden at that place, and grew, it is said, the finest tulips and gilliflowers procurable. It is to his passion for this pursuit that he owed his place on a pack of satirical cards published during the Commonwealth, where the Eight of Hearts bears a small full-length of him, holding a tulip in his right hand, with "Lambert Kt. of $y^{\mathrm{e}}$ Golden Tulip" beneath. $\mathrm{He}$ had withdrawn into what was then the country from political life; but, amid his recreations as a florist, was doubtless watching the opportunity for a return to the field 
of his professional work. Next to Monk he was probably the most able of the generals of the Commonwealth and Protectorate, and it was an error on the part of Cromwell to have estranged him. But to his temporary retirement we owe this little glimpse of his taste for a pursuit more genial and more humane than that of war.

The earliest human scene is laid in a garden. The Old Testament contains numerous allusions to gardens. Throughout Oriental literature and folk-lore, and in most of the stories derived from the East, a garden occupies a conspicuous position; and likewise in the mythology of other countries we find legendary or traditional witness to the instinctive love of our race toward the neighbourhood of verdure and shade, toward whatever vegetation conditions of temperature and climate begot.

"God Almighty," says Bacon, "first planted a garden; and, indeed, it is the purest of human pleasures; it is the greatest refreshment to the spirits of man; without which buildings and palaces are but gross handy-works; and a man shall ever see that, 


\section{Gleanings in Old Garden Literature.}

when ages grow to civility and elegance, man comes to build stately sooner than to garden finely : as if gardening were the greater perfection."

Modern science has brought our gardens to their present state, and the development of society evolved from the ancient and original idea of plantations for the general benefit, of which we seem to have a sort of foreshadow in the Book of Genesis, the conception of enclosures dedicated to particular service. Our nature, modified by circumstances and interests, gradually outgrew its contentment with the free and unrestricted use of the fruits of the earth, and each man or each tribe claimed and held, personally or in common, the ground adjacent to the dwelling or the settlement.

Centuries elapsed before the garden became what we see it; and at the present moment every country is governed in its system of planting, and in its principles of cultivation and husbandry, by the resources of its soil and the demands of its population.

The dawn of the British primeval life was spent amid dark and boggy forests, and 
on the barren and interminable moor, in a harsh and precarious climate, with slender opportunities of development within, and the scantiest external communications. Our knowledge of their social organisation is very slight, and is almost entirely drawn from the imperfect testimony of Cæsar. But we obtain no insight, from that or any other source, into their mode of preparing such portions of their food as depended on the cultivation of the ground.

The ancient English garden was, indeed, as widely divergent from those to which our eyes have grown accustomed, as the hanging terraces of Babylon or the Platonic groves of Athens. There was, till the sixteenth century at least, no attempt at artistic arrangement or methodical distribution. The fruit and forest trees seem to have grown side by side; and the flower-borders and beds would have fallen very short of modern demands, or even of the views of the men who introduced into our country the foreign schools of horticulture. But the fifteenth century saw something like an advance in the direction of separation 


\section{Gleanings in Old Garden Literature.}

and order, for we hear of the orchard and the herbary; and another useful institution was the midden or muck-hill.

I can do no more within the restricted space which is accorded me, than call attention to the very admirable picture which Mr. J. A. St. John has drawn of the system of horticulture and floriculture among the Greeks, in his Manners and Customs of Ancient Greece (I842); and, to some extent, the English versions of the Charicles and Gallus of Bekker will prove of service to the student.

Perhaps the best summary of this subject of gardening among the Ancients is that of Sir William Temple, in the second part of his Miscellanea, in the very valuable paper headed "Upon the Gardens of Epicurus; Or, Of Gardening in the Year I685."

Every reader is familiar at least with the reputation of the Georgics of Virgil, which, with Hesiod, Varro, and the other Rei Rustica Scriptores, form the source to which we must go for information on the subject in hand; and during the medixval period such 


\section{Preliminaries.}

writers as Petrus de Crescentiis of Bologna, whose Ruralia Commoda appeared at Florence in $147 \mathrm{I}$, helped to carry down the old Roman traditions and experiments, and constituted a link between ancient and modern agricultural economy.

Until certain later publications enjoyed a long run and experienced a succession of issues during forty or fifty years, - even when they had been, in some measure, superseded, like Mrs. Loudon's botanical manuals, - the books on gardening do not appear, as a rule, to have had a very prolonged life, or to have often passed into a second impression. Evelyn's Kalendarium Hortense, whṭch first came out in 1664 , and arrived at a tenth impression in 1706 , was an exceptional longliver.

This fact may be possibly explained by the preference of those, who felt an interest in the subject, for actual practice, and the appeal of the majority of publications to the book-buyer rather than the horticulturist. Besides, the proportion of persons of both sexes, whose education enabled them to 


\section{Gleanings in Old Garden Literature.}

study technical works, was relatively small; and the great commercial success of such productions in a sister art-that of cookery -as The Book of Cookery, Mrs. Glasse, and Mrs. Rundell, may have been due, to some extent, to the more general patronage of private female buyers. The cook, both professional and amateur, has always perhaps been more disposed to work by book than the gardener, whose operations are more dependent on circumstances.

A notion has, I think, prevailed for a long time in this country that Evelyn was the first writer on tree-culture and gardening among us, just as Mrs. Glasse was the pioneer in the literature connected with the culinary art, and the author of the Pilgrim's Progress the earliest writer of allegory! General readers -by which ought to be understood gentlemen and ladies who generally don't read-do not care to go back too far into the dim past, and for them Mr. Evelyn and Mrs. Glasse are old enough; just as Johnson's Dictionary is, for aught they know or care, the earliest book of the kind, and Johnson himself as much of 
an antique as if he had been the author of the Promptuarium Paroulorum. They must have their chronological terminus. Their past must be a known quantity. It is a symptom of an unhealthily restless mind to question the date assigned in the common dictionaries to the exodus from Eden.

The truth is, that when the illustrious Evelyn began to manifest an interest in those subjects with which his name is so affectionately connected, and when the hardly less renowned Mrs. Glasse took hers in hand, Englishmen had for many centuries attained a very fair proficiency in the twin sciences of cookery and arboriculture.

Specialists in horticulture, as well as in other sciences, are sometimes apt to be jealous of each other, and intolerant alike of too much excellence in their professional brethren and too little. The author of a monograph on the cultivation of the auricula gives us to understand that many of the gardeners of his time were "blue-aproned pretenders,"-a curious point, because such an article of dress long continued to form 
IO Gleanings in Old Garden Literature. one of the external insignia of the cloth, and has at last been transmitted as an heirloom to the florist's cousin-german, the greengrocer.

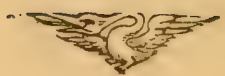




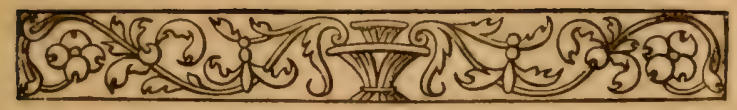

II.

Literary Antiquities - The VocabulaRIES-The First ENGLISH WORK ON GaRdening.

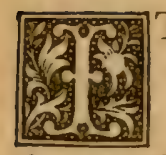

$T$ cannot be very surprising to find the firstfruits of gardening literature tinctured by the prevailing superstitions of the day about astronomical influences. In the library of Trinity College, Cambridge, is the poem of John the Gardener, written in the fourteenth century, and the most ancient production of the sort in our language. It was to have been edited for the Early English Text Society by Mr. Aldis Wright; but the plan was not carried out. I regret that $I$ have not seen it. But even at a much later period the faith in astrology governed the operations of the gardener, as we can easily judge from the tract in the 


\section{2 Gleanings in Old Garden Literature.}

Porkington MS. (fifteenth century), ${ }^{1}$ entitled A Treatise for a man to know which time of the year it is best to graft or to plant trees, and also to make a tree to bear all manner of fruit of divers colours and odours, with many other things.

This compilation sounds voluminous, but it occupies only ten small octavo pages in type. You are instructed what you should do under sundry signs of the zodiac, and lessons are given in pruning and grafting. A good deal of it seems to be abstracted from Aristotle and Palladius; but the under-quoted reads like a little trait of primitive English whimsicality :-

"Also, for to make that a pearl, or a precious stone, or a farthing, or any other manner of thing be found in an apple, take an apple or a pear, after it has flowered, and somewhat waxen, and thrust in hard at the bud's end which one thou wilt of these things aforesaid, and let it grow, and mark well the apple that thou didst put in the thing, whatever it be."

Some very fanciful ideas are advanced

${ }^{1}$ Early English Miscellanies, Warton Club, I855, pp. 66-72. 
here on the subject of grafting, and great stress is laid on the use, not only in that process, but where a limb was severed from any tree, of a bandage of clay to exclude the air and prevent hæmorrhage. It is evident that in the fifteenth century a taste prevailed for novelties and hybrids : how to grow cherries without stones, how to have peaches with kernels like nuts, how to make a peach produce pomegranates; and the same ingenious experiments were made in the flowergarden.

The first regular treatise on gardening was the work, not of a technist, but of a man of letters, Thomas Hill, a native and inhabitant of London, but at a time when the limits of the City were infinitely more contracted than now, and even Holborn was regarded as a suburb. It appeared in or about 1560 , and was often republished. But it is scarcely a satisfactory performance, as Hill fills up a good deal of his not very substantial volume with passages from ancient writers; he belonged to the old school, which loved to begin at the beginning. But luckily he 


\section{I4 Glcanings in Old Gardcn Literature.}

draws the line at the Old Testament, and chiefly cites Varro and Columella; and whatever the shortcomings of Hill's work may be, it marked an advance in horticultural knowledge, and presents some valuable suggestions for the position and arrangement of a garden. He recommends that the garden should be near to a plain or level field, or should be, if possible, on a slope, with courses of water flowing through it, and in default of this, that there should be either a well or a pond within its limits. We find careful directions for planting, sowing, and other operations; an account of the medicinal virtues of certain herbs; advice as to hedges, of which Hill prefers one composed of briars and thorns; and two schemes for forming a maze, a round and a square one. We have learned to identify this as a feature peculiar to Hampton Court and a few other historical places; but it was once considered an ordinary adjunct to pleasuregrounds of any pretension or size. These mazes were contrived by the gardener, and seem to have been very usually rendered 


\section{First English Work on Gardcning. I 5}

useful as well as ornamental and decorative, by consisting of kitchen herbs. It might have been judged, from the low growth of the latter, that the structure was of a different kind from that with which we have grown up acquainted; but Hill clearly says that the object was "to sport there at times," so that the rosemary and other plants must have been trained in some particular manner, to carry out our idea of such a thing.

The taste for the capricious and fantastic in the disposition of the garden and ornamental grounds was probably imbibed by noble or rich Englishmen, who brought back with them a desire to imitate fashions which they had seen abroad. The mazes which Hill introduces into his earlier book were elaborated by him in one called the Gardener's Labyrinth, which he did not live to complete, and which was published in 1577 by Henry Dethicke. But the designs in this volume appear to have been borders devised in various forms, and not the piece of intricacy for persons to disport themselves, and the title-page explicitly declares 
I6 Gleanings in Old Garden Litcrature.

that the following pages dealt, inter alia, with "divers herbers [arbours], knots and mazes, cunningly handled for the beautifying of gardens."

These artifices, which modern feeling has by no means eschewed, had of course a tendency to excite competition, and it was the aim of every artist to outdo his predecessor. As it is not a production which belongs to the chronological series, I shall take the opportunity to indicate as a curiosity the engraved views of the gardens at Wilton, which were laid out probably by Isaac de Caus, an engineer and a native of Dieppe, for Philip, Earl of Pembroke and Montgomery, about $\mathrm{I} 645$, and are at all events described by De Caus in a series of engravings called Hortus Penbrochianus, ou Le Jardin de Wilton.

It is, no doubt, to be regretted that there are not other graphic representations of early English gardens, besides those at Wilton, Cobham, etc. In his Gleanings on Gardens (1829), Felton supplies us with some highly interesting glimpses of the ornamental grounds 
which once abounded even in London and its immediate vicinity; his pages are professedly experimental and tentative; and he laments that even then it would have been probably vain to acquire an accurate and complete pictorial view of the horticultural achievements and progress of our ancestors. The chief difficulty which Felton perceived was the cost of properly executing such a work ; but to that difficulty is now superadded, in numerous instances, a second still more insuperable-the disappearance of the material, the gardens themselves.

Let us take an illustration from such a place as Twickenham House, once the residence of Sir John Hawkins, at a more recent time and until quite lately that of Dr. Diamond, who loved to gather round him all the men of taste and culture of his acquaintance on Sundays. Every one who had the entrée was at liberty to come every week, if he chose; and the talk over and after dinner, which was at half-past three, was of old china, old books, old friends, and old recollections. 
I 8 Gleanings in Old Garden Literature.

The present writer has met under that roof Durham and Woolner, the sculptors, Hepworth Dixon, Cordy Jeaffreson, and many more men of mark in their respective ways. But the house and its grounds will soon be numbered with the things of the past, and nearly all those who contributed to make the Sundays pleasant and profitable, including the Doctor himself, are no more.

But I must confine myself to my more immediate point. In the Thames Valley Times of February 2nd, I 887 , occurs this paragraph :-

"The threatened ravages of the builder in the grounds of Twickenham House seem specially unwelcome, not only because of associations, but also on account of the extreme beauty of the ancient turf, which, in the times to which we have referred, was a finely-kept lawn of exceptional verdure and springiness. Like stately trees, such singularly rich turf is the result of time, suitable soil, and careful conservation, as those well know who are familiar with the verdant beauty of the lawns of the ancient Oxford Colleges. The grounds are also interesting on account of an extraordinary and luxurious growth of all kinds 


\section{Leonard Mascall.}

of old herbs, and a curious fence of sword-blades, which are said to have been collected on the field of Culloden."

Such notices as these, brief and imperfect as they are, of the numerous seats in early suburban London, more especially in Old Brompton, Kensington, Putney, and Fulham, are what we should have desired to possess, and are sorry to have lost for ever, except in a few isolated and accidental cases, or to such a limited extent as Felton has rescued them from oblivion.

A conversance with the arts of planting and grafting was promoted by a curious Elizabethan publication, which purports to have been rendered into English from two distinct sources-a French book by a brother of the Abbey of St. Vincent, and a Dutch one, of which the author is not suggested. The English editor was Leonard Mascall, and the volume became popular. It doubtless supplied a want, and was reprinted several times between $x_{569}$ and ${ }_{596}$. Mascall, who is known as the compiler of two or three other treatises on husbandry and 
angling, set forth his gardening manual under this title:-A Booke of the Arte and Maner howe to plant and graffe all sortes of trees, honve to set stones, and sorve Pepines to make zoylde trees to graffe on, as also remedies and medicines. With divers other new practises, with an Addition in the ende of this Booke, of certaine Dutch practises.

This production owes its chief value to the fact that it is seemingly the parent attempt to enlarge the still narrow enough experience of our native gardeners by enabling them to see in print, if not in actual working, what was being done in the same direction abroad, and not only in France, with which the English had always had tolerably close relations, but in the Netherlands, where the science of horticulture was receiving greater attention than at any former period.

But it does not appear that the Dutch ideas met at this time with much favour at our hands. Those who did not admire French models for laying out their grounds had recourse to the Italian; and there were some who adopted a sort of compound of 


\section{Various Schools of Gardening. 2 I}

various styles, or struck out an original programme for themselves, as Bacon may perhaps have done, if the notions broached in his essay Of Gardens were carried by him into effect at home. 


\section{III.}

Elizabethan Gardening-The Earliest Gardener's Calendar-Bacon and Evelyn.

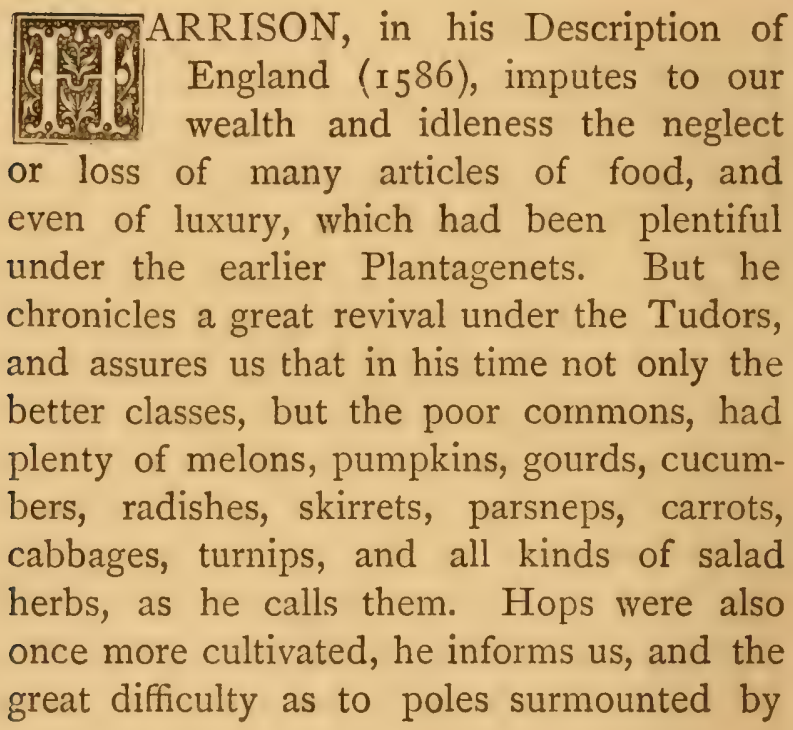


the establishment of ashyards, whence the hop-growers could be supplied from season to season. Tusser, before Harrison's time, lays down regulations for the culture of the hop and the arrangement of hopyards; but perhaps the earliest monograph on the subject is that of Reginald Scot, who published his Perfect Platform of a Hop Garden in I574. ${ }^{1}$ It seems, from Harrison's account, that our gardens in Elizabeth's reign were beginning to wear a very improved aspect, not only as regarded the variety of flowers, trees, and herbs, but as regarded the colour and size of the species, which the nurserymen and others were then taking great pains to study and develop. At this period the spirit of adventure, which led many of our countrymen to explore distant regions, gave a powerful stimulus to botanical science, and was of infinite service to our horticulturists and florists, as the vessels which had touched

${ }^{1}$ Lysons notes that in 1792 about seven acres were employed in Barnes, Surrey, as a hopyard,-a circumstance to be remarked, since nowhere else in the vicinity or county has such a crop been grown within memory. 
at American and West Indian ports, and in certain cases remained there for some time, brought back plants and seeds previously unknown, and laid the foundation of that passionate taste for the pursuit, which gradually converted the suburbs of London into a girdle of nurseries and marketgrounds.

There is one point in which the evidence of Harrison is to be received with allowance, and that is, where he begs us to believe that in very remote days the English raised plenty of wine, but afterwards, as in other matters, lost the art. Now, it is out of the question to suppose that at any epoch our climate permitted the free cultivation of the vine in sufficient measure to yield a vintage ; Orazio Busino, to whom I shall return presently, manifestly entertained a very indifferent opinion of the grapes reared at such a place as Burleigh, when he visited it in I6I7-I8; there was not sufficient sun to ripen the fruit in the open air; and artificial mediums had scarcely come into existence, for Evelyn, on his visit to the Physic Gardens 


\section{The Earliest Gardener's Calendar. 25}

at Chelsea, as comparatively late as $\mathbf{1 6 8 5}$, was struck by the warming apparatus used in the conservatory there, as an interesting innovation. The utmost that our predecessors set themselves, as a rule, to achieve, was the exclusion of the cold or damp air, and the frost, by a very experimental process described in a future section.

Richard Weston, in the Gentleman's Magazine for 1804, terms Evelyn's Kalendarium Hortense (1664) the earliest gardener's calendar; but such is not really the case; for Bacon, in his essay Of Gardens, has in some - sense and measure anticipated him, and set forth the plants and flowers which were then in perfection throughout the year. Bacon says: "I do hold it in the royal ordering of gardens, there ought to be gardens for all the months of the year, in which severally things of beauty may be then in season;" and then he leads us through the months, specifying the flora of each with an affectionate minuteness, which augments, if possible, our admiration of his versatility and grasp. $\mathrm{He}$ concludes his rehearsal thus: "These par- 
26 Gleanings in Old Garden Literature.

ticulars are for the climate of London; but my meaning is perceived that you may have ver perpetunum, as the place affords."

The essayist speaks of the peach-tree as in blossom in March, but his March might be our April. It seems useless to copy from a book so common and so famous; yet there are points of some importance to be recorded, namely, that artificial warmth was now effected by means of stoves of some rude type to the protection in winter of exotics and delicate trees, and that among these the lemon occurs for the first time in company with the orange and the myrtle. The latter thrives in the west of England in the open air; but the other two seldom prosper in this climate, even under a tropical temperature.

Bacon places under April in his calendar, with the double white violet, the stock, and others, the tulip, which has not hitherto occurred. But he does not mark it as a novelty. I shall have more to say of it hereafter. It is an historical flower. Under February he cites the mezereon-tree 
as in blossom, and the yellow and grey crocus.

Bacon's Essay is rather too elaborate and technical for my immediate purpose. $\mathrm{He}$ contemplates grounds laid out on an extensive scale, and gives thirty acres as the area requisite for his scheme, which consists in a green or lawn of four acres, a heath or desert of six, and a main garden of twelve, with alleys between. Bacon preferred the square form, "encompassed on all the four sides with a stately arched hedge, the arches to be upon pillars of carpenter's work, of some ten feet high and six feet broad, and the spaces between of the same dimension with the breadth of the arch." The minuteness with which this great man describes all the particulars, and the interest which he evidently felt in the subject, are very striking; he found in his own grounds an agreeable and soothing diversion from public employments. It is worth observing that he had no taste for the fantastic or grotesque. "As for the making of knots or figures, with divers-coloured earths, that they may lie 
under the windows of the house on that side which the garden stands, they be but toys: you may see as good sights many times in tarts"; and when these lines were composed the fashion was running very strongly in the direction of these artifices, and two or three of the writers of the day recommended them as novel experiments. Nor was Bacon's condemnation of them in print sufficiently influential to suppress a taste which, in some form or other, has ever since prevailed.

Bacon approved of fountains in a garden, but not of aviaries. His heath or desert, as he calls it, he wished to be "framed as much as may be to a natural wildness." It was to be a plantation, not of trees, but purely of undergrowth and bushes, including sweetbriar, honeysuckle, and the wild vine, "and the ground set with violets, strawberries, and primroses; for these are sweet, and prosper in the shade." The strawberry here mentioned must have been, like the vine, the wild sort, for the cultivated one prefers and requires the sun. "I like also," he goes on, "little heaps, in the nature of molehills 


\section{Bacon's Essay on Gardens.}

(such as are in wild heaths) to be set, some with wild thyme, some with pinks, some with germander, that gives a good flower to the eye. ..." Some were to be creepers, some standards, among the latter of which he names roses; and altogether this division was to be a kind of artificial wilderness, where a man might roam (for there were to be six acres of it), and forget the cares of life and statesmanship.

While I am upon Bacon's remarks in reference to gardens, it may be worth while to note that in $165^{8}$ Ralph Austen pleaded his practical experience against Bacon as a speculative writer for publishing observations on some parts of the Natural History, where the other treats of flowers, fruit-trees, and fruit; and the criticisms of Austen are, it must be owned, both sound and interesting. I perceive that, among other matters, he animadverts on Bacon's observations respecting strawberries and their preference for the shade, and points out that such, in his judgment, was not the case. But Bacon probably intended the wild berry, which 


\section{Gleanings in Old Garden Literature.}

prospers without much sunshine, whereas his scholiast had in his mind probably a cultivated variety.

Austen, when he penned these strictures on Bacon, was already favourably known by his Treatise on Fruit-Trees $\left(4^{\circ}, \mathrm{1} 653\right)$.

Richard Brathwaite, a contemporary of Bacon, makes "The Garden" a short section in his tract on the management of an earl's household. Among the vegetables he quotes the cucumber. But he recommends fair bowling-alleys, well-banked, as a desirable feature in a nobleman's pleasuregrounds, and he intimates that, if well kept, they are profitable to the gardeners-they received gratuities, that is to say, from visitors to the master.

The name of Evelyn is customarily associated with his learned book on Forestry (I664); but a few years prior to that date he was induced by his friend Thomas Henshaw to put into an English dress a work called The French Gardener. The first edition was ready in $165^{8}$, and a third was demanded in 1675 . The second I 


\section{Evelyn's "French Gardener." 3 I}

have not seen; the third has some plates by Hertochs, and, as I shall presently explain, an additional tract at the end. Evelyn, it seems, had met Henshaw abroad, and speaks of him as an old acquaintance. The French Gardener was regarded by the translator as the best extant production on the subjects of which it treated. In the preface he observes :-

"I advertize the Reader, that what I have couched in four sections at the end of this Volume, under the name of an Appendix, is but a part of the Third Treatise in the Original; there remaining three Chapters more concerning preserving of fruits with sugar, which I have heretofore expressly omitted, because it is a mystery that I am assured by a lady (who is a person of quality, and curious in that art) that there is nothing of extraordinary amongst them, but what the fair sex do infinitely exceed, whenever they please to divertise themselves in that sweet employment."

Beyond the mere technical interest of this volume, which time and experience have probably much lessened, there is a charm and a tone about it, which can only belong to a book produced by a man of letters and an enthusiast. At page 108 occurs "A 
Catalogue of the Names of Fruits known about Paris," which occupies no fewer than twenty-six pages. Thirty-seven varieties of the peach are enumerated, and many kinds of early and keeping apples, and plums, early and late, among which we still notice the apricot. But of pears there is an astonishing proportion, parcelled out among the months of the year, all of which have their share; allowance must be made for sub-varieties of the same species; but the total is $3 \mathrm{I} 5$ ! One of those usable in September and October is the Pear Evelyn; but the names are, in many other instances, highly curious and even historical. We have, for example, the LadyDear Muscat, the Ladies-Thigh, the Twoheaded Pear, the Fine Gold of Orleans, the Gloutes de Gap, the Pucell of Xaintonge, the Father-in-Law, the Good Micat of Coyeux, the Younger Brother, The Maiden's Flesh, the Ciacciole of Rome, the Graccioli or Cucumber Pear, the Clown of Anjou, the Clown of Reatte, the Goose's Bill, Ancy (the English Pear), the Toad Pear, the St. Samson or Ditch Pear, the Sausage Pear, the Ugly 
Good, the Great Mary of Amiens, the Grey Messire John, Messire John Green, the Virgin of Flanders, the Burnt Cat, Venus' Nipple, the Musk Bon-Chrétien (allied to our Williams pear), the white Milan Pear, the Onionet, the Little Dagobert, the Incognito of Persia, the Winter Bagpipe, the Bourbon, and a hundred others. It is from France, no doubt, that we have borrowed our pears; but the French, in their turn, evidently transplanted from Italy, Savoy, and elsewhere some of those which form part of Evelyn's list. His catalogues of apples, plums, cherries, and figs are also worth study; but he admonishes us in a note that some of the English equivalents are not absolutely reliable, and that we had not attained at that time to "so ample a choice and universal as to supply the deficiency of the Dictionary." 


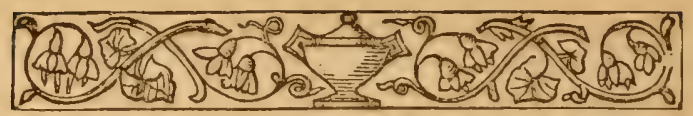

IV.

The French and Dutch Schools-Evelyn AND THE "French GaRdener"- His "Sylva"-John Worlidge-GardenING IN SCOTLAND.

अar $\mathrm{HE}$ second part of the French Gardener (I675) deals with a class of vegetable-fruits which had become in the seventeenth century common enough, but of which we hear very little in more ancient records-melons, cucumbers, gourds; and a section is devoted to the artichoke and asparagus. Of melons and gourds I trace no cognisance in the technical treatises of the time; but they are recited, with leeks, onions, and garlic, in Newbery's Dives Pragmaticus (1563):

Vast progress had now been made in the development of the kitchen-garden and in 


\section{The French and Dutch Schools. 35}

the science of sub-division, by which foresttrees, fruit-trees, herbs, flowers, and vegetables were no longer grown side by side, as it were; and the cultivation of the delicate plants introduced from milder climates necessitated systematic precautions for screening them from the weather. The directions for rearing and protecting the melon, which is emphatically termed "the most precious fruit that your kitchen-garden affords," are very elaborate indeed. They seen to have enclosed the ground selected within a palisade of reeds to exclude the wind, and to have dressed the soil freely with horse-dung; and new sorts were occasionally received from abroad. Only a few days before his trial, Charles I. is said to have ordered some Spanish melons to be planted in his garden at Wimbledon, then still a royal possession and residence.

In the last century, the fruit had probably attained as great a perfection as possible. A curious note accompanies a copy of Foote's Dramatic Works ( 1762 ), to the effect that it was Foote who taught the owner's father to 
eat melon with a spoon-." "So far as the spoon will cut, it is ripe." We continue to grow this fine fruit under glass; but in the south they flourish like cabbages, or like the small Indian cucumber, in the open air.

In his early and curious tract on Brewing, published at Frankfort in $i 585$, Thaddeus Hagecius speaks of the melon as a species of cucumber: "Hic obiter notandum," he writes, "quod etiam, quæ frigida sunt, dulcia sunt: sicut etiā sunt Cucumerum genera, quæ Melones vulgo vocantur." But Hagecius (or Haycke) may almost be taken to mean rather the pumpkin, or some other species of gourd.

Oddly enough, the culture of the artichoke and of asparagus is treated as if it had been considered a matter of equal delicacy and gravity; but we look on asparagus as not less difficult to handle with the experience of two or three centuries than it was in Evelyn's day, while both sorts of the artichoke will succeed with very little care in ground of tolerable quality.

The grand and inalienable institution of 


\section{Evelyn and the "French Gardener." 37}

JAM, as an ingredient in our culinary economy, does not date much further back than the middle of the seventeenth century, when the French Gardener was adapted by Evelyn to English readers. The third part of this work, in the original, is occupied by directions for preserving, candying, and pickling fruits; and in the English version this is digested and abridged in four sections, accompanied by an engraving, in which we are admitted to the interior of a chamber, where women are engaged in the various processes.

Evelyn produced in $\mathrm{r} 664$ his tripartite volume, containing the Sylva or Discourse of Forest Trees; Pomona, or An Appendix concerning Fruit-Trees, in relation to Cider; and the Kalendarium Hortense, or Gardener's Almanac, Directing what he is to do monthly throughout the year. The first division comprises many plants, such as jessamine, laurel, and holly, which rather belong to the flowergarden or shrubbery. But it is a piece of work to be taken as it is found, for it was really the earliest effort to draw attention, not merely to the various kinds of trees in our 
plantations and woods, but to the proper mode of propagating and pruning them, and of course the writer introduces anecdotes and touches which impart a zest and price to the volume. He could hardly go into print without telling us something new and useful ; and I must particularly commend to attention the account of ancient and celebrated trees, contributed to his pages by the Auditor of his friend, Henry Howard of Norfolk.

The Kalendarium Hortense, which (after Bacon's essay) was the precursor of all other experiments of the same nature, proved more popular and saleable than the Sylva itself, and passed through several editions. To the ninth he added a sort of supplementary or companion volume, called Aietaria, a Discourse of Sallets, in which he included many articles which are no longer thought to fall within that category, such as spinach, asparagus, melons, dandelion, hops, and a number more. It was to some of the later impressions of the Calendar that Cowley appended his poem of the Garden, with a 


\section{John Worlidge.}

preface which opens with these words:-

"I never had any other desire so strong, and so like to Covetousness, as that one which I have had always, that I might be master at last of a small house and large garden, with very moderate conveniences joined to them, and there dedicate the remainder of my life to the Culture of them and study of Nature."

Besides the contributions which he left behind him to botanical literature, Evelyn has made his Diary and even his correspondence a small storehouse of curious facts in relation to the same subject; he has not failed to record for us particulars of all the public and private gardens which came under his observation, either at home or abroad; and there can be little doubt that he was instrumental, both directly and indirectly, in naturalising among us numerous beautiful examples of the flora and sylva of other countries, and enabled such a book as Worlidge's Systema Horticultura to aspire to far greater completeness than it could otherwise have attained. The benefits of this thrice-happy possessor of noble tastes, ample means, and influential friends survive 
the triumphs of the politician and the soldier.

I would particularly solicit the attention of the reader to Evelyn's letter to the Earl of Sandwich, of August 2 Ist, I668, in which he exhibits his enthusiasm for the study no less than his mastery of the details. It is to be recollected that at this time there was a method of transporting plants and roots from distant places in barrels.

Nor can I forbear to put on paper my pleasurable feeling about Evelyn and Pepys, that they seem, both of them alike, to form an inseparable part of the period to which they belonged. You cannot touch any point appertaining to the social and domestic affairs of the second half of the seventeenth century, without finding yourself in contact somehow with them; and they are names which do not pall by repetition.

The Systema Horticultura of John Worlidge (1677) was apparently the earliest manual for the guidance of those forming and cultivating gardens, and it deals methodically and seriation with the treatment and virtue of 
different soils; the form of the ground, of which he furnishes two schemes, both calculated for a more extensive plot or area than the majority could command; the structure and material of walls, fences, and other enclosures; the erection of arbours and summer-houses, garden seats and benches, among which he enumerates some within niches of the wall, protected by a cupola supported on columns-a fashion not yet extinct; the means of irrigation; fountains and grottoes, statues, obelisks and dials ; and then he proceeds to discuss the main subject - the contents of a garden, and how to choose and manage them. There are some excellent directions and information on certain heads; but the book is scarcely what I should designate a comprehensive treatise. It reappeared with some additions in 1683 .

Nor is Worlidge very systematic in his Systema, for he intermingles in his text plants, herbs, and forest-trees in an admirable confusion. The same page describes the evergreen oak, the tree stone-crop, the arbutus, and the rosemary. Yet it is a book which, 


\section{Gleanings in Old Garden Literature.}

as Charles Lamb would have put it, we would much rather not not have; for it is replete with instruction and interest. The author was one of those men who wrote from a love of the subject, begetting practical experience and insight. We shall never know how much we owe in the waxing taste about this time for such studies to the example and stimulus of Evelyn.

The Scots' Gardener, by John Reid (I683), is the parent-production in this class of literature, and purports to have been compiled by a practical observer with a special view to the climate of Scotland. It is divided into two portions, of which the first is occupied by technical instructions for the choice of a site for the garden, the arrangement of the beds and walks, and other particulars, all tending to shew that the author had in his eye exclusively the richer class of patrons, who could afford to carry out operations on an ambitious and costly scale. The book concludes with a calendar.

Reid furnishes very explicit rules for grafting, pruning, and propagating byseed, cutting, 


\section{Gardening in Scotland.}

and sucker; but he does not say so much as one might have expected about the berry tribe, which has always been regarded as thriving northward better than in England. $\mathrm{He}$ enumerates among standards apples, pears, cherries, gooseberries, currants, barberries, quinces, walnuts, chestnuts, filberts, and service-nuts. For the wall he recommends apricots, peaches, nectarines, almonds, the vine, figs, currants, apples, pears, cherries, plums, etc. ; but, he says, "you need not take up much with almond, vine, fig, nor nectarine." Probably there was not sun enough to ripen them. The book altogether contains a fair amount of curious information, serviceable for comparison; but the method, as in all these early treatises, is faulty and confused. He has much to say on the subject of pruning, and commences by observing:- "Some Ignorants are against pruning, suffering their trees to run and ramble to such a head of confusion, as neither bears well nor fair."

Reid's book did not acquire much popularity; but it was reprinted in $\mathrm{I} 72 \mathrm{I}$ and $\mathrm{I} 766$. 
The approximation to Holland through the House of Orange, culminating in the great political changes of 1688,1 affected every department of horticulture, and introduced the Dutch school, as it is still to be seen in a few old-fashioned places, where a corner is kept as a specimen of former ways of thought, as bygone as a monastic ruin among new buildings.

This dynastic agency enriched our gardens and conservatories with many rare and beautiful species of flowers and bulbs, and perhaps assisted in inoculating the English collectors with the tulip-mania.

Yet, while that bulb was carried to unprecedented perfection in the Low Countries, it had been a familiar object in English gardens since the time of Elizabeth at least; but when Bacon wrote, the cultivators of it either here or abroad had not succeeded in procuring that wide variety of

${ }^{1}$ Dr. Walter Harris, physician to William III., when he was Prince of Orange, printed, in 1699, an account of His Britannic Majesty's palace and gardens at Loo, with a plan of the grounds. It is a quarto tract of considerable rarity. 
hues which brought the flower into such increased celebrity.

At the same time, it is due to the Dutch to say that, at all events in the first quarter of the seventeenth century, considerable progress had been made among them in the propagation both of the tulip and hyacinth; and in 1615 Crispin de Passe the younger published at Utrecht his Hortus Floridus, with an English descriptive letterpress, seeming to shew that at that early date the interest in these bulbs had increased with ourselves. The engravings to the work above-cited exhibit numerous species of the tulip and other flowers of the same family or growth, and in the copy which is in the British Museum they are presented in their natural colours.

At a somewhat later period, namely in I630, Crispin de Passe published at London his Book of Beasts, Birds, Flowvers, Fruits, etc., of which there is a copy in the Museum. The chief part of works of this class there are from the benefaction of Sir Joseph Banks. 


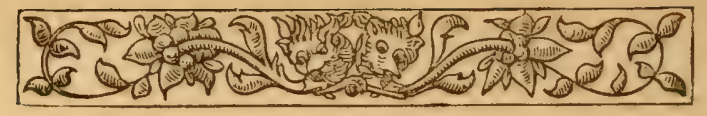

V.

Herbals, Physic-Gardens, and Bees.

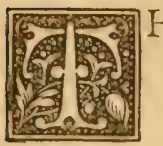

$\mathrm{HE}$ most ancient printed Herbals in our language are translations from the French and Latin, and are not anterior to the time of Henry VIII. The Great Herbal, an English version of a French work, appeared in 1516 , and was reprinted in $1526,1_{529}, 1_{539}$, and ${ }_{5} 6 \mathrm{r}$. The Little Herbal, taken from the Latin, was published in 1525 , and had a second edition in 1526 . Besides these two guides to a knowledge of the subject, we had only a translation of the swall herbal of Macer, of which two editions appeared about the middle of the sixteenth century from the press of Robert Wyer, and the earlier contributions to a branch of letters and science which he was to make his own, of William Turner, who 
Herbals, Physic-Gardens, and Bces. 47

printed in 1538 his Libellus de Re Herbariâ, and in 1549 A List of the Names of Herbs, with their common designations. Turner's Herbal was partly given to the world in I 55 I, but was not completed till I $_{5} 68$, when the author republished it with a remarkable preface addressed to Queen Elizabeth, in which he exposes and laments the ignorance of the apothecaries of those days. This preliminary matter, for its curiosity and permanent interest, the present writer included in his volume of Prefaces (1874).

Turner's example encouraged, perhaps, Henry Lyte, of Lytescary, in Somersetshire, to undertake a translation of the Herbal of Rembert Dodoens, which came out in 1578 , and was reprinted in $15^{8} \mathrm{I}$ and 1619.

But while the printed literature of the country is comparatively late and barren, there were of course innumerable MSS. treatises on the subject in circulation from the Saxon era downwards, chiefly in the form of catalogues and glossaries, such as still exist in the Harleian and other public collections, and which were prepared some- 
times for professional and sometimes for scholastic purposes. Many of these are incidental or fragmentary; but they tend to impress one with a somewhat more favourable notion of the conversance with such matters than Turner entertained; and, by the way, the same may be said of the general knowledge of medicine which, let us recollect, has not even yet quite lost its old empirical taint.

The early English apothecary laboured under the disadvantage of a very defective training, and of the absence of adequate literary lights and helps. The education which he received was necessarily of the most rudimentary character, and the old Latin and French companions to the Pharmacopœia were a tissue of ignorance and absurdity. It was only by such men as Turner, who thought and worked for themselves, and broke away from the trammels of prejudice and usage, that the medical art was gradually enfranchised and advanced.

In the reign of James I., and perhaps even earlier, Edward Lord Zouch, of whom 
Herbals, Ply'sic-Gardens, and Bces. 49

there is an interesting account in Kennet's Parochial Antiquities, under "Chilton," had a physic-garden attached to his seat at Hackney, the earliest thing of the kind in England, though of long standing in Italy and elsewhere on the Continent. It was under the superintendence of Matthew de l'Obel, an apothecary, who wrote one of the earliest books on tobacco. ${ }^{1}$

Lord Zouch, whose other residence at Bramshill, in Hampshire (of which there is a view in Nash's Mansions of the Olden Time), is commemorated by Browne in the dedication of his Shephcrd"s Pipe (I6I4) to that nobleman, had also ornamental and fruit gardens at his place near London; and Sir Hugh Platt, in his Garden of Eden (1653), quoted by Lysons, states that he removed apple and damson trees of thirty years' growth with success.

The second institution of this kind was

1 In the Antiquary for February, I885, I have drawn attention to the physic-garden founded at Venice in 1334 by the surgeon Gualtieri, the most ancient in Europe. 
established at Oxford by James, Earl of Derby, in the reign of Charles I. Catalogues of the plants were published-of the Medical Garden in 1648 , and of the botanical collection in 1658 , the latter under the care of Philip Stephens, M.D., and William Browne, A.M.

Evelyn was here in I654. "I 2 th July. Hence [from Magdalen] to the Physic-Garden, where the sensitive plant was showed us for a great wonder. There grow canes, olive-trees, rhubarb, but no extraordinary curiosities. ..." He paid a second visit ten years later, when he saw the locust-tree and the plane.

The physic-garden at Chelsea dates only from the year 1673 , when it was first rented by the Apothecaries' Company, and the ground laid out. It became their freehold in I $72 \mathrm{I}$ by the gift of Sir Hans Sloane, lord of the manor. The two cedars on the south side of the garden were planted in $\mathbf{I} 68_{3}$, being then about three feet high. In August, I 793, the girth of the larger at 3 feet from the ground was found to be 12 feet I $1 \frac{1}{2}$ 
Herbals, Plyysic-Gardens, and Bees. $5 \mathrm{I}$

inches, that of the smaller I 2 feet and $\frac{1}{4}$ inch.

The visit of Evelyn to the garden at Chelsea was paid on the 7 th August, I685.

"I went," he notes, " to see Mr. Watts, keeper of the apothecaries' garden of simples, at Chelsea, where there is a collection of innumerable rarities of that sort, particularly, besides many rare annuals, the tree bearing Jesuits' bark, which had done such wonders in quartan-agues. What was very ingenious was the subterranean heat, conveyed by a stove under the conservatory, all vaulted with brick, so as he has the doors and windows open in the hardest frosts, excluding only the snow."

This account bespeaks a condition of affairs which was not at all likely to be attended by a successful issue.

Mr.and Mrs. Blackwell, of whom the former wrote a work on Agriculture, and the latter a once popular and celebrated Herbal, lived opposite the physic-garden, while the lady was engaged in her work. It consisted of two folio volumes, and appeared in 1737. The preparation of such a stupendous production mus! have entailed very heavy labour and 
there must have been some good in it ; but it dealt with a progressive science, and very much of the paper on which it was made visible to the public has long "suffered a change."

Besides the physic-gardens at Chelsea and elsewhere, considerable acreage has, from the middle of the last century, been dedicated at Mitcham, in Surrey, to the cultivation of medicinal herbs and plants, especially peppermint, lavender, liquorice, aniseed, camomile, and rhubarb. The peppermint, however, is used in the preparation of a species of dram, and in the time of Lysons ( 1792 ) one hundred acres were given up to the growth of this plant alone, for the purpose of distillation as well as for the use of the apothecary.

The somewhat extended notice of herbals in these pages, as well as the list of others, which will be presently given, will require an explanation only, I think, from such as are not aware that this description of book embraces a wider category than the mere title seems to import, and cannot well be neglected by floricultural inquirers. 


\section{Herbals, Plyysic-Gardens, and Bees. 53}

It is particularly to be predicated, if I do not err, of William Turner, that he was the first, in his little book published in $\mathrm{r} 549$, to give the vulgar names of herbs and plants, as well as their scientific denominations.

Our remote forerunners, long before the Conquest, made mead or metheglin from the honey of wild bees; and this product was at the same time, in the absence of any other sweetening medium, the only substitute for sugar. Bee-culture, therefore, acquired by degrees considerable importance and development, and there were persons who reared them specially, and owned what might be termed bee-farms, with hinds to attend to the hives.

An account of the principal works on bees will be furnished hereafter.

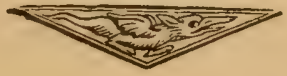


VI.

The Kitchen - Garden - Alexander Neckam and Johannes de Garlandia -The Gardens at Sheen, Greenwich, and Somerset House-Sir William Temple's Garden at Sheen - Kew Gardens - Gardens in aND ABOUT LONDON IN I69I - EARLY CATALOGUES of Plants-The Duke of Bedford's Botanical Publications.

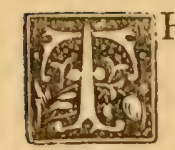

HE kitchen-garden is supposed by Wright to have preceded the flower-garden; he imagines the flowers, among the Anglo-Saxons, to have been planted in enclosed spaces or beds near the house. The orchard, which we now identify with fruit-trees, had its origin in wyrt or ort geard, the garden for wyrtan, a term generally employed to signify any sort of 
vegetable or herb. In ort one recognises the Latin hortus; but the Romans gave to the locality the name which our ancestors bestowed on the produce. Our word garden, which used to be understood of a series of enclosures and plantations for various purposes, as the apple-yard, the ash-yard (where the ash for hop-poles was grown), the ort-yard, and the vine-yard, looks like the plural of geard; and this notion is confirmed by the northern form garth, and apple-garth for apple-yard. ${ }^{1}$ The French jardin is evidently from the same root. In the Privy Purse Expenses of Henry VII., under I 493, we come across the term coney-garth, which seems to be a place for keeping rabbits, rather than, as the editor explains, a rabbit-warren, particularly as the charge is for a coney-garth pale.

The leek was universally cultivated, and

1 Mr. Lucas, in his Studies in Nidderland, devotes a section to an etymological essay on Garth and its allied meanings in sundry northern languages.

But he does not note the application of the plural to form a collective phrase. Yard and garth are absolutely the same word; and Mr. Lucas specifies many other variations in other dialects. 


\section{Glcanings in Ola Garden Literature}

was not peculiar to Wales; it was the favourite table vegetable, and the onion (ynne-leac $=$ inula of Johannes de Garlandia) and garlic (gar-leac, perhaps the Latin gerum) were so designated, because they were taken to be varieties of it. Many kinds of flowers, which form at present part of the ornamental enclosure, were considered to belong more properly to the kitchen department: the sunflower, the violet, the marigold, the gillyflower, the honeysuckle, the perriwinkle, the peony, and the bay-tree; in addition to which the Saxon had his apple-yard or garth, where he grew the trees to make what he called apple-wine-our cyder. Wright has pointed out that the trees and plants which were known to the Saxons, are, as a rule, distinguishable from those which were subsequently imported by the Normans and others by the names, as in the case of the pear, the cherry, the pea, the turnip, the radish, the colewort, the cabbage, and many herbs, as parsley, mint, rue, and sage.

The picture which Alexander Neckam 
draws of a garden in the latter half of the twelfth century corroborates the opinion that that institution at the outset corresponded to our kitchen-garden; but his description was taken from some princely or baronial establishment, and bespeaks a certain share of taste in arranging the herbs, plants, and fruit-trees. His narrative, although it is of no service as a guide to the resources of the humbler classes in this respect, is very precious, from its early date and the superior intelligence of the writer, as a kind of clue to what was then in cultivation and use; and, in addition to what I have enumerated from other sources, he recites fennel, savory, cresses, melons, the cucumber, the poppy, anise, mustard, white pepper, wormwood, peaches, pears of St. Regle, citrons or lemons, pearmains, oranges (Mala aurea), almonds, dates, and figs. How some of these were reared, he omits to explain; he characterises them as features only in a noble garden, it is true ; but artificial warmth was not available, and in the open air the almond would scarcely bear, and the date and the orange would not live. 
The orange, which forms, as we perceive, part of Neckam's twelfth century list, soon became a favourite, and was a comparatively cheap fruit in this country. It appears from one of the Household Books that in 1480 ten were to be had for a silver penny; but in I 290 some had come over from Spain, and were purchased for the Queen of Edward I., Eleanor of Castile. They are described in the record as Ponce de Orange; and they are associated with a variety of other fruit, so that there is little doubt that the Seville orange, imported thither from Arabia, is meant, more especially as the Spanish parentage and tastes of Eleanor were calculated to favour the importation of the produce of her native land. Yet Sir Antonio More painted Sir Thomas Gresham with an orange in his hand, as the introducer of it into England. He was no more entitled to that distinction than the Flamborough family mentioned in the Vicar of Wakefield.

The account of Johannes de Garlandia (an English resident in France) of his own garden at Paris is not very dissimilar from 
Neckam's. As the relations between the two countries became closer and more regular, the French improvements in horticulture and additions to the flora were not long in finding their way across the Channel.

This worthy writer divides his grounds into garden, shrubbery, wood, and grove; so that, as he was in the middle class of life, land must have been cheap at that time, and space of no moment. He mentions his gardener (ortolamus), and tells us what the latter cultivated in the way of kitchen herbs. We learn that Magister Johannes grew not only his own onions and cabbages, but his own mustard. But the cardinal aim of Master John was to render his strings of names as long as possible, and he mixes up fruit-trees and forest-trees, shrubs and creepers, in a way which one can scarcely suppose to be true to reality. In his wood (nemus) he informs us that he had the celsus bearing celsa, which his editor explains to be mulberries. Such, however, is not likely to have been the case. As I have hinted, the author's aim was lexico- 
60 Gleanings in Old Garden Literature.

graphical primarily, and Mr. Wright himself points out that in one place he enumerates among the birds which the fowler captures in the wood, not only the eagle, which is improbable enough, but the phœnix!

His twelfth-century labour is very instructive on many accounts; but immediately it transports us across seven centuries of spent life into the remarkably comfortable quarters at Paris of a very remote predecessor of Dr. Johnson in the art of dictionary-making.

The earlier portion of the Diary of Evelyn may be consulted with advantage for a view of the public and royal gardens, and private pleasure-grounds, seen by him during his continental tour.

Of our own country the development in the same respect was to sume extent retarded by the climate and the absence of native talent for the purpose; and information on the state of ancient gardens, public and private, is at first very scanty. Even Bacon, though himself a gardener, does not allude to this part of the matter in his Life of Henry the Seventh. 
The Prizy Purse Expenses of that prince appear to contain only two direct references to the king's garden at Sheen, the venerable riverside manor-house, out of which gradually developed itself the palace of our Tudor princes. One is under February $\mathrm{I} 7$ th, I $497-8$, and is a grant of $£ 2$ to the gardener for grafts. The second is of the 26 th January, I 498-9, and registers a payment of Ios. for "sope hashes," or the lees of soap, which were found useful in killing slugs and other vermin.

In the Privy Purse Expenses of Henry VIII., under I530, there is an item for "weeding, delving, and ordering the royal garden at Greenwich," and the amount, $£$ I 4 s. 6d., must have been for a considerable period. At the same time the price of herbs might appear to have been high, as twenty shillings were paid to the bringer of some to the king; but the amount was given in largess rather than as the commercial value of the articles, in the same way as Henry ordered $3 s .8 d$. to some countryfolk who had presented him with wild strawberries, and as elsewhere we meet with a record of a pottle 
of the same fruit realizing rod. to the seller. These are early material for any future history of the "Origin of Tips." According to some of the entries under I $53 \mathrm{I}$, it seems as if the gardening charges at Greenwich were paid quarterly, for a man named Walsh received $£_{1} 5^{s}$. $6 d$. for trimming the garden there at the end of November in that year; and this, like some of the other payments, may have been in advance for Christmas.

In my edition of Randolph's Poems, with a view to rendering it more complete, rather than from any hope of making it more acceptable to the drawing-room table, I inserted from a MS. in the British Museum some verses "On a Maid seen by a Scholar in Somerset House Garden." This must have been before 1635 , the date of the writer's decease; and it seems to shew that the indifferent reputation of the mansion was shared by the grounds. Probably, when Queen Henrietta Maria resided there, a little more decorum was observed; but even this is questionable. The garden of the old palace was far more extensive than the 
present aspect of the site would lead one to suppose, for the Protector Somerset cleared a large area before he erected his residence here, partly to obtain with greater facility from the demolished buildings the material for his own. This was in I 549. Part of the clearance consisted of the old inn of Chancery, called Strand Inn.

The scholar in these lines was doubtless Randolph himself. He speaks of the place as the haunt of glittering courtiers. It was one of the splendid inns, as they were called, along the south side of the Strand, and the grandest, perhaps, of all. Is it changed for the better or the worse? Since the last century the river front has suffered much alteration.

I would add that Mr. Wheatley, in the chapter on Hyde Park printed with his Round About Piccadilly (1870), has collected some very interesting information concerning that park itself and Kensington Gardens, and the Green and St. James's Parks are treated in the next section.

The same writer has pointed out the 
papers on the subject of horticulture in the seventh and twelfth volumes of Archaologia. To the latter I shall have to recur ere long.

The reader of Macaulay's essays will call to mind his account of Sir William Temple and the delight which the latter took in his garden at Sheen. This was the site of the ancient priory, and here, during many years, Temple amused his leisure in horticultural experiments, and had for his amanuensis no less a person than Jonathan Swift. Lysons says :-

"King William, who had known Sir Willian Temple on the Continent, and had a great esteem for his talents and character, frequently visited hin at this place and pressed him to become his Secretary of State. When his patron was lame with the gout, Swift usually attended his Majesty in his walks round the garden. The king is said on one of these occasions to have offered to make him a captain of horse, and to have taught him to cut asparagus in the Dutch manner."

In 1667 , it is to be gathered from his correspondence that Temple was paying special attention to the culture of cherries, 
so as to have a succession of kinds from May to Michaelmas, and also to the more successful propagation of the vine.

Several publications have appeared in connection with the gardens at Kew. The most noticeable is the Hortus Kereensis, first printed in 1763 . At least, that is the earliest date given by Watt in his Bibliotheca. But of course the immense development which these fine public gardens have experienced under the Hookers, renders such descriptions imperfect and obsolete. Nor is there any special account at present procurable of the kindred establishments at Chiswick and Regent's Park.

In an essay dedicated to the literary rather than to the technical aspect of the present subject, the labours of such men as Gibson, Kent, and Capability Brown can hardly be treated sufficiently at large to do justice to them or the theme itself. Gibson enters into my plan so far that he wrote an account of the gardens near London in $169 \mathrm{I}$ first printed in the twelfth volume of Archeologia. 
There is no doubt that the successive exertions of Evelyn and Pope, brought to bear on their noble and powerful friends, were instrumental in achieving many valuable improvements, by encouraging, on the one hand, the taste, and, on the other, the genius for landscape-gardening. It would be impossible, I conceive, to name two Englishmen who respectively exercised so healthy and important an influence for good in this direction as the authors of Sylva and Windsor Forest.

In Gibson's sketch of the principal gardens, public and private, near London, in 1691 , there is a considerable degree of interest. He includes some of the nurserymen. Subjoined is a list of the names which he furnishes :-

Hampton Court.

Kensington Gardens.

The Queen Dowager's Garden at Hammersmith.

Beddington Garden, leased to the Duke of Norfolk.

Chelsea Physic-Garden.

My Lord Ranelagh's Garden.

Arlington Garden, in the possession of my Lord of Devonshire.

My Lord Fauconberg's Garden. 
Sir William Temple's, at Sheen.

Sir Henry Capel's Garden at Kew.

Sir Stephen Fox's Garden at Chiswick.

Sir Thomas Cook's Garden at Hackney.

Sir Josiah Child's Plantation of walnut, etc., at Wanstead.

Sir Robert Clayton's Plantation, at Marden, in Surrey.

The Archbishop of Canterbury's Garden at Lambeth.

Dr. Uvedale's Garden at Enfield.

Dr. Tillotson's Garden near Enfield [? Ilford].

Brompton Park Gardens.

Mr. Raynton's Garden at Enfield.

Mr. Richardson's Garden at East Barnet.

Captain Foster's Garden at Lambeth.

Mr. Anthony Vesprit's Garden.

Ricketts, )

$\left.\begin{array}{l}\text { Darby, } \\ \text { Pearson, }\end{array}\right\}$ Nurseries at Hoxton.

Mr. Evelyn's Garden at Deptford.

Mr. Webb's Garden near Enfield.

Clement's Nursery at Mile End.

Gibson does not speak very highly of Evelyn's grounds or greenhouse. He describes in enthusiastic terms the Orangery at Beddington, near Croydon, the seat of the Carews, but then let to the Duke of Norfolk. He says it was two hundred feet long, and 
the trees thirteen feet high, and growing, not in pots, but out of the ground. They yielded in the season when Gibson wrote ten thousand oranges. ${ }^{1}$

I have stated that the old grammarian, Johannes de Garlandia, has furnished us with a most interesting and precious account of the contents of his garden at Paris, simply by way of philological illustration. This was in the closing years of the thirteenth century. In our own country we have nothing of the kind so early; but in $\mathbf{1 5 9 6}$ and $\mathbf{1 5 9 9}$ John Gerarde printed a catalogue of the trees and plants growing in his grounds in Holborn. The latter is a small, thin folio volume, and has been lately republished in facsimile.

At a later period these descriptive lists became common; but our literature does not possess many of them till we come down to comparatively recent times.

Gerarde's was the prototype. He styles himself on the title-page, "Surgeon and Citizen of London."

'See further particulars in the Appendix, where Gibson's tract is republished entire. 
John Russell, Duke of Bedford (1802-39) did good service in his time toward the promotion of objects connected with horticulture, and by publishing the results of experiments made on his estate and accounts of his botanical collections. These works, of which the first-quoted passed through as many as four editions between 1816 and 1828 , were :-

I. Hortus Gramineus Woburnensis. With numerous dried specimens of Agricultural Grasses cultivated by the Duke of Bedford. Folio, I816; royal 8vo, I824, I855, I858. The first edition contains dried specimens of the grasses, the others lithographic plates. The editor was Mr. George Sinclair.

This was followed by :-

2. Hortus Ericcaus Woburnensis. A catalogue of Heaths in the collection of the Duke of Bedford at Woburn Abbey. Alphabetically and systematically arranged by James Forbes. 4to, 1815. With plates, coloured.

3. Salicetum Woburnense; or, A Catalogue of Willows, Indigenous and Foreign, in the collection of the Duke of Bedford. Systematically arranged by James Forbes. 4to, I829. With coloured plates. 
4. Hortus Wobumensis. A Descriptive Catalogue of upwards of Six Thousand Ornamental Plants, cultivated at Woburn Abbey. With numerous Illustrated Plans for the Erection of Forcing Houses, Green Houses, and an account of the management throughout the year. By James Forbes. 8vn, 1833. With plates, which in the large-paper copies were coloured.

5. Pinetum Woburnense : or, A Catalogue of Coniferous Plants in the collection of the Duke of Bedford at Woburn Abbey. Systematically arranged by James Forbes. Imperial 8vo, I839. With plates.

A series such as I have described must have proved of very great service to the cause of tree and flower-culture. The design of the work on grasses was to communicate to those interested in the subject the results of tests made in the production and nutritive value of different species of gramineous plants used as food by domestic animals. The volume, illustrated with a hortus siccus of specimens which had been actually employed, contains remarks on their natural habits, and points out the soils best adapted for them, the kinds most profitable for growth in various 


\section{Duke of Bedford's Publications. $7 \mathrm{I}$}

sorts of ground, permanent pastures, irrigated meadows, dry or upland pasture, and the alternate system.*

* See "A Letter addressed to Dawson Turner, Esq., on the Death of the Duke of Bedford, particularly in reference to his Services to Botany and Horticulture." By Sir W. J. Hooker. Privately printed, I840, imperial 8vo.

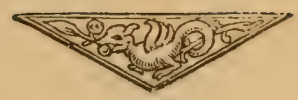




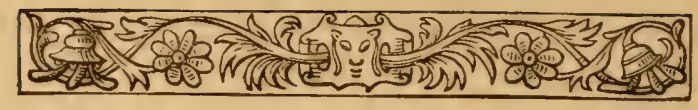

\section{VII.}

The Ancient and Modern ArbourGrottoes-Garden Life.

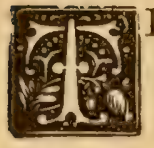

$\mathrm{HE}$ description of the squire's garden in the delightful romance of the Squire of Low Degree is worth copying, because it corroborates the notion as to the indiscriminate arrangement of early times, even allowing for the exigencies of metre :-

"The tree it was of cypress,

The first tree that Jesu chose :

The sothern-wood and sycamore,

The red rose and the lily flower:

The box, the beech, and the laurel-tree :

The date, also the damise;

The filberts hanging to the ground :

The fig-tree and the maple round :

The peony, the poplar, and the plane."

But more noteworthy, perhaps, is the fact 
that our ancestors evidently drew a clear distinction between the garden and the arbour-not our modern summer-house, but an inner enclosure so called. This point has already received attention in the notes to Warton's Poetry. But the few lines there extracted from an old metrical tale may be worth their room here :-

"And in the garden, as I ween, Was an arbour, fair and green; And in the arbour was a tree, A fairer in the world might never be."

The curious circumstance, after all, however, is not that the early Englishman should have had an inner garden called an arbour, but that he should make it a receptacle for forest-trees, and, as we presently learn, that the heroine had an arbour in which her dwelling lay-a building, too, of some pretension, according to the story. Therefore, whereas now the arbour forms part of the garden, it anciently seems to have been the ornamental ground which surrounded the house, and if it be derived from herba, it was perhaps in grass, with walks interspersed. 
74 Gleanings in Old Garden Literature.

But we might infer from a passage in an early sixteenth-century poem, the Debate and Strife between Summer and Winter, which is, however, little more than a translation from a French piece with a similar title, that the arbour was coming into use in the modern sense of a summer-house in the time of Henry VIII. For Summer, in this metrical interlocution, says that it is better to be in a green arbour (herber), where one may embrace and kiss one's mistress, than to be at the fire, chafing one's feet. This notice of the thing is fortified by the curious item in the Privy Purse Expenses of Henry VII. under April 8th, 1503: "For making of an arbour at Baynardes Castell, 5s."-which certainly imports the construction of an inexpensive summer-house, rather than the more elaborate contrivance described in the Squire of Low Degree.

That the arbour had in the commencement or first quarter of the sixteenth century acquired its actual character, I find a further proof, if one were needful, in the story which forms No. 64 of A Hundred Merry 
Tales (1526), where the fair young lady admits to her confessor to having been guilty of an indiscretion in a pleasant green arbour.

But before Bacon's time, and even so early as the fifteenth century, the arbour, in the modern acceptation, had become a regular institution, and in the pleasuregrounds of royalty and the wealthy was constructed of carpenter's work, and often expensively decorated. It formed at once a pleasant retirement for members of the family and a convenient place for amours.

A sort of survival of the Arbour of our romances appears in the garden-house of the early drama. The institution was at this time in a transitional state from what it had. been-a villa in grounds-to what it has become among ourselves, a mere summerhouse. The old garden house is stigmatised by Stubbes in his Anatomy of Abuses ( $\mathrm{I}_{583}$ ) as a medium and theatre for intrigues and assignations.

But in 1644, when $A$ Looking-Glass of the World was written (as I presume) by 
Colonel Mercer, something like the modern summer-house had come into regular vogue, for the author there speaks of "seated arbours covered with woodbine."

In reference to grottoes in noblemen's grounds, Worlidge observes :-

"The most famous of this kind that this kingdom affords, is that Wiltonian Grotto near unto Salisbury, on which no cost was spared to make it compleat, and wherein you may view, or might have lately so done, the best of water-works, far excelling what Rapinus sings of late Richlieu's palace in France."

Mr. Wright has inserted in his volume of Domestic Manners and Sentiments an engraving from the romance of Alexander, in which we are introduced to a garden where two crowned personages are playing at chess, and a third individual in some outer court is apparently engaged in making a selection from the plants around him. We can see most of him, as, although there is a palisade nearly as high as the gateway between us, it reaches very little beyond his knee, and if he stretched across, he might, judging from the very Chinese perspective, readily pick a man 
off the chessboard, or tap one of the kings on the crown with the bough in his hand.

There is a mediæval Latin fabliau of a man who invited some friends to dinner, and insisted on having the table spread at the riverside, contrary to the wish of his wife, who was not fond of being crossed. She sat with her back to the stream, and the more he begged her to look pleasant, the nearer she pushed her seat to the water, till at last she fell plump in. Her husband thereupon procured a boat, and went up against the tide in search of her; and when , his friends remonstrated with him for rowing up the stream, he said that his wife was so opposite all her life that he was sure her body must have floated against the current. This story occurs in a mutilated form in Merry Tales and Quick Answers, and again in Pasquil's Jests. Its value to us lies in its casual elucidation of old English al fresco life.

In the romance of Sir Cleges, the hero kneels in prayer under a cherry-tree. 


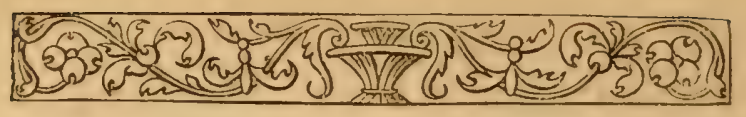

\section{VIII.}

Window-Gardening - Cottage Gardens in I677-INFLUENCE OF ASTROLOGYWARMing APParatus - Variegation of Foliage.

Findow-gardening is of very remote antiquity, and even before the use of glass the lattice was embowered in foliage and flower, or the hardy out-of-door vine-the "vinettes running in the casements" of the poet Lydgate. Alexander Neckam, who flourished in the twelfth century, long before Dan John, makes us love the damsels of his day, and think that they must have had other gentle and pretty tastes, when, in his treatise Of the Nature of Things, he tells us of their fondness for this innocent and sweet species of decoration. 


\section{Window-Gardening.}

The love and extension of window-gardening in London is illustrated by one of the stories in Pasquil's Jests (1604). Some merrymakers at a country inn, inquiring of the landlady after the latest news, she tells them of one of the greatest wonders that she ever saw or heard of, and it was the work of a stranger in London in respect to gardens and the preservation of flowers; and she had seen it, she averred, with her own eyes; and it was the new art, which this person taught the citizens, of taking in their gardens every night at their windows, and letting them out again in the morning. They agreed to go up with mine hostess to judge for themselves; and the tale proceeds to relate that, after taking her friends through Cheapside, to the Exchange, Westminster, London Bridge, the top of St. Paul's, and the Bear Garden, their conductor eventually shewed thern, in a little lane, a widow putting out of a garret-casement a box, in which she arranged pots of gillyflowers, carnations, and herbs. The point for us here is, of course, the casual indication of what was a more or less general 
So Gleanings in Old Garden Literature.

usage in London itself, if not in other towns.

This little pleasantry and hoax becomes of peculiar interest as an aid to our knowledge of this branch of the inquiry, and to a more accurate realisation of the appearance of the thoroughfares, or at least some of the minor arteries, of Jacobean London.

The liking for this sort of ornament has of late years increased among the inhabitants of all crowded centres. The earliest commencement of the fashion preceded the present necessity for it, and the casements of the citizens of London were planted and trellised, at a time when the City itself was far more thinly populated and built, and all beyond a limited area was open and verdant. But the facilities for rendering the windowsill a receptacle for flowers scarcely existed until the apertures for the admission of light and air into dwellings were placed on a more or less modern footing.

Speaking of a garden, Worlidge says, writing in 1677 :-

"Such is its pre-excellency, that there is scarce a 


\section{Cottage Gardens in $1677 . \quad 8 \mathrm{I}$}

cottage in most of the southern parts of England but hath its proportionable garden, so great a delight do most of men take in it, that they may not only please themselves with the view of the flowers, herbs, and trees, as they grow, but furnish themselves and their neighbours upon extraordinary occasions, as nuptials, feasts, and funerals, with the proper products of their gardens."

The cottage garden is a subject of special interest, inasmuch as it comes home to so many who have neither the space nor the fortune to cultivate on any ambitious scale. I do not suppose that it is an institution which can be confidently referred to a date much anterior to Worlidge; and many of the lovelinesses of the sweet small plots which stand before our cottages were unknown even in his day. But the succeeding century saw most of the productions which now grace the cottage garden supplied from various sources.

Hazlitt, recalling the scenes and memories of his childhood, brings up before us in one of his essays the Montpelier Tea Gardens, at Walworth, as they appeared in 1787 . They 


\section{Gleanings in Old Garden Literature.}

exhibited a flora analogous to that of the cottage ground.

"I see," he says, "the beds of larkspur with purple eyes; tall hollyhocks, red and yellow; the broad sunflowers, caked in gold, with bees buzzing round them; wildernesses of pinks and hot-glowing peonies; poppies run to seed, the sugared lily, and faint mignonette."

He remembered, too, the barberries, which he had seen in America, while he was there from $I 783$ to $I 787$.

"The taste of barberries which have hung out in the snow during the severity of a North-American winter, I have in my mouth still, after an interval of thirty years; for I have met with no other taste in all that time at all like it. It remains by itself, almost like the impression of a sixth sense."

The early gardener restricted his culture to the proper periods for planting and sowing, and that was partly influenced by the writings of the ancients, or traditional precepts derived from them, and partly by astrological laws. $\mathrm{He}$ was not altogether ignorant of professional subtleties, for it 
appears that by grafting and other more occult processes, he endeavoured to modify the colour and flavour of fruit, and to bring it forward, so that, for instance, the grape and the cherry might be ready at the same time, which the mediæval expert sought to accomplish by grafting a vine slip on a cherry stock. The use of clay in grafting was already familiar. But seeing how imperfectly this important branch of the science is at present understood, we need not wonder at the rudeness of its development in the middle ages.

In Bacon's time tender fruit and other trees appear to have been protected by some system of stove, as he tells us in a passage of his Essays, already quoted; but neither Evelyn nor Worlidge goes beyond a hot-bed constructed in the ordinary way for bottom heat, and screened from the weather at night, or during the prevalence of frost, by an arched canopy of thatch or matting. Worlidge thought that the best description of a hotbed which he had yet (I677) seen was in Evelyn's Philosophical Discourse of Earth, 


\section{Gleanings in Old Garden Literature.}

commonly called his Terra; and he has transferred it to his own pages.

Evelyn considered stoves prejudicial in the conservatories, however. In his letter to the Earl of Sandwich, August 2 Ist, I668, he observes:-

"Stoves absolutely destroy our conservatories; but if they could be lined with cork I believe it would better secure them from the cold and moisture of the walls, than either mattresses or reeds with which we commonly cover them."

Beyond question, the science of constructing heating apparatus and regulating it, with the use of proper fuel, was in its infancy; and if certain classes of coal, heavily charged with sulphur, were burned, or coke, no delicate vegetation could exist in the atmosphere so created; and at Chelsea, according to Evelyn's testimony, a remedy for the smoke seems to have been found by keeping the doors and windows open! An account of the subterranean contrivance and other precautions formerly in use at the Apothecaries' Garden seemed to belong more fitly to the antecedent section, where it occurs. 
Breton, in his Fantasticks (1626), tells his reader to beware of hot-houses in November, lest he should catch cold. But whether he intends the word in a horticultural sense, or in what was in his time the more common one of a bagnio, is not altogether clear.

But there is little doubt that it was always the case in our country, as Breton states under March, that the cultivation of such delicate fruit as lemons, oranges, and pomegranates cost a good deal more than the result commercially justified.

The occupations connected with horticulture multiplied as time progressed, and the necessities or experience of consumers developed themselves more and more. To the simple gardener were gradually added the hoer, the engrafter or pruner, the fieldman, the mower, although these latter two appertain more properly to the agricultural department; and where, as at present, pigs, cows, and poultry were kept as part of the demesne, they had their cowherds, swineherds, and the like; and, on the whole, in looking over the 
historical and literary evidences, one is irresistibly led to the conclusion, that the facilities possessed by the fifteenth-century gardener and husbandman, while they were of course vastly inferior to those in our hands, were neither scanty nor relatively barbarous.

In the treatise of Walter de Biblesworth (fourteenth century), which is a general manual of education and demeanour, the author instructs his reader, as children of good right love to eat apples, to pare the fruit, take out the stalks, and plant the pips.

In his Fantasticks (1626) Breton says, under March :-

"The dayes begin to lengthen apace : the forward Gardens give many a fine Sallet; and a nose-gay of violets is a present for a Lady: the Prime-Rose is now in his Prime, and the Trees begin to bud, and the green spices (spikes) of grasse to peep out of the earth. Now is Nature as it were waking out of her sleep.

"It is now time, honest Country-man, to make an end of sowing of all sorts of small pulse. Graffe all sorts of fruit-trees, and with young Plants and Syens (scions) replenish your Nurcery. Cover the roots of all Trees that are bared, and with fat and pregnant 
Earth lay them close and warme. If any Trees grow barren, bore holes in the Roots, and drive pins or hard wedges of Oake wood therein; and that will produce fruitfulnesse. Transplant all sort of Summer Flowers, especially the Crown imperiall, Tulips, Hyacinths, and Narcissus of all shapes and colours."

He instructs us under September to make conserve of quince and barberry, to sow winter herbs, and set artichokes, rose-trees, apple-trees, wardens, strawberries, violets, and gillyflowers, to sow parsnips, and in dry weather to gather hops. Nor is it, says he, bad housewifery to make verjuice and pluck hemp.

Under April, in the same work, are enumerated citrons, melons, cucumbers, artichokes, and pole-hops. That month was considered the proper season for setting all these.

Breton gives us some good advice under September on the subject of windfalls :-

"Now as touching Windfalls, or such fruit as falleth from the trees, and are not gathered, they must not be laid with the fruit that is gathered; and of fallings there are two sorts, one may fall through 


\section{Gleanings in Old Garden Literature.}

ripeness, "and they are best, and may be kept to bake or roast; the other beaten down by the wind, and they must be spent as fruit (not being ripe), else they will wither and come to nothing ; and therefore it is not good by any means to beat down fruit with poles, or to carry them in carts, loose or jogging, or in half filled Sacks, where they may be bruised."

The practice of variegating the foliage of plants and shrubs was in the time of Charles II. evidently of some standing, for Worlidge devotes a chapter to what he calls "Variegated or Gilded Leafed Plants." $\mathrm{He}$ specifies the laurel, the box, the periwinkle, and rosemary. But he relates an anecdote, which may shew that the process was sometimes accidentally accomplished without human agency:

"Travelling," he writes, "through some part of Glamorganshire, and discoursing of these Variegated greens, one of that country assured me that in that country was a very large Holly with all its leaves curiously Gilded, growing wild in a wood, which was not unlikely, for from the woods they first came."

He brings his narrative about variegation 


\section{Variegation of Foliage. $\quad 89$}

of foliage to a close with an account of an embroidered elder.

"It happened about two years since (being Anno I674), A Gardener near London by accident discovered in a hedge an Elder-tree, whose leaves seem'd to be embroidered by the swelling of the veins that spread themselves throughout the Leaf, and appearing of a different colour from the rest of it; they being of a curious texture made them appear to the eye most beautiful and rare."

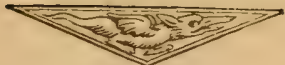




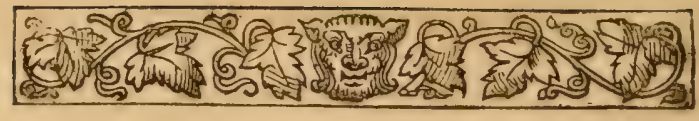

IX.

Bacon as a Gardener.

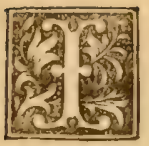

HAVE drawn attention in a former place to the warm interest manifested by this great man in his Essays in the subject before us. But there the topic was treated in an incidental and cursory way. In his Sylva Sylvarum, or A Naturall Historie, In Ten Centuries, a posthumous publication edited by Rawley, and printed in 1627 , he enters upon the matter copiously and systematically; it occupies in fact the whole of the fifth and sixth, and part of the seventh, Century.

Bacon, for whose immense intellectual grasp no point of research was too large or too small, is supposed to have had a hand in laying out the fine grounds which, before 


\section{Bacon as a Gardener. $9 \mathrm{I}$}

their lamentable curtailment, adorned his own Inn of Court; and doubtless the experiments in horticulture which he reports in the Sylva Sylvarum were made by himself or under his auspices and direction at Gorhambury. It is affecting, even at so long a distance of time, to contemplate the lifelong struggle for the mastery of universal knowledge in the regions of philosophy and science, and the indefatigable labours involved even in arriving at the results, which are presented to us in this volume.

Bacon did not witness the appearance of - his Natural History in print, and from the mode in which the text is arranged, it is almost inferable that the editor is responsible for the order of the contents. For the section opens rather abruptly with an account of tests made with various sorts of manure, as regards their influence on crops :-

"There were sowen in a Bed," the author tells us, "Turnip-seed, Radish-seed, Wheat, Cuccumberseed, and Pease. The Bed we call a Hot-bed, and the Manner of it is this. There was taken Horse-dung, old, and well-rotted. This was laid upon a Banke, 
halfe a foot high, and supported round about with Planks; And upon the Top was cast Sifted Earth, some two Fingers deepe, and then the seed Sprinkled upon it, having beene steep'd all night in Water mixed with Cow-dung. The Turnip-Seed, and the Wheat came up halfe an inch above Ground, within two days after, without any Watring. The Rest the third day. The experiment was made in October; And (it may be) in the Spring the Accelerating would have been the speedier. This is a Noble Experiment ; For without this helpe this would have beene foure times as long in comming up. . . . It may be tried also with Cherries, Strawberries, and other Fruit, which are dearest, when they come early."

\section{He adds as to strawberries :-}

"Strawberries watered now and then (as once in three dayes) with Water, wherein hath beene steeped Sheepes-Dung, or Pigeon-dung, will prevent and come early. And it is like the same Effect would follow in other Berries, Herbes, Flowers, Graines, and Trees. And therefore it is an Experiment, though vulgar in Strawberries, yet not brought into use generally : For it is usuall to helpe the Ground with Mucke; And likewise to recomfort it sometimes with Mucke put to the Roots; But to water it with Muckewater, which is like to be more forcible, is not practised."

Here we have our liquid manure fore- 
shadowed. I proceed to cite another experiment with different kinds of dressing :-

"There was Wheat, steeped in Water, mixed with Cow-Dung, other in Water mixed with Horse-Dung, other in Water mixed with Pigeon-Dung, other in Urine of Man, other in Water mixed with Chalke powdred : other in Water mixed with Soot, other in Water mixed with Ashes, other in Water mixed with Bay-salt, other in Claret wine, other in Malmsey, other in Spirit of wine. The proportion of the mixture was, a fourth part of the Ingredients to the others, save that there was of the Salt not above an eighth part. The Urine, and Wines, and Spirit of wine, were simple without mixture of water. The time of the steeping was twelve houres. The Time of the yeare October. There was also other Wheat sowen unsteeped, but watered twice a Day with warme water. There was also other Wheat sowen simple to compare it with the rest. The Event was : that those that were in the mixture of Dung, and Urine, and Soot, Chalke, Ashes, and Salt, came up within six dayes : And those that afterwards proved the Highest, Thickest, and most Lustie, were : first, the Urine; next, the Salt ; next, the Wheat simple of it selfe, unsteeped and unwatered; next, the watered twice a day with warme water; next, the Claret wine. So that these three [two] last were slower than the ordinary Wheat of it selfe ; and this Culture did rather retard than advance. As for those that were steeped in Malmsey and Spirit of 


\section{Gleanings in Old Garden Literature.}

Wine, they came not up at all. This is a Rich Experiment for Profit."

In the Jewel-House of Art and Nature, by Sir Hugh Platt, I594, there is a representation of an ear of summer barley, forty-five inches long, grown in ground manured with soap ashes. In South Australia the experiment has been tried of placing a peach-stone in the ground, and dressing the latter regularly with soapsuds, with the result that a strong plant has been reared, and abundance of fruit obtained.

Bacon was, of course, aware that excessive nourishment was prejudicial to vegetation; but we are accustomed to consider that that is more universally the case than he seems to intimate as his opinion, for he says : "Dung, or Chalke, or Bloud, applied in Substance (seasonably) to the Roots of Trees, doth set them forwards. But to doe it unto Herbs, without a mixture of water or earth, it may bee these Helpes are too Hot." No doubt; and the result often is also in regard to many fruit-trees, that where the ground is too rich, they run to wood, except such plants as 


\section{Bacon as a Gardener.}

strawberries and raspberries, or such as the rose, which are not easily over-manured.

He does not forget that there is another essential requisite in keeping trees in a state of full bearing strength.

"Besides the two Means of Accelerating Germination formerly described, the Mending of the Nourishment and Comforting of the Spirit of the Plant, there is a third ; which is the Making way for the Easie Comming to the Nourishment, and drawing it. And therefore gentle Digging and Loosening of the Earth about the Roots of Trees, And the Removing Herbes and Flowers into new Earth, once in two yeares, (which is the same thing; For the new Earth is ever - looser,) dothe greatly further the Prospering and Earlinesse' of Plants.

"But the most admirable Acceleration by Facilitating the Nourishment, is that of Water. For a Standard of a Damaske Rose with the Root on, was set in a Chamber, where no Fire was, upright in an Earthen Pan, full of Faire Water, without any Mixture, halfe a Foot under the Water, the Standard being more than two foot high above the Water: Within the Space of ten dayes the Standard did put forth a faire Greene leafe, and some other little buds, which stood at a stay, without any Shew of decay or withering, more than seven Daies. But afterwards that Leafe faded, but the young Buds did sprout on; which after- 
ward opened into faire Leaves, in the space of three Moneths; and continued for a while after, till upon Removall wee left the Triall. But note that the Leaves were somewhat paler, and lighter-coloured, than the Leaves use to bee abroad. Note that the first Buds were in the End of October ; and it is likely that if it had beene in the Spring time, it would have put forth with greater strength, and (it may be) to have growne on to beare Flowers. By this Meanes, you may have, (as it seemeth) Roses set in the Middest of a Poole, being supported with some stay; Which is Matter of Rarenesse and Pleasure, though of little Use. This is the more strange, for that the like Rose-standard was put, at the same time, into Water mixed with Horsedung, the Horse-dung about the fourth Part to the Water; and in foure Moneths space (while it was observed) put not forth any Leafe, though divers Buds, at the first, as the other.

"A Dutch Flower, that had a Bulbous Root, was likewise put, at the same time, all under Water, some two and continued long after further Growing. There were also put in a Beet-Root, a Borrage-Root, and a RaddishRoot, which had all their Leaves cast almost close to the Roots, and within six weekes had faire Leaves, And so continued till the end of November.

" Note that if Roots, or Pease, or Flowers may bee Accelerated in their Comming and Ripening, there is a double Profit; The one in the high price which these things bear when they come early; the other in the 
Swiftnesse of their Returnes : For in some Grounds which are strong, you shall have a Raddish, etc., come in a Month; that in other Grounds will not come in two; And so make double Returnes."

These and other similar memoranda have for us a high and enduring interest-an interest created and sustained by the vast and imperishable fame of the writer. It is excessively likely that we have at the present moment among us many respectable nurserymen who have never heard the name of Bacon, and who, if this book were placed in their hands, would pronounce his experiments empirical and his remarks obsolete. From a commonplace standpoint most assuredly they are, and yet I deem them worth reproducing here, because they illustrate one of the less familiar aspects of a many-sided intellect.

The value and bearing of these observations in the eyes of practical or scientific specialists of our day are not a matter, I apprehend, of the smallest consequence. But we have to look at the man and the time. We have to $r$ nember his imperfect 
training and opportunities, the incessant demands on him from official and social duties, and his manifold literary engagements. Yet what minute and affectionate attention to all the details of the garden, what a wide and inexhaustible sympathy with the beauties and wonders of Nature, these pages of the Sylva Sylvarum disclose to us! No point is too minute to attract and deserve his notice; and the operations conducted under his eye are described as copiously and enthusiastically, although they may refer to some comparatively trivial matter, as if they formed the key-stone to a new system of philosophy. Of this we have witnessed evidence in the passages already cited, and we shall meet with abundance of similar traits as we proceed.

After a series of elaborate directions for grafting roses, Bacon refers to a common notion of his time in relation to fruit trees.

"Men have entertained a Conceit," says he, "that sheweth prettily, Namely, that if you graft a Latecomming Fruit upon a Stocke of a Fruit-tree that commeth early, the Graft will beare Fruit Early; as a 


\section{Bacon as a Gardener.}

Peach upon a Cherry; And contrariwise, if an EarlyComming Fruit upon a Stocke of a Fruit Tree that Commeth late, the Graft will beare Fruit late, As a Cherry upon a Peach. But these are but Imaginations, and untrue. The cause is, for that the Cions overruleth the Stocke quite; And the Stocke is but Passive onely, and giveth Aliment, but no Motion to the Graft."

Here is another idea, which still forms part of the popular creed, and perhaps rightly :

"A Tree, at the first Rooting, should not bee shaken, until it hath taken Root fully: And therefore some have put two little Forkes about the Bottome of their Trees, to keepe them upright; But after a yeares Rooting, then shaking doth the Tree good, by Loosening of the Earth, and (perhaps) by exercising (as it were) and stirring the Sap of the Tree."

It is in this case, as in others, a truism, that there is scarcely perhaps a first-class florist of the day, who could not revise every page of the Sylva Sylvarum, and who might not characterize it as a waste of time even to peruse such a volume. Of course, the same argument may be employed towards all obsolete treatises on progressive sciences; 


\section{Ioo Gleanings in Old Garden Literature.}

but it is really one of small validity as a rule, and so far as Bacon is concerned of none whatever.

What we have to do here is to throw ourselves back two centuries or so, and stand by the side of this illustrious man, realizing the difficulties under which he worked, the important public avocations which demanded his time and thought, the slender encouragement afforded to such subjects and such inquiries; and then, when we have armed ourselves with the means of more truly judging, let us consider his ardour in experimental philosophy, his minute attention to details, his cordial interest in all topics connected with Nature, his wide range of culture and largeness of sympathy, his comprehensive grasp and his profound and delicate insight, and his descent from the woolsack to investigate the economy of manure beds. Only More before him had displayed any share of this versatility of genius and breadth of learning on the part of a professional lawyer and a lord chancellor; and in the long roll of keepers of the Great 
Seal there is but a single other name which we can couple with those earlier two-the name of Brougham. But to return to the Sylva Sylvarum. Speaking of wall fruit, the author observes :-

"It is usually practised, to set Trees that require much Sunne, upon Walls against the South; as Apricots, Peaches, Plumn, Vines, Figs, and the like. It hath a double Commoditie; The one, the Heat of the Wall by Reflexion; The other, the Taking away of the Shade; For when a Tree groweth round, the upper Boughes over-shadow the lower : But when it is spread upon a Wall, the Sunne commeth alike, upon the upper, and lower Branches.

"It hath also been practised (by some) to pull off some Leaves from the Trees so spread, that the Sunne may come upon the Bough and Fruit the better.' There hath been practised also a Curiositie, to set a Tree upon the North-Side of a Wall, and at a little height, to draw him thorow the Wall, and spread him upon the South. Side: Conceiving that the Root and lower Part of the Stocke should enjoy the Freshnesse of the Shade; and the Upper Boughes, and Fruit, the Comfort of the Sunne. But it sorted not ; the Cause is, for that

${ }^{1}$ This idea is not generally approved at present, because, if the foliage is too thin when the fruit is swelling, the heat of the autumn sun on the wall is apt to draw the moisture. 
the Root requireth some Comfort from the Sunne, though under the Earth, as well as the Bodie: and the Lower Part of the Bodie more than the Upper, as wee see in Compassing a Tree below with straw.

"The Lownesse of the Bough, where the Fruit commeth, maketh the Fruit greater, and to ripen better; For you shall ever see in Apricots, Peaches, or Melo-Cotones, upon a wall, the greatest Fruits towards the Bottome. And in France the Grapes that make the Wine, grow upon low Vines, bound to small Stakes. And the raised Vines in Arbours make but Verjuyce. It is true, that in Italy, and other Countries, where they have hotter Sunne, they raise them upon Elmes, and Trees ; But I conceive, that if the French Manner of Planting low, were brought in use there, their Wines would be stronger and sweeter. But it is more chargeable in respect of the props. It were good to trie whether a Tree grafted somewhat neare the Ground, and the lower boughes onely maintained, and the higher continually proined off, would not make a larger Fruit."

These are his remarks and suggestions on grafting :-

"There is no doubt but that Grafting (for the most Part) doth meliorate the Fruit. The Cause is manifest; For that the Nourishment is better prepared in the Stocke, than in the Crude Earth: But yet note well, that there bee some Trees, that are said to come up more happily from the Kernell, than from the Graft; As the 
Peach and Melocotone. The Cause I suppose to bee, for that those Plants require a Nourishment of great Moisture; And though the Nourishment of the Stocke be finer, and better prepared, yet it is not so moist, and plentifull, as the Nourishment of the Earth. And indeed we see those Fruits are very Cold Fruits in their Nature.

"It hath beene received, that a Smaller Peare, grafted upon a Stocke that beareth a greater Peare, will become Great. But I thinke it is as true, as that of the PrimeFruit upon the Late Stocke; And ècontroverso; which we rejected before : for the Cions will governe. Neverthelesse it is probable enough, that if you can get a Cions to grow upon a Stocke of another kinde, that is much moyster than his own Stocke, it may make the Fruit Greater, because it will yeeld more plentifull Nourishment; Though it is like it will make the Fruit Baser. But generally the Grafting is upon a drier Stock; As the Apple upon a Crab; the Peare upon a Thorne; \&c. Yet it is reported, that in the Low-Countries they will graft an Apple-Cions upon the Stock of a Colewort, and it will beare a great flaggy Apple; The Kernell of which, if it be set, will bee a Colezvort, and not an Apple. I.t were good to trie, whether an Apple-Cions will prosper, if it be grafted upon a Sallowi, or upon a Poplar, or upon an Alder, or upon an Elmee, or upon an Horse-Plumme, which are the moystest of Trees. I have heard that it hath been tried upon an Elme, and succeeded.

"It is manifest by Experience, that Flowers Removed wax greater, because the Nourishment is more easily 
come by, in the loose Earth. It may bee, that Oft Regrafting of the same Cions, may likewise make Fruit greater; As if you take a Cions, and graft it upon a Stocke the first yeare; And then cut it off, and graft it upon another Stock the second yeare ; and so for a third; Or fourth yeare; And then let it rest, it will yeeld afterward, when it beareth, the greater Fruit."

Naturally Bacon is more or less frequently found basing his conclusions on imperfect information or data; but at all events he discarded most of the vulgar errors of his time in relation to philosophical and scientific investigations. He says :-

"There are many Ancient and Received Traditions and Observations, touching the Sympathy and Antipathy of Plants; For that some will thrive best growing neare others; which they impute to Sympathy: And some worse; $w^{\text {ch }}$ they impute to Antipathy. But these are Idle and Ignorant Conceits; And forsake the true Indication of the Causes; as the most Part of Experiments, that concerne Sympathies and Antipathies doe. For as to Plants, neither is there any such Secret Friendship, or Hatred, as they imagine; And if we should be content to call it Sympathy, and Antipathy, it is utterly mistaken; For their Sympathy is an Antipathy, and their Antipathy is a Sympathy: For it is thus; Wheresoever one Plant draweth such a particular Juyce out of 
the Earth, as it qualifieth the Earth; So as that Juyce which remaineth is fit for the other Plant, there the Neighbourhood doth good; Because the Nourishments are contrarie, or severall : But where two Plants draw (much) the same Juyce, there the Neighbourhood hurteth ; For the one deceiveth the other."

A little farther on, he has more to tell us about these superstitions, absurdities, and prejudices:-

"Some of the Ancients, and likewise divers of the Moderne Writers, that have laboured in Naturall Magick, have noted a Sympathy, between the Sunne, Moone, and some Principall Starres; And cetaine Herbs, and Plants. And so they have denominated some Herbs Solar, and some Lunar; And such like Toyes put into great Words. It is manifest, that there are some Flowers, that have Respect to the Simne, in two Kindes; The one by Opening and Shutting; And the other by Bowing and Inclining the Head. For Mary-golds, Tulippa's, Pimpernell, and indeed most Flowers, doe open or spread their Leaves abroad, when the Sunne shineth serene and faire: And againe, (in some part,) close them, or gather them inward, either towards Night, or when the Skie is overcast. Of this there needeth no such Solemne Reason to be assigned ; As to say, that they rejoyce at the presence of the Sunne; And mourne at the absence thereof. For it is Nothing else, but a little Loading of the Leaves, 
and Swelling them at the Bottome, with the Moisture of the Aire; whereas the drie Aire doth extend them: And they make it a Peece of the wonder, that Garden Claver will hide the Stalke, when the Sunne sheweth bright; Which is nothing, but a full Expansion of the leaves. For the Bowing and Inclining the Head; it is found in the great Flower of the Sumne; in Marigolds, Wart-wort, Mallow-Flowers ; and others. The Cause is somewhat more Obscure than the former; But I take it to bee no other, but that the Part against which the sumne beateth, waxeth more faint and flaccide in the Stalke ; And therby lesse able to support the Flower."

Like his contemporary Shakespeare, he did not scruple or disdain to avail himself of all possible vehicles for illustration or comparison. When he wrote the passage which I copy below, he had in his remembrance a scene at which he had been present; it is a curious bit-a fragment of the popular street-life of London, which one would have rather expected to encounter in the pages of Strutt or Brand :-

"What a little Moisture will doe in Vegetables, even though they be dead, and severed from the Earth, appeareth wel in the Experiment of Iuglers. They take the Bcard of an Oate; which (if you marke it well,) 


\section{Bacon as a Gardener.}

is wreathed at the Bottome and one smooth entire

Straw at the Top. They take onely the Part that is Wreathed, and cut off the other, leaving the Beard halfe the Breadth of a Finger in length. Then they make a little Crosse of a Quill, long-wayes of that Part of the Quill, which hath the Pith; And Crosse-wayes of that Peece of the Quill without Pith; The whole Crosse being the Breadth of a Finger high. Then they pricke the Bottome where the Pith is, and thereinto they put the Oatun-beard, leaving halfe of it sticking forth of the Quill: Then they take a little white Box of wood, to deceive Men, as if somewhat in the Box did worke the Feat: In which, with a Pinne, they make a little Hole, enough to take the Beard, but not to let the Crosse sinke downe, but to stick. Then likewise by way of Imposture, they make a Question; As, Who is the Fairest Woman in the Company? Or, Who hath a Glove, or Card? And cause Another to name divers persons : And upon every Naming they stick the Crosse in the Box, having first put it towards their mouth, as if they charmed it; And the Crosse stirreth not; But when they come to the Person that they would take; As they hold the Crosse to their Mouth, they touch the Beard with the Tip of their Tongue, and wet it; And so stick the Crosse in the Box; And then you shall see it turne finely and softly, three or foure Turnes; which is caused by the untwining of the Beard by the Moisture. You may see it more evidently, if you sticke the Crosse betweene your fingers, in stead of the Box; And therefore you may see, that this Motion, which is 
Effected by so little Wet, is stronger than the Closing or Bending of the Head of a Marigold."

His Sixth Century Bacon opens with a disquisition on what he calls Curiosities, such as the growth of several kinds of fruit on one tree, coreless fruit, double flowers, and flowers of special colours. I wish very heartily that I had space to accommodate a few more extracts from this extraordinary work ; but I must ask the reader to be satisfied with one more, and that on the subject of degeneration by neglect:-

"The rule is certaine, that Plants for want of Culture, degenerate to be baser in the same Kinde; And sometimes so farre, as to change into another Kinde. I. The Standinglong, and not being Removed, maketh them degenerate. 2. Drought, unlesse the Earth of it selfe bee moist, doth the like. 3. So doth Removing into worse Earth, or Forlicaring to compost the Earth; As wee see that IVater-MInt turneth into Field-Mint; And the Colewort into Rape by Neglect, \&c.

"Whatsoever Fruit useth to be set upon a Root, or a Slip, if it be sowne, will degenerate. Grapes sowne, Figs, Almonds, Pomgranate Kernels sozune; make the Fruits degenerate, and become IVilde. And againe, Most of hose Fraits that use to be grafted, if they be set of 
Kernels, or Stones, degenerate. It is true, that Peaches, (as hath beene touched before,) doe better upon Stones Set, than upon Grafting: And the Rule of Exception should seeme to be this; That whatsoever Plant requireth much Moisture, prospereth better upon the Stone, or Kernell, than upon the Graft. For the Stocke, though it giveth a finer Nourishment, yet it giveth a scanter, than the Earth at large.

"Seeds, if they bee very Old, and yet have strength enough to bring forth a Plant, make the Plant degenerate. And therefore skilfull Gardiners make triall of the Seeds, before they buy them, whether they be good or no, by Putting them into Water gently Boyled; And if they bee good, they will sprout within halfe an Houre.

"It is strange which is reported, that Basill too much exposed to the Sunne, doth turne into Wilde Time: Although those two Herbs seeme to have small Affinity; but Basill is almost the onely Hot Herbe, that hath Fat and Succulent Leaves; Which Oylinesse, if it be drawne forth by the Sunne, it is like it will make a very great Change.

"There is an old tradition, that Boughs of Oake, put into the Earth, will put forth Wilde Vines: Which if it be true, (no doubt,) it is not the Oake that turneth into a Vine, but the Oake-Bongh Putrifying, qualifieth the Earth, to put forth a Vine of it selfe."

He has a good deal to say about the colours of flowers and fruit, and after pointing out to 


\section{I Gleanings in Old Garden Literature.}

us that in berries the white is commonly more delicate and sweet in taste, as in grapes, rasps, currants, and strawberries, so in fruit the white is usually inferior :-

"As in Peare-Plumns, Damasins, \&c. And the Choicest Plummes are blacke; The Mulberrie, (which though they call it a Berry, is a Fruit,) is better the Blacke, than the White. The Harvest White-Plumnne, is a base Plumme; And the Verdoccio and White DatePlumme, are no very good Plummes. The Canse is, for that they are all Over-watry: Whereas an higher Concoction is required for Sweetnesse, or Pleasure of Taste; And therefore all your dainty Plummes, are a little drie, and come from the Stone; As the MinsklePlumme, the Damasin-Plumme, the Peach, the Apricot, \&c. Yet some Fruits, which grow not to be Blacke, are of the Nature of Berries, sweetest such as are Paler; As the Cour-Cherry, which inclineth more to White, is sweeter than the Red; but the Egriot is more sowre."

Bacon was instrumental in laying out and planting the garden and grounds of the Inn, of which he is the greatest ornament. Much of the space which he secured for this object still remains consecrated to the original purpose; but Verulam Buildings have en- 
croached on a portion; the average lawyer or parson has no sentiment; the Antients of Gray's Inn are as destitute of esprit as the members of Convocation or the Dome of St. Paul's.

Contemporary with Bacon lived Richard Gardiner, of Shrewsbury, who in 1603 put forth Profitable Instructions for the Manuring, Sowing, and Planting of Kitchen Gardens.

The Preface of this work is addressed by the writer to "his loving neighbours and friends, within the towne of Shrewsburie, in the countie of Salop;" and it is manifest from the tone and language of it, as well as from the presence of two prayers at the end by way of peroration, that Gardiner was in holy orders, although no mention of that fact occurs on the title. He seems to say that at that date the condition of horticulture in Shropshire among the lower ranks was very unsatisfactory ; but he trusts that his publication will inaugurate an improved state of affairs, and in a copy of encomiastic verses by a friend, Edward Thorne (or Thornes, of Melverley), this sanguine view is supported 
I 2 Gleanings in Old Garden Literature.

and echoed. I am afraid that I should not be thanked for quoting Thorne at large; yet let me give four lines of his doggerel eulogy :-

"The rich likewise and better sorte,

His labours could not misse :

Which makes them many times to thinke,

That Salop London is."

To do no more than justice to Gardiner himself, however, his tract deals in a sensible and practical way enough with the subject undertaken. He includes beans, carrots, turnips, onions, cucumbers (which Thorne, by the way, approaches nearer to the French by terming concombers), artichokes, cabbages, lettuces, and parsnips; and he very strongly represents the advantage which might accrue from a more extended cultivation of these vegetables, especially carrots, instead of depending on the continental supply, which afforded to the foreigners so lucrative a trade. He dwells most in detail on the carrot.

He particularises three species as being 
then known among us, or at least in Shropshire,- - the great long yellow carrot, the great short carrot, and the wild carrot; of which the last was worthless for culinary purposes. We cannot help observing that, besides his devout preface and the prayers which wind up his Instructions, he lays stress, in common with most, if not all, of the old school, on an observance of the planetary conditions essential to the successful growth of crops. But he quaintly intersperses ordinary rules for sowing or planting with pious sentiments and even objurgations; for, in speaking of the vendors of bad seed, he denounces them as Caterpillars, declares them worthy of execution, avers that the Almighty God doth behold this monstrous deceit, and trusts that $\mathrm{He}$ will either turn their hearts or confound their proceedings.

So saith the mild and meek pastor. If he had only known it, his little book would have been infinitely more agreeable without this theological bitterness and invective. It is so far a gain that in the concluding Prayers 
I I4 Gleanings in Old Garden Literature.

he has not brought in any pleasant wishes for the fraudulent seedsmen, and, indeed, these compositions seem to have nothing to do with the rest of the volume, as they might with equal propriety have been tacked on to anything else.

If one turns back to Bacon, after perusing the pages of such a man, what a distance in intellect there seems to be between the Viscount St. Alban and this worthy Salopian kitchen-gardener; and yet, measured by his rural contemporaries, the latter is to be viewed as a reformer and the holder of enlightened opinions. 


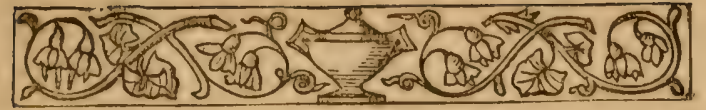

$\mathrm{X}$.

Herbs and Vegetables-High Price of Vegetables in Early Times - The Suburbs of London celebrated as a GROWING-GROUND-RARITY AND ESTImation of the Potato-AsparagusSanitary Value of Vegetables.

ARSLEY, garlic, fennel, chibbals or small onions (the civolli or 2.5 cepula of Johannes de Garlandia), the leek, and other important factors in the culinary art were now in general use, not only among the professed cooks of the wealthier classes, but among the cottagers, whose humble fare they contributed to render more savoury.

Among vegetables the surviving records of the fifteenth century indicate the parsnep, the beetroot, the lettuce, the green pea, and 
others of which I shall give an account; and of fruit and other trees, the pearmain (a species of apple mentioned in Drayton's Polyolbion as a novelty), the pomegranate, the bullace-plum, the mulberry, the masculum (which is glossed orange), the damson, the filbert, the almond, the dog-rose, the sycamore, and the cedar. The peach was also known, as well as the apricot or apricock; but the nectarine is not specified; it may, like the apricot, have been included among the plums, although in the stone and skin both so materially differ therefrom.

Onion (yne-leac) and garlic (gar-leac) have been noticed as entering into the cookery of the eleventh or twelfth century.

Now enters the onion-seller as an independent calling, shewing how largely that precious esculent began to enter into our cookery; and also the vendor of apples.

The Spanish onion was in use in the time of Charles II. Evelyn reports it in his letter to Lord Sandwich (r668) :-

"The Spanish onion seed is of all other the most excellent, and yet I am not certain whether that which 
we have out of Flanders and St. Omers be all the Spanish seed which we know of. My Lady Clarendon (when living) was wont to furnish me with seed that produced me prodigious crops."

The radish, as well as the onion, had been known in the eleventh century. Worlidge says: "Radishes in the more Southern Countries are a delicate meat, especially if sown in brackish lands, or watered with brackish waters, and therefore were they in such esteem with the Egyptians." He goes through the various known kinds, including the horse-radish, which was then already in vogue as a sauce.

An entry in the Privy Purse Expenses of Henry VII., under May 24th, r496, seems to point to the payment of a reward-and a very handsome one-for a dish of green peas very early indeed in the season. They must have been reared in a very sheltered spot, or with artificial warmth. The amount given to the donor was $3^{s .} 4 d .=£ \mathrm{I}$ of our money. The item runs thus: "To a man for a present of pescoddes $3 s$. $4 d$." This could scarcely have been for seed, as it was 
too late to sow them; the character of the premium offered suggests a more immediate gratification of the royal palate.

The peck of green peas, which is said to be offered for sale annually at Covent Garden Market for sixpence as a customary obligation, is not claimed till the Ist of June.

The artichoke described by Turner and Gerarde, authors of Herbals between $155^{\circ}$ and 1597 , is that of which the head supplies the edible portion. Turner recommends that the leaves should be boiled with wine and oil. Gerarde tells us that they were sometimes eaten raw with pepper and salt, or else boiled in broth with pepper seasoning, and served "with other junkets." Parkinson, in his Theatre of Plants (I629), speaking of the Terusalem or sun-flower artichoke, which is totally distinct, seems to say that they used in his day to make pies of the tubers boiled, "which," he assures us, "are a delicate kind of baked meat."

The common artichoke is evidently, as Pliny noticed, an evolution from the thistle; 
and it is the only species of the latter which is eaten on the hither side of the Tweed.

The suburbs of London were enjoying in the time of James I., as they probably had under his predecessor, a high character for the vegetables, especially cabbages and lettuces, which they sent to market. Busino the Italian, who was here in $1617-I 8$, and who disparages our wine and our fruit, speaks highly of our cabbages. It is highly curious to find a custom, which I remember still prevalent at Brompton in and about 1840 , mentioned by our visitor as coming under his observation more than two centuries before-I allude to the practice of partaking of fruit at the nurseries, and gathering it on the spot; and another odd thing Busino noted, which was the way the people in London had of eating fruit in the streets as they went along, as well as at places of amusement.

It is incidentally brought to light, at the same time, that in 1619 the prices for some descriptions of vegetables were extravagantly high. Lysons says that "in the bill for 
Alleyn's foundation dinner at Dulwich, September I3th, I6I9, two cauliflowers are charged $3 s$. (about $9 s$. perhaps according to the present value of money), thirty lettuces $4 d$., sixteen artichokes $3 s .4 d$., while carrots, turnips, rosemary, and bays are estimated only at $4 d$. altogether.

It is well known that the POTATo was introduced into England in the reign of Elizabeth, and Gerarde the Herbalist, who had some in his garden in Holborn, figures a specimen in his book printed in 1597 . $\mathrm{He}$ informs us that he had received one from Virginia; but we are left under the necessity of conjecturing whether he was indebted for the present to the hands of Sir Walter himself, and whether it is the very one engraved. Both he and Dr. Venner of Bath considered the potato conducive to flatulency, like the Jerusalem artichoke.

A recipe for a tart which occurs in Dawson's Good Houservife's Jervel ( 1596 ) treats a potato as a leading ingredient, - a testimony to the rate at which the vegetable was then prized, 
like some newly-landed product from rich Cathay or Araby the Blest:-

"Take two quinces, and two or three burre rootes and a Potaton, and pare youre Potaton and scrapeyour roots, and put them into a quart of wine, and let them boyle till they bee tender, and put in an ounce of dates, and when they be boiled tender, drawe them through a strainer, wine and all, and then put in the yolkes of eight eggs, and the braynes of three or four cockesparrowes, and straine them into the other, and a little rosewater, and seeth them all with sugar, cinnamon, and ginger, and cloves, and mace ; and put in a little sweet butter, and set it upon a chafing-dish of coles between two platters, to let it boyle till it be something bigge."

Long after the age of Elizabeth the potato remained a rarity in this country. As Dr. Rimbault has pointed out, it was long ranked with the date, the orange, and the plum of Genoa; and from a passage in Massinger's New Way to pay Old Debts (1633), it may be inferred that it was at that period still regarded as a dainty.

It seems to be thought that potatoes were first propagated in Ireland in 16 Io or there- 
I 22 Gleanings in Old Garden Litcrature.

abouts, just when James I. was carrying out the plantation of Ulster.

Worlidge remarks that potatoes are much used in Ireland and in America as bread, and are of themselves also an usual food; which is to some extent an explanation of the pains which John Forster, of Hanlop, took in 1664 to bring the potato into notice and more general use as a vegetable. They planted them in the same way as ourselves; and Worlidge acquaints us that in Wales they were accustomed to cultivate both them and the artichoke on the vacant spaces along the highways,-those green slips of ground about which so much is being now said.

But while we listen to what Worlidge has to tell us about the conversion of the potato to farinaceous objects, we must bear in mind what Venner has set down about its ordinary employment as a vegetable in 1620 . The reader of these pages will recollect the tradition that the first tubers from Virginia were given by Sir Walter Raleigh to the grandfather of Sir Robert Southwell. The root had, perhaps, been known in Spain prior to 
its introduction among us; but, although those imported from Spanish ports hither were distinguished from such as came from America, both doubtless were of a common Virginian parentage. In the earlier part of the seventeenth century, however, the Spanish potato was still preferred to those of English growth.

In the most ancient bills of fare many products of the kitchen-garden, which have long acquired a commonplace character, were still deficient, as asparagus, sea-kale, the cucumber, the artichoke, and, among fruits, the melon, the gooseberry, and the currant; unless, owing to the obscure nomenclature, they evade our recognition.

But the asparagus was extensively grown in the seventeenth century, and the cultivated sort seems to have been brought from Holland, although it was found wild in Worlidge's time (1677) in many places, including some meadows near Bristol; "wild or at least some bastard kind of them," are his words, and he adds, "But our more fair and large, usually called Dutch Asparagus, 
are propagated from seed." He goes at greater length into the method of propagation than I have any commission or need to do ; but I may just note that he judged it time to let the plants run to seed, when green peas and the Jerusalem artichoke came in.

Evelyn, in his letter to Lord Sandwich, August 2 Ist, I668, confirms his lordship's estimate of the wild asparagus in Lincolnshire and elsewhere, and describes it as "small and bitter, and not comparable to the cultivated."

The practice of salting vegetables in early days probably arose from the imperfect knowledge of the succession of sorts, especially in the north, rather than from their scarcity. But it appears that so late as 1595 high prices were still paid for imported cabbages and carrots. At a later date, Hull was a celebrated mart for cabbages and onions, of which the latter were sold, as now, by the rope. From abroad, particularly from the Netherlands, new varieties found their way to us, and a specimen for seed was, of course, at all times a welcome gift either to the professional or private grower. 
Vegetables, however, in the course of time, really abounded. With the exception of a few, which have been more modernly introduced, the tables of Charles II.'s Englishman and Englishwoman wanted little in this way.

Their more extensive use in England was attended by the unexpected and beneficent effect of diminishing the ravages of leprosy. This fact was first pointed out by Gilbert White, in his Natural History of Selborne; and there is little doubt, as I have suggested elsewhere, that the public health of England, and our pecuniary interests also, would be profited by a larger recourse to fish and green food and a more restricted employment of butcher's meat.

A free resort to vegetables, together with the removal of the necessity for using salt flesh to so great an extent, has also been instrumental in liberating us from a second scourge,- - the scurvy, for which an English naval surgeon,* in the time of Charles I., was

* The Surgeon's Mate, or Military and Domestique 
I 26 Gleanings in Old Garden Literature.

the earliest who discovered and recommended the old remedy of lemon-juice.

Sungery. By John Woodall, Master in Chirurgery. London, 1639, folio. For fuller particulars see Hazlitt's Bibliographical Collections, 2nd series, I8S2, p. 659 .

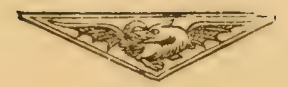




\section{XI.}

Fruit-Trees - Home-made Wine- Beer

-Bacon and Shakespeare on the STRAWBERRY.

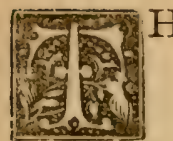

$\mathrm{HE}$ cultivation of the vine was prosecuted with much assiduity here in the sixteenth century. A Nominale of that date devotes a short section to the several terms applied to that valuable plant and its parts, and to the fruit. We find four Low Latin words for the grape, besides one for what is called the raisin; and the compiler, in introducing vinea, does so in a way which helps us to believe that grape-growers had become in his day numerous and successful. He says : "Hec vinea, est locus ubique usitatus."

The Italian visitor to Burleigh in James I.'s time, Orazio Busino, already cited, expressed 
I 28 Gleanings in Old Garden Literature.

to Lord Exeter a doubt whether the grapes which he tasted there could be made into good wine; but there is no doubt that wine of domestic vintage was commonly used, though not many degrees removed, perhaps, from the true vin ordinaire which you find in the cottages of the French peasantry. Lord Exeter told his Italian caller that his people were more hopeful as to the kind of compound which the Burleigh grapes would make. But until the artificial process of growth under glass at a high temperature was understood, our home-reared grapes were as sour as the October peach in a cold autumn is to-day. It is only in exceptional seasons that our out-of-door sweet-water grape arrives at present to anything approaching perfection. Wine of all sorts was, of course, to be had here from a very early date at a comparatively moderate price. Whittinton, in his Vulgaria (I 524), says: "A gallon of swete wyne is at viii. pens in London." It appears from an original license, granted by $\mathrm{Sir}$ Walter Raleigh in 1584 to Jeffery Bradshawe of Bradford, Yorkshire, to keep a wine 
tavern, that the price of French wines wholesale was then about $£$ II a tun, and the retail price sixteen pence a gallon, and that sack, malmsey, and other sweet sorts were $£ 8$ the butt or pipe, and about two shillings the gallon.

The culture of the vine and the utilisation of its fruit as well as that of other trees and plants for producing wines, attracted considerable attention during the reign of Charles II.

The principal early authors on this particular branch of the subject are Hughes, Worlidge, and Rose, of whom the last had been gardener to the Duchess of Somerset, and was subsequently taken into employment by the king. He was on friendly terms with Evelyn, and to the third edition of the French Gardener (1675) is annexed his English Vineyard, on the separate title of which he is described as "Gardiner to His Majesty at His Royal Garden in St. James's." The essay arose out of a conversation between Rose and Evelyn in the garden at Essex House, and the remarks of the former ap- 


\section{30 Gleanings in Old Garden Literature.}

peared so pertinent, that Evelyn advised him to commit his notions to paper, and supplied him with the portion of it which relates to the preparation of wines.

The other two publications to which I have referred above were not identical in scope. That by Hughes, printed before I670, deals principally with the treatment and propagation of the vine, while the Vinetum Britannicum of the accomplished Worlidge $(\mathrm{i} 676)$ was dedicated rather to the manufacture of cyder and other drinks derived from fruit, with a description of a cyder-press; and when he re-issued his volume in 1678 and $169 \mathrm{r}$, he appended an Apiarium, or Discourse on Bees, - a subject which, as I must take this opportunity of mentioning, had been handled by Thomas Hill and Edmund Southerne in the reign of Elizabeth, and by Remnant, Levett, and others, in the following century, but by no one so capably as by Worlidge.

Besides such men as Evelyn and Rose, and the professional writers on the subject, we find Sir William Temple trying to improve this 


\section{Home-made Wine.}

branch of horticulture, in his beloved retreat or "corner," as he called it, at Sheen. In August, I667, he tells Lord Lisle, that he is contriving how the riches of Sheen vines may be improved by half a dozen sorts which are not known there, "and which I think much beyond any that are."

There is a vine of hoar antiquity at Valentines, near Ilford, in Essex, the residence of my late friend Dr. Ingleby; I question whether there be many such in England. That at Hampton Court is venerable enough, but the Ilford one is alleged to be its senior, nay, the very plant to which it owed its being, as sire and son are seen of a like altitude and girth, the one mounted to his prime, the other still undeclined from it.

But while natural causes have always precluded England, as they always will in human likelihood, from becoming a winegrowing centre, there is no doubt that for a considerable length of time in what may be called the middle period of our history, not to speak of the Anglo-Saxon epoch, the vine was industriously cultivated here, and some 
sort of crude beverage extracted from it, which, under the name of verjuice, was largely utilized in ancient cookery. In recent times, moreover, as at Kirke's Nursery, at Old Brompton, grapes were reared with success for wine; and no doubt both the white and black small sorts in favourable seasons may still serve such a purpose on an inconsiderable scale; but that England could have ever produced grapes as she produces other crops, or that the manufacture was ever used at the tables of the great and rich, I apprehend to be most improbable.

Yet Lysons, in his Environs (I 795), refers to a caper tree in the garden at Campden House, Kensington, as having flourished and borne fruit every year for a lengthened period in the open air. It was sheltered from the north, and looked to the south-east.

In the fifteenth century it was not a bunch, but a branch of grapes.

Mead, which was among ourselves, in a ruder condition of social development, a staple article of supply and a favourite stimulant, and for which recipes are found 
in cookery books down to the last century, continues to be in general demand in Africa, where most of the tribes, according to the account of Commander Cameron, manufacture this liquor, just as we used to do, from the honey of the wild bee.

They have a second liquor there called pombé, distilled from rice, like our arrack. There are many still living who recollect the rack punch at Vauxhall, and at the old restaurant kept by Simpson at Billingsgate.

In Norway they have a similar liquor extracted from the potato, and called the natives are very partial to it, and not un- $W_{0}$ ! frequently take it to excess. But they also use arrack.

Mead and metheglin are, of course, the same word. Horman, in his Vulgaria (I 5 I9), has "we shall drynke methe or metheglen."

The learned and enthusiastic Worlidge, in the second edition of his Vinetum Britannicum ( 1676$)$, describes, as I have mentioned, the new ingenio or mill for making cyder; but I have before me a tract which he published 


\section{34 Gleanings in Old Garden Literature.}

some years later, entitled The Most Easie Method for making the Best Cyder (1687).

$\mathrm{He}$ speaks very highly of this beverage, saying :-

"It is generally known, that few foreign drinks, as they are handed to us, are comparable to our English Cyder well made : Those being so adulterated in the several hands through which they pass, that they corrupt instead of repair, the Natures of them that drink them ;"

so that the dishonest sophistication and illegal marriage of wines are an old story.

$\mathrm{He}$ divides his monograph into sections, thus :-

"I. The choice of the Fruit.

"II. The Times for gathering and grinding Apples for Cyder.

"III. The manner of grinding and pressing of Apples for Cyder.

"IV. The ordering of Cyder after it is pressed.

"V. The ordering of Cyder in the first Reeking. "VI. The ordering of Cyder after it is superfine."

At the end he announces that

"This subject will be treated of more at large in the Second Part of Vinetum Britannicum, now ready for the Press." 
But there was no edition between 1678 and $169 \mathrm{r}$. The account is very interesting, but at the same time purely technical.

Perry is first named, so far as I can find, in Nicholas Breton's Fantasticks (1626). I quote from the edition of I66I, published under his own name by Matthew Stevenson, with the title of the Truelve Moneths; he mentions it under October thus :- " Make your Winter Cider and Perry."

The pear and apple orchards of Herefordshire were already famous in the seventeenth century.

The early manufacture and development of beer among the English is of course connected with the culture of the hop plant; and I may refer the reader to what is, perhaps, the first work where the matter is treated technically and specially, though certainly not in detail - the Treatise on Brewing, by Hagecius or Hajck (I585), which seems to be the most ancient monograph upon this science that we possess.

The passage where this author describes our drink is not very lengthy, and as it 
occurs in a little volume of the utmost rarity, I shall venture to copy it:-

" Potus, quo communiter Angli vtuntur, multiplex est : nempe vehemens, medius \& imbecillior. Discrimē inter hos penes vehemētiam \& imbecillitatem calfactionem \& refrigerationem, \& penes substantix crassitiem et tenuitatem habetur. Apud Anglos triplex semper paratur potus, nempe aquosus, quem simpliciter Ceruisiam dicunt; medius, quem tricapaninam; potens, quem duplam Ceruisiam nuncupant. Simplex eosdem effectus præstat, quos vinum aquosum: aperit siquidem, refrigerat et distributionem adiuvat. Nec decipiatur aliquis credens, ob eius amaritudine calfacere partes enim, quæ Ceruisiam amaram reddunt, pauca admodum sunt, si ad reliquas conferas, qux in ipsa refrigerant. Quod colligere ex ratione lupulorum poteris ad aquæ et hordei portiones. Citò preterea amaritudo a Ceruisia euanescit : reliquarum verò partiū facultas tam diu permanet, donec in aliam transmutatur substantiam. Potens Ceruisia, quā duplium dicunt, potenter calefacit, et aliquid habet vehementix, ut potens vinum. Tricapanina medix naturæ est; manifestè calefacit, in mallo tamen vehemens est."

He proceeds to remark on another kind of beer, called Ale (Alla); and the whole passage is worth attention, since we seem 


\section{Bacon on the Strawberry.}

to be without any English work equally early, which deals with the malt liquor, brewed from hops, in use during the Tudor period.

The raspberry, under the name of the hindberry, occurs in the eleventh century vocabulary, which we have so often had occasion to cite, as a herb. It was probably the wild variety, and may have been used for distillation. The strawberry is in the same list.

The white strawberry Bacon, in his Sylva Sylvarum (1627), seems to prefer to the red, just as he does the white currant, white rasp berry, and white grape. But the ordinary red variety is certainly the favourite at present, and has a superior flavour. The white, or rather pink, one is very common in Ireland, and used to be much grown also here.

In the Privy Purse Expenses of Henry VII., under June 3 oth, I493, a woman receives Is. $8 d$. for bringing the king cherries and strawberries. This amount was, as in other cases, not the price of the fruit, but "in 
I 38 Gleanings in Old Garden Literature.

reward," otherwise royal largess. This fact is nowhere, perhaps, more curiously exemplified, than in another item in the same record, where a woman gets five shillings on November 7 th, I494, for two glasses of water.

I think it exceedingly probable that both the strawberry and the raspberry were at first only known in this country in their wild varieties still surviving. In Shakespeare's time both descriptions of fruit had doubtless been improved; and he probably transfers to the previous century his observation of the strawberries which grew in Holborn in his own day, where he makes the Duke of Gloucester, in Richard III., ask the Bishop of Ely to send for some of the "good strawberries" which the Duke said he had seen lately growing in his lordship's garden. The glimpses which we shall presently gain of the much earlier garden of Lord Lincoln in that locality, and of the royal grounds at Westminster, with the cherries and peaches which they yielded, taken with the fact that Holborn was the 
residence in 1597 of Gerarde, author of the Herbal, encourage a presumption that the strawberry had in the Elizabethan period attained some degree of development.

There is this in regard to its early history to be noted, that, while Shakespeare, in a play published in 1597 , makes a bishop grow strawberries which live in the memory of a king, his contemporary Bacon, in the essay lately cited, only names a fruit which flourished in shady places. Both writers were describing alike what they had personally seen and eaten. But, on the whole, there is very slight likelihood that in the Elizabethan time the strawberry was very much advanced beyond the plant which still grows luxuriantly in certain soils and aspects, and the longshaped fruit of which yields an edible seedvessel of small size but agreeable flavour. In the West of England it occurs at the present day of a larger size than usual, and the elongated form of the vessel, which constitutes the fruit, is very noticeable.

The pottle in which strawberries used to be sold within living recollection, and which 
helps to attest the small size of the fruit in former times, goes back to the fifteenth or even the fourteenth century; it is as old as the days of Lydgate. But the term was also applied to a vessel for holding liquids. Wolsey and the Prior of Dunmow are both commemorated as regaling themselves on strawberries and crearn. In 1549 a pottle of strawberries is said to have cost tenpence, which is rather to be attributed to some accidental circumstance than to any improvement in the culture, for Henry VIII. ordered $3^{s .} 8 d$. to be given to some peasants who brought him what can only have been the wild berries.

From a Metrical Vocabulary of the fourteenth century we may add the ban-nut or walnut, the warden-pear, the poplar, the wild vine, the juniper, the ivy, and the bay-tree.

The warden-pear was formerly much used for cooking purposes, as well as for baking; and our ancestors in the time of Shakespeare had warden-pies. One Quinby, of New College, Oxford, they say, having been 
imprisoned by his warden for favouring the Reformation, was asked by his friends what he would eat, and he replied, $A$ Warden-pie:

"But I would have it made only of two wardens," he added, "our Warden of Oxford and our Warden of Winchester. For such a Warden-pie might do me and many another Christian good; but give me no wardens of the tree, for they could not be any comfort to me."

The warden-pie was composed of meat as well as pears. In the Winter's Tale, the clown is made to say: "I must have saffron to colour the warden-pies." From a passage in Beaumont and Fletcher's Cupid's Revenge - (I6I5), we may conclude that the pear itself was usually eaten roasted :-

؛ I would have him roasted, like a warden, In brown paper."

The French call this pear poire de garae.

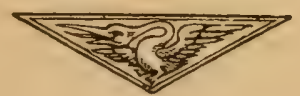




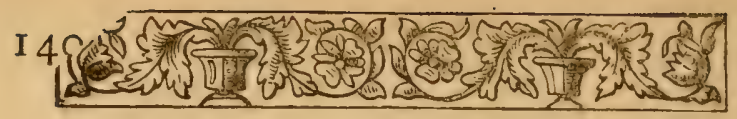

\section{XII}

Fruit-Trees (continued)--The Peach, the Quince, the Medlar, the Pine-apple, and the Pomegranate - IntroducTiON OF THE Black MUlberryRhubarb-Lemons-The Tool-House Espaliers and Pruning-Forest Trees-Ancient Survivals-Hooke's "Micrographia" and Mosses.

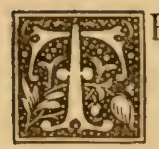

HE peach, which is far hardier even than some sorts of pears and plums, seems to have been successfully grown. Mr. Wright notices an official record of slips planted in the royal garden at Westminster in 1276 ; and we have evidence equally formal of the presence of the pear of St. Règle and many others in the Earl of Lincoln's garden in Holborn twenty years 
later. Both these gardens were also well provided with cherry trees, and the latter was assiduously cultivated from the twelfth century downward. Gower, the poet, who died an old man in r 40 S, refers to cherry feasts, as well as cherry fairs, in his Confessio Amantis.

In the Dictionary of Garlandia (thirteenth century) occurs persica, which Mr. Wright interprets persica $=$ Mala persica $=$ peaches ; but I should not like to be sure of this without some corroboration. The garden in which these persica grew was not in England, but at Paris.

The French Gardener (1658) gives thirtyeight varieties of this noble fruit. Perhaps there are as many still in use. The large October Peach only arrives at perfection with us, as regards flavour and sweetness, in late seasons-at least in the open air.

The quince, which is no longer used to any large extent in cookery, and seems to have grown out of favour, was among our Saxon forefathers a rather conspicuous factor in its particular province. One almost regrets its 
deposition from its antique rank among its peers, for it is a noble ingredient in an apple tart in the proportion of one to twelve, and as a conserve it is quite sui generis.

Recipes for pickling quinces are very usual in early collections. The fruit thrives best in the immediate neighbourhood of running water, and it requires a boat to gather it from the branches of the trees overhanging the Wandle in Surrey.

It is singular that the flesh of the quince in texture and odour resembles the pine, whose partiality for water it partakes, while it leaves behind on the palate a flavour similar to an onion.

"Quinces," says Breton, in his Fantasticks (1626), under September, "should not be kept with other fruit, for the scent is offensive both to the other fruit, and to them that keep it, or come amongst it ; therefore lay them by themselves in sweet straw, where they may have Ayr enough ; they must be packt with Medlars, and gathered with Medlars."

A reference to the present writer's Monograph on Cookery in this series, where he furnishes a Selection of Recipes, will at once 


\section{The Medlar and the Pine-Apple. I 45}

shew how far more extensive than in these days was the utilisation of the quince, not only for preserving purposes, but for the manufacture of wine.

The medlar occurs under January and, 1498-9, in the Privy Purse Expenses of Henry $V I I$, where $3 s .4 d$. is given to Sir Charles Somerset to reimburse him for some medlars and warden pears, which he had received for the king at Westminster.

This old-fashioned fruit, which seems to have been in great vogue with former generations, had a popular name, which supplies the pith of one or two stories in the JestBooks, but which is scarcely reproducible.

The picture, formerly at Strawberry Hill, which represents Rose, the royal gardener, presenting to Charles II. a pine-apple or ananas, is the earliest testimony to the native cultivation of that plant, in which the English growers still maintain a pre-eminence. Attention to it was doubtless drawn by specimens imported from America, where, as in any other climate which is at once warm and moist, it flourishes without care, but 
never approaches the excellence of the cultivated sorts.

In swampy tropical districts the pine flourishes and grows wild. But even in the genial climate of the south of Italy and France it does not come to any perfection, owing to the too great prevalence of dry weather.

We learn from Maloniana that Mr. de Vyme, who was present during the earthquake at Lisbon in I755, first introduced it into Portugal. It was long, however, before it was much grown there.

In India they have, besides other varieties, a sort much smaller than the West Indian one.

In regard to the pomegranate, Evelyn's letter of 1668 to Lord Sandwich contains the subjoined paragraph :-

"Your Excellency has rightly conjectured of the pomegranate. I have always kept it exposed, and the severest of our winters does it no prejudice. They will flower plentifully, but bear no fruit with us, either kept in cases and the repository, or set in the open air; at least very trifling, with the greatest industry of stoves and other artifices." 
Among the valuable importations from North America, at the end of the sixteenth and opening of the next century, was the Common or Black Mulberry tree, a fruit-bearer of slow growth in a strange climate, but precious on account of its fruit and foliage. We do not hear much of the former, however, which constitutes its chief attraction in our eyes; nor do I, I confess, subscribe to the conjecture (for it is apparently no more) that the pyne of the ancient Nominalia is identical herewith; but about 1607 an energetic endeavour was made to propagate the tree throughout England for the sake of breeding the silkworm, and establishing a native manufacture of the produce. James I., however, requested lieutenants of shires to co-operate in this enterprise. Instructions for the planters were printed; and Olivier de la Serre, a Frenchman residing in London, and Nicholas Goffe prepared between them a substantial volume on the subject, with an address to the reader, dated from Bacon House, May 20th, 1607 , almost as if the owner was one of the prime movers in the 
business-a not unlikely thing, as the king evidently had its success so much at heart. It was rather an unfortunate scheme, for the black variety grows very slowly, and its leaves are not so favourable for the purpose as those of other kinds; yet at the same time it was not a matter of option, since no other sort would have lived in England.

Besides the request addressed to the lieutenants of counties, a strenuous effort was made in the metropolis itself, or rather in what was at that time a suburb,-namely, in the immediate vicinity of St. James's Palace and adjacent to the present Buckingham Palace, where some ground was appropriated to a mulberry plantation, with the necessary houses and appliances for the rearing of the silkworms and the manufacture of the fabric.

But the experiment failed; royal commands will not always prevail ; and the only advantage which the country derived from it was that very few districts within a moderate distance of London were unprovided with specimens of the Virginian Forester. In the immediate neighbourhood of the metro- 
polis there are several, especially about Chelsea and Fulham. One in Cheyne Walk, Chelsea, has the honour of having been planted by Queen Elizabeth claimed on its behalf; and so have one or two others, sooth to say.

It is scarcely likely, indeed, that any of the original trees planted at the commencement of the seventeenth century are now in existence; but that may be what the writer of an excellent paper on the subject in the revised edition of Chambers's Encyclopadia (I874) means, when he refers to living specimens which had weathered three centuries.

Even in the city of London itself they had the mulberry. Until the ground was devoted to the formation of wharves, the garden of Vintners' Hall, in Upper Thames Street, ran down to the river, and contained some of these trees, under which the members and their friends sat and smoked. The mulberry is reared from seedlings or from truncheons.

The Gentleman's Magazine for February 
I 50 Gleanings in Old Gardon Literature.

$x 797$ notices the death of Mr. S. Brigs, the last surviving member of a Society of Herbarists at Norwich, who, among other services to horticulture,

"Were the first to cultivate and propagate the rhubarb plant in this country; which they effected so successfully, as to rival in colour, flavcur, and medicinal virtue, the roots of the Russia and Turkey kind."

But the fact is that rhubarb, as a drug, had been known more than two centuries prior to the decease of Mr. Brigs. For in Gosson's Plays Confuted in Five Actions (I580), it is said that the physicians considered this medicine hot, yet it cooled the hottest fevers. Nor is the writer in the magazine happier, I think, in his statement that the home-grown root equalled that imported from China, and popularly known as Turkey rhubarb. It has not even yet reached that point of perfection. Evelyn saw it growing in the Physic Garden at Oxford in 1654 .

The application of the plant to the purposes of the table does not seem to go farther 
back than I820, when Mr. Myatt, of Deptford, undertook the utilisation of the stalks as a fruit.

In all these very early sources of information we fail to meet with certain esculents, which have grown too familiar to ourselves to attract much attention,-sea-kale, the tomato, the vegetable marrow. These have been of comparatively recent introduction.

Preserved lemons were sold by the confectioners in James I.'s time. Perhaps they were so imported from the Continent. Brathwaite, who wrote in or before $16 \mathrm{I} 7$ his Rules and Orders for the Government of the House of an Earl, in adverting to the growth of luxury and extravagance, says that the old plain fashion of bringing the dishes to the table pleased no longer, but they must come-

"Garnished about with sugar and preserved plums, the meat covered over with orangeade, preserved lemons, and with divers other preserved and conserved stuff fetched from the confectionaries."

Citrons are mentioned, however, as I have 
I 52 Gleanings in Old Gardcn Litcrature.

shown above, in Breton's Fantasticks ( 1626 ), as being usually set in April-probably under glass.

Mr. Wright has explained the frequent occurrence of the pine and the reason for its cultivation among the Anglo-Saxons by the employment of its kernels in the same way as we now use olives.

The favourite flavouring and colouring ingredient in ancient cookery was saffron. In the home counties, Saffron-Walden in Essex was the leading nursery-ground, and in token and recognition the arms of the town bear three saffron plants. But in the country the nobility had their own saffron beds in a separate enclosure or yard under lock and key, pans for drying it, and tubs for preparing it for culinary purposes. For a long period it was far too dear to come within reach of the middle class; in the reign of Henry VI. a pound must have been worth nearly a sovereign of money of the time; and it at first occurs sparingly even in recipes for dishes of the most expensive character. 
One or two of the plates to the French Gardener (1675) exhibit the systems of walled enclosures and parterres, which still survive in many places, and the walls are trellised for fruit-trees or vines. But the art of nailing up the branches with shreds appears to have found its way among the horticulturists in the succeeding century.

The bygone gardener had at first a very narrow assortment of tools. The vocabularies mention, so far as I can see, only an axe, a grafting-knife, a spade, and a pruninghook.

But later onward-in the Tudor time-he was much better provided, or at all events our information as to his implements grows ampler. We hear of a barrow, a mattock, a spade, a shovel, a short and a long rake, and two kinds of fork, one called in the vocabularies a furca, the other a merga.

But the conduct of horticultural operations, however imperfect according to modern ideas, involved the employment of many other appliances, which at once suggest themselves to the mind, and of which 


\section{54 Gleanings in Old Garden Literature.}

we possess no actual record at first, because they did not fall within the scheme of the makers of the Nominale and the Glossary, and had become too established and familiar to attract special attention, when the earliest writers on the garden appeared.

It is only in a casual way that our acquaintance with the contents of the Anglo-Saxon or later English tool-house comes to us. Such men as Evelyn and Worlidge did not dream that we should like to have been informed, not merely of the seasons and modes of planting and pruning, and of the trees and plants which our ancestors cherished and handed down to us, but likewise that we should care to have had it in our power to contrast with the present facilities for managing a garden those which prior generations enjoyed.

A pruning-hook is seen in the hand of one of the figures in the plate illustrating April in Stevenson's Twelve Moneths (r626-6r). In the same engraving a woman holds a primitive watering-pot. Stevenson, under June, judiciously remarks :- 
"Take heed of cutting Trees, Hedges, or Herbs with a knife, but rather gather them with your Finger."

But the truth is that the graphic portion of the volume is merely a series of foreign prints, Dutch or German, utilised to lend an additional attraction to the English publication, though it is at the same time likely enough that our own implements and those of Germany and Holland were almost identical ; and in fact, not merely the illustrations, but the text of Stevenson, are largely borrowed from Breton's Fantastics ( 1626 ).

From a fifteenth-century MS. of Bartholomeus De Proprietatibus Rerum, it is inferable that some system was known and employed of training fruit-trees in the espalier mode now so familiar; it was a word derived from the old French espaule.

A very fair general notion of the policy and taste of our ancestors, a couple of centuries since, in laying out their grounds and gardens, according to their respective means, is derivable from such works as Les Delices de la Grande Bretagne, and from the illustrations to some of the treatises on 
gardening. Incidentally we come across helpful light of this sort in books not specially dedicated to horticulture, as in two or three of the plates to Kennett's Parochial Antiquities (1695), where there are views, very serviceable for the immediate purpose, of Borstall manor house, of Mr. John Coker's residence, of Robert South's Manse at Islip, and of Sir John Walter's seat at Saresden, all in Oxfordshire. In these representations the details are furnished with a fidelity and minuteness for which one ought to be grateful, as it puts us in possession of the manner in which the men of the end of the seventeenth century arranged their borders and walks, of the aspect of their demesnes and frontages, and of the course which they pursued in walling or paling the space round their houses. All these interesting points are more lucidly worked out in the engravings to Kennett than in others, where little more than a ground-plan is visible, as in the Jardin de Wilton by Isaac de Caus, for instance.

I do not find in our own early literature 
any data for forming an opinion as to the method of pruning pursued in former times here; and it is fairly questionable whether our ancestors bestowed much attention on the matter, as it remains one of which comparatively few gardeners possess a competent knowledge.

In the time of George III. William Forsyth enjoyed a good share of royal patronage and favour, and was appointed to the charge of the gardens at Kensington. He seems to have been an intelligent man, and to have devoted attention to the very important subject of pruning fruit-trees. $\mathrm{He}$ also made an attempt to provide a remedy for that serious evil, the canker, for the cure of which he invented some composition, but which is, however, still among the problems to be solved in arboriculture. Some trees, such as the Ribstone pippin, seem to be peculiarly prone to this malady.

$\mathrm{He}$ published his book on gardening in I802, under the title of $A$ Treatise on the Management and Culture of Fruit-Trees; there is an edition as late as 1824 , with a 
portrait of the author; and it has been translated into French.

The willow is mentioned in the fourteenth century treatise of Walter de Biblesworth; but it is not the willow of our meadows and gardens, which was not introduced till a much later period. It is, in fact, the common withy.

Among the additions to our stock of foresttrees in Worlidge's time ( 1677 ) was the Horse-Chestnut.

"The tree," he narrates, "is very lately made English, being brought in its seed or Nuts from Constantinople; it prospers very well here in good light mold; its buds all the winter, and until it springs, are covered with a shining, glutinous matter or gum, and about the beginning of May it usually makes its whole year's shoot in eight or ten days."

The sweet or true chestnut is of older naturalisation here, and with the ash has been long used, specially grown in coppices, for hop-poles. The visitor to Cowdray Park, near Midhurst, in Sussex, should note the fine avenue of Spanish chestnuts. But this variety is very common in all parts of England. It is only one of many edible sorts. 
The subject of Forest-trees brings us to a thought of those venerable contemporaries of so many generations, some of the ancient tenants of our parks and chases, which have seen race supplant race, dynasty succeed to dynasty; veterans which form a link almost between the Anglo-Saxons and ourselves. If the Talking Oak of Tennyson had been of this group, what might it not have told us of our national story beyond the possibilities of pen and ink! I refer with much pleasure to the paper by Mr. Brailsford "On Some Ancient Trees," in the tenth volume of the Antiquary.

Mr. Joseph Lucas, in his valuable Studies in Nidderdale, remarks :-

"Nidderdale and its moors have formerly been covered by an extensive forest. Many trees lie buried in the peat upon the moors. In the thousands of sections nade by little water-courses the birch appears almost everywhere predominant. Hazel, 'sealh [sallow],' thorn, oaks, etc., also occur; but the birch must have formed a thick and almost universal forest by itself, such as may be seen on the west coast of Norway at the present day."

This graceful tree is extraordinarily hardy. Among the Alps it flourishes in rocky ground 
I60 Gleanings in Old Garden Literature.

with scarcely any apparent soil to nourish and support its roots.

Mr. Lucas adds a table of the various trees of which remains are traceable in the peat.

The nature of mosses was beginning to be better understood in Charles II.'s day, and the invention of the microscope enabled the student to arrive at a more accurate knowledge of the plant and its mode of reproduction. It is interesting to find that the uses of science were in this case so promptly applied to practical purposes. Hooke had published his Micrographia in r667, and therein foreshadowed the telephone. 


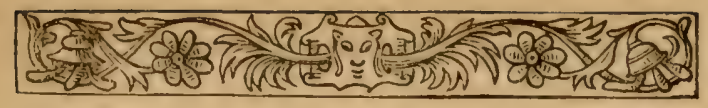

\section{CHAPTER XIII.}

Flora-The Tulip, the Rose, the JESSAMINE-ABERCROMBY'S WORKS.

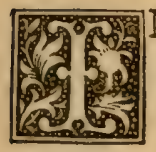

N Alfric's tenth-century vocabulary, under the Names of Trees, we have various kinds of oak, two sorts of hazel, the nut, the beech, the laurel, the apple (probably a crab), the pear, the medlar, the pine, the yew, the plum, the fig, the palm, the fir, the elm, the broom, the maple, the poplar, the heath, and many others. The list is extremely curious, and from the absence of any attempt at classification we may be entitled to form some idea of the want of any settled principles for laying out shrubberies, plantations, and gardens. It is much the same in the passage where Johannes de Garlandia is communicating to us what grew in his own grounds; he adds, by the way, the vines, the 
I62 Gleanings in Old Garden Litcrature.

chestnut, and others. The plum mentioned above was apparently not the sloe, as the latter also occurs lower down in the catalogue ; the palm was, of course, the common plant which is popularly so christened, and does duty for the real kind; and the pear, like the plum, must have been at this time very imperfectly cultivated here. It may be added that in the two eleventh-century vocabularies there are other plants and herbs, such as mint, white clover, fern, foxglove, two or three sorts of thistle, and mugwort, and among trees box and ash. But as regards many of the names the compiler seems not unfrequently to have had confused and erroneous notions of the Saxon equivalents for the Latin denominations. The virtues of mint were understood very early; it is said that in the time of Edward I. it was in vogue as a condiment, much in the same way that it is now, under the name of aigre-douce.

The anonymous vocabulary of the succeeding century adds sothern-wood, the rose, the peony, linseed, gorse, the nettle, the knee-holly, and many others, sufficient to 
shew that our Saxon ancestors were abundantly supplied in, or not much later than, the age of Alfred with the means of forming gardens and ornamental enclosures, and with material for the distillery and the surgery.

We may also judge that at this distant time our moors and commons were already clothed with that exquisite and brilliant gorse which is yet so luxuriant among us, but, singularly enough, unknown in climates similar to our own. What accident or agency brought it hither? What prevented it from making other northerly regions sharers with ourselves in its unique nature and beauty?

The story of the great Swedish naturalist, when he visited England and beheld the bush for the first time, is too familiar for repetition.

Even in the list of trees which we find in the fourteenth century treatise of Walter de Biblesworth the various kinds are mingled together without any effort to discriminate; the apple, pear, cherry, ash, broom, plum, and hawthorn occur in consecutive order; 
and as they are connected, so probably they grew in the gardens of our forefathers.

Among the flora of the fifteenth century occur the lily, the water-lily (of two varieties), the cowslip, the poppy, the pimpernel, the violet, the primrose, the wild thyme of Shakespeare, the columbine, and many moresome disguised by obscure and obsolete designations.

In Worlidge's work the tulip engrosses a section. He places it at the head of the Bulbs, and says that there was then (1677) so great a variety that they were not to be enumerated.

"Nor is it," he continues, "all the words I can invent can convince you of the beauty of these Glories of Nature, but must refer you to the choice your self or friend for you can make out of that Magazine of varieties that are collected for the ingenious Florist."

This is historically interesting; and it seems to denote that our supply was imported from Holland, and that our own dealers were only agents. Worlidge does not allude to any extraordinary enthusiasm for the bulbs, 
The Tulip, Rose, and Jessamine. I 65

nor does he particularise the rare black sort. Brilliancy of hue, on the contrary, he commends, and suggests when the flower discovers a tendency toward a sadder colour, that it should be taken up just before the flowering season and laid in the sun.

$\mathrm{He}$ describes the Persian and Indian jessamines, the Spanish broom, by which he means the cultivated yellow variety, and the double flowering peach and cherry; and among bedding or bordering and other plants, the lily, the hyacinth, the anemone, the lily of the valley, auriculas, primroses, cowslips. The Indian Jucca (or Yucca) he also mentions; and his pages clearly demonstrate the rapid development which maritime discovery and horticultural enterprise had imparted to the British Flora and Sylva in the second moiety of the seventeenth century.

The example and encouragement of men like Evelyn in his day, and Worlidge in his, contributed to the formation of a public taste, which in the succeeding generations received further expansion and refinement at the hands of the friends and contem- 
I 66 Gleanings in Old Garden Literature.

poraries of Pope; and, later again, of those who directed these maiters for George III. and his surrounders.

Worlidge considered that the rose should be placed between the tulip and the gillyflower, and he preferred the yellow Provence rose. How the latter was obtained he thus explains :-

"It hath been obtained by budding a single yellow rose to the stock of a flourishing Frankfort rose, near the ground; when that single yellow is well grown in that branch, inoculate your double yellow rose; then cut off all suckers and shoots from the first and second, leaving only your last, which must be pruned very near, leaving but few buds. . . . "

$\mathrm{He}$ furnishes us with a long catalogue of roses then grown, and adds the Gelder-rose, which he not improbably supposes to be a corruption of Elder-rose, from the resemblance of the foliage to that of the sonamed tree.

The Provence rose seems to have been sufficiently familiar in Shakespeare's time to have been worn as an article of ornament, for in Hamlet, iv., 2, the Prince of Denmark 
speaks of a man likely to get admission into a cry of players as wearing two Provençal roses in his slashed shoes.

Abercrombie's work, Every Man his ozen Gardener (I 766), had a very lengthened run, and was no doubt deserving of the popularity which it so long enjoyed. Although it did not appear till the latter half of the eighteenth century, it represented the experience of a man who must have recollected Pope and the traditions of 1688 . I have before me an edition printed in 1827 , in which it is said to be "by Thomas Mawe, Gardener to His Grace the Duke of Leeds, and John Abercrombie, sixty years a Practical Gardener," and now to be "Enlarged and Improved by R. Forsyth." This I take io be the son of the Forsyth who was so much patronised by George III.

In I 784 Abercrombie followed up Every Man his own Gardener by an even more important work:-The Propagation and Botanical Arrangement of Plants and Trees, Useful and Ornamental, Proper for Cultivation in every Department of Gardening; Nur- 
I 68 Gleanings in Old Garden Literature.

series, Plantations, and Agriculture. ... 2 vols, small octavo. The title, which is a sort of Table of Contents, is followed by a Preface, dated from 319, Oxford Street, London, in which the author claims credit for his work as " a truly original performance, upon a plan never before attempted." The First portion is devoted to directions for propagation, pruning, etc., on a more copious scale than former works; the Second contains the botanical classification and nomenclature. We see what rapid progress had been made, when these volumes appeared, in the acclimatisation of exotics and enrichment of our gardens with the hardier varieties of Asiatic and American plants and shrubs.

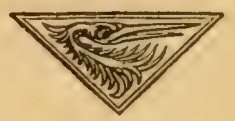


XIV.

Market Gardens in the Suburbs of LONDON--TESTIMONY OF AN ITALIAN VISITOR IN 'I6I4-NURSERIES AND Grounds at Old Brompton, Fulham, Battersea, aNd Deptford.

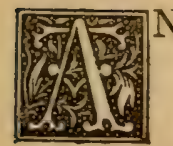

N Italian, named Giacomo Castelvetri, who was in London in 1614 , wrote a species of Herbal, still in MS. in the British Museum among the books of Sir Joseph Banks, in which he introduces us to a knowledge, which we should not otherwise have possessed, of the condition of market gardening near London in the reign of James I. He does not tell us much; but what information he supplies is especially valuable. The asparagus, he says, was very small and very dear in London, its culture not 
being well understood; he expresses his surprise that it was not cultivated to a greater extent, since an acre of asparagus would, in a short time, yield more profit than ten acres sown with corn. Artichokes in England, he observes, lasted the greatest part of the year, much longer than in Italy. Cucumbers were then eaten when they were big and yellow, in England; in Italy they ate them when small and green. The English had two plentiful crops of strawberries, the first in the middle of June, the second in October.

As regards asparagus, the English did not neglect the suggestion that it might be advantageously grown in the vicinity of a profitable market. A fair quantity is still cultivated at Mortlake. Since Bacon's time, the strain of the strawberry had no doubt improved; but I hardly understand what Castelvetri intends by a second crop in October. The first is now seldom ready in the open air before July, except in very sheltered localities; but October sorts are unknown. 
Lysons, writing in 1795, says that the nursery at Brompton Park, established by Messrs. London and Wise, gardeners to William III. and Queen Anne, dated from about the latter end of the seventeenth century. And Evelyn records in his Diary his visit to it with his friend Mr. Waller (not the poet) in 1694. He was there again in I 7or. " 2 nd of September.-I went to Kensington, and saw the lawn, plantations, and gardens, the work of Mr. Wise, who was there to receive me." The grounds lay between Brompton and Kensington; from Evelyn mentioning only Wise, it is presumable that he had lost his partner, Mr. London. The stock of plants here in $I 700$ is represented by a contemporary as so large that they would have been worth $£ 40,000$ at a penny a-piece. This place belonged, when Lysons wrote, to Messrs. Gray and Wear, and the Grays were still there in 1840 . The present writer recollects their grounds, as well as several others.

George London seems to have quitted the 
I 72 Gleanings in Old Garden Literature.

metropolis whose name he bore, and to have settled in Nottinghamshire, where he had something to do with the gardens of Count Tallard, in the vicinity of Nottingham. $\mathrm{He}$ gave to the world, as a sort of farewell memorial of a long and useful professional career, The Reiir'd Gard'ner, with the Manner of Planting and Cultivating all Sorts of Flowers for beautifying Country Seats (I 706, 2 vols., small octavo). The book was accompanied by a description and plan of Count Tallard's gardens, and by a series of plates and woodcuts.

Possibly London was related to William London, of Newcastle, a bookseller, who settled in the metropolis, and published two well-known catalogues, which some of the old bibliographers imagined to have been the work of Bishop Juxon, because that prelate signed himself William London.

I have spoken of London and Wise with appreciative respect, because in relation to the prevailing taste they held an honourable position, and according to their training, and the fashion in such matters which they found 
current, did their part. But, as we shall see, not merely did those florists belong to a bad school, but they must be said to have contributed by their influence and advice to exaggerate the errors and barbarisms of it.

In common with the leading members of every profession, this great firm had much in its hands for good or the contrary, and that it had not the genius to detect the falsity of the principles, in which it had been brought up, we ought not to be astonished or offended, inasmuch as those principles came to them with the weighty sanction of the most distinguished men of the century. In a condemnation of London and Wise we involve a condemnation of Evelyn.

The passion for seeking in the statuary's yard decorations for the garden had found its way, like so many other equivocal blessings, from a country where the line between the sculptor and the stonemason was more defined, and where the climate made marble work interspersed with foliage more easily endured. 
I 74 Gleanings in Old Garden Literature.

But it was to the Hollanders that London and his partner were indebted for that preposterous plan of deforming Nature by making her statuesque, and reducing her irregular and luxuriant lines to a dead and prosaic level through the medium of the shears. Gods, animals, and other objects were no longer carved out of stone ; but the trees, shrubs, and hedges were made to do double service as a body of verdure and a sculpturegallery. The free growth of the box, the yew, and the holly was sacrificed to the mania for the quaint and grotesque in art, and from the occasional survivals of this bastard style one gets some imperfect conception of what it must have been, when it was in its full glory.

As far back as 1715, the founder of Lee's Nursery at Kensington came up to London, and acquired extensive grounds adjacent to the Holland House estate; it was a flourishing concern during the whole of the last century and the first half of this; the firm grudged no labour or expense in obtaining the rarest plants, trees, and 
flowers from every part of the world; but the greater portion of the nursery is now covered by buildings.

Curtis's Botanical Garden, which had been in Lambeth Marsh, was removed to the north side of the Fulham Road, near the Queen's Elm, about I 789. The proprietors published an annual catalogue, and there was a botanical library; subscribers of a guinea a year were entitled to admission to the gardens for self and friend, and a payment of two guineas gave an unlimited right of entry and a certain quantity of seeds, roots, etc. The space occupied by this business remained open within my recollection, and under other management was devoted to similar objects, though not on the same ambitious scale.

Besides the nurseries instituted by London and Wise, and by Curtis or his successors, there were others kept in the first half of this century by Rigby, Siggers, Conway, and Kirke in the same neighbourhood. There was another on part of the site of the South Kensington Museum and Brompton Oratory, 
between Pollard's School and Ingestry House. Kirke's ground was contiguous to that of Hale or Cromwell House, and Kirke used to point out an ancient gateway communicating with the latter, through which he was fond of telling visitors that Cromwell used to pass on his way to London, the site of the nursery in his time being, according to tradition, used as an exercise ground for his bodyguard. Those whose associations connect them with other outlying portions of the metropolis, when it was still a city encompassed by villages, as mine do me with Old Brompton, will readily call to mind similar spots in the north, south, and east of London, now no more. But I may mention Middlemist's Cape Nursery at Shepherd's Bush, where many novelties from the North African flora were exhibited, the proprietor having resided there during many years; and the Arboretum at Paddington, to which it is said that the earliest consignment was made, at the end of the last century, of the American vegetable marrow, - at least, of our variety of 
it, for there are many which our climate does not suit. Other sorts have since been introduced, including a bush marrow and a small prickly kind, which used to be grown at Sion House, Isleworth; but the finer and more delicate species, like some descriptions of American fruit, more especially that which grows in the subtropical parts, are scarcely known.

At the end of the last century no fewer than one hundred and forty acres of land at Bethnal Green were held by market gardeners.

Battersea, as well as Fulham and Old Brompton, was a favourite resort of the calling. Lysons, writing in 1792 , when the aspect of this and other suburban neighbourhoods had been scarcely altered, says :-

"About three hundred acres of land in the parish of Battersea are occupied by the market gardeners, of whom there are about twenty who rent from five to six to near sixty acres each. . . The soil of the ground occupied by the gardeners is sandy, and requires a great deal of rain. The vegetables which they raise are, in general, very fine; their cabbages and asparagus, particularly, have acquired celebrity. 


\section{78 Gleanings in Old Garden Literature.}

Fuller, who wrote in the year 1660 , speaking of the gardens in Surrey, says, 'Gardening was first brought into England for profit about seventy years ago, before which we fetched most of our cherries from Holland, apples from France, and had hardly a mess of rath (early) ripe peas but from Holland, which were dainties for ladies, they came so far, and cost so dear. Since gardening hath crept out of Holland to Sandwich, Kent, and thence to Surrey, where, though they have given $£ 6$ an acre and upwards, they have made their rent, lived comfortably, and set many people on work. Oh, the incredible profit by digging of ground ! for though it be confessed, that the plough beats the spade out of distance for speed (almost as much as the press beats the pen), yet what the spade wants inthe quantity of ground it manureth, it recompenseth with the plenty of the food it yieldeth, that which is set multiplying abundant-fold more than that which is sown. 'Tis incredible how many poor people in London live thereon, so that, in some fashion, the gardens feed more people than the field."

This extract is very pertinent at the present moment, when we are agitating the expediency of reconverting into pasture the unprofitable plough-land. A chronological catalogue of political grievances might prove curious; but it is at any rate remarkable that complaint was formerly made, when 
arable was applied to grazing purposes. The subject is one which has always possessed great interest; but it is now invested with a new and special importance, and I am tempted to transcribe from Lysons some farther remarks on the state of market gardens near the metropolis in old times, and at the period when he wrote (I792). After stating that the culture of vegetables for sale commenced about I 590 , he proceeds :-

"In some bills of fare for dinners in I373, I find several charges for parsley, sorrel, and strong herbs, and one charge of $12 d$. for two dishes of buttered peason on the Ist of July, which, supposing the value of money to have been then four times greater, would now at that season purchase about eight pecks." $[\mathrm{He}$ then repeats what Fuller says above about early peas.] "What they cost in his time he [Fuller] does not inform us; the usual price now, at their first coming, is from about five shillings to lalf a guinea a pottle, afterwards from ten to fifteen shillings the halfsive. ... .

"Gardens for the raising of vegetables for sale were first cultivated about Sandwich, in Kent. The example was soon followed near the metropolis, whose markets are the chief vent for this produce. In proportion as this great town has increased in population and opulence, the demand for every species of garden 
luxury has increased also; and from time to time fields have in consequence been converted into garden-ground, till a considerable proportion of the land within a few miles of London became occupied for that purpose. The culture of garden-ground is principally confined to those parishes which lie within a moderate distance of the river, on account of the convenience of water carriage for manure, which since the prodigious increase of carriages, as well of hackney and stage coaches, as of those kept by private families, is procured in great abundance from the London stables.

"By a general calculation, founded upon inquiries made in each parish, it appears that there are about five thousand acres within twelve miles of the metropolis constantly cultivated for the supply of the London markets with garden vegetables, exclusive of about eight hundred acres cropped with fruit of various kinds, and about 1,700 acres cultivated for potatoes. Besides which there are perhaps $\mathbf{I , 2 0 0}$ acres cropped with various garden vegetables for the food of cattle, principally cows. This culture is carried on most extensively in the parishes of Camberwell and Deptford St. Paul's, by persons who are called farming gardeners. Their method is to manure their land to the highest pitch of cultivation for garden crops, both for the market and for cattle, after a succession of which they refresh it by sowing it with corn.

"In the parish of Fulham the cultivation of gardens 
Nurseries at Fulham, Deptford, etc. I 8 I

for the market is carried on to a greater extent than in any other in the kingdom. The quantity occupied by market-gardeners only is about eight hundred acres, to which may be addled nearly two hundred more, cultivated for the market by farming gardeners.

"The cultivation of asparagus is carried on to the greatest extent in the parishes of Deptford St. Paul's, Chiswick, Battersea, and Mortlake, there being about ISo acres of it in the four parishes, of which about seventy are in Mortlake, which may be said to produce a greater quantity of that vegetable than any parish in England.

"Deptford is famous also for the culture of onions for seed, of which there are on an average about twenty acres. About ten acres are cultivated for this purpose in the parishes of Mortlake and Barnes. . . .

"The average rent of garden-ground, in most of the parishes near London, is now $£ 4$ per acre." 


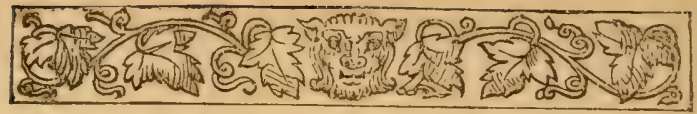

\section{$\mathrm{XV}$.}

Sir William Temple-Walpole and the Gardeners of the Eighteenth CenTURY.**

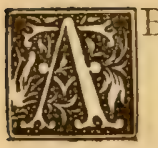

BOUT midway between Bacon and the horticultural amateurs or professors of the Georgian period, there is Sir William Temple, whose fine gardens at Sheen, already noticed in a cursory way, occupied a leading rank among the private grounds in the vicinity of London, and derived an enhanced interest from the

* Essay on MTodem Gardening, by Mr. Horace Walpole [1770]; Essai sur l'Art des fardins Modernes, par M. Horace Walpole. Traduit en François par M. Le Duc de Nivernois, en MDCCLXXXIV. Imprimé à Strawberry Hill, par T. Kirgate, MDCCLXXXV ; 4to, pp. 94, and a leaf with the first title. With the English and French texts on opposite sides. 
personal prestige of their owner, whom we remember at present through them and his associations with William III. and Swift.

It is fortunate for us that Temple, besides being a politician and a practical horticulturist, possessed literary tastes, and thought proper to insert among his essays one which he entitles "Upon the Gardens of Epicurus; or, Of Gardening in the year I685."

The heading of the paper is rather apt to mislead us till we look through the pages which are occupied with it, and find that it commences with an account of the Gardens of the Ancients, and then proceeds to the end with one of the state of gardening and fruit-culture, especially at Sheen, as it stood at the close of the reign of Charles II.

I cannot say that the former or introductory portion has anything approaching to the attractive influence which I feel in perusing, at a distance of two centuries, the opinions and experiences of so distinguished a personage on a topic so enduringly fascinating and important. I have not room 
for much in the way of extract, but let me copy out a paragraph or so, where he begins to speak of his own country and his own seat :-

"But after so much Ramble into Ancient Times, and Remote Places, to return Home and consider the present Way and Humour of our Gardening in England, which seem to have grown into such Vogue, and to have been so mightily improved in Three or Four and Twenty Years of IIis Majesty's reign, that perhaps few Countries are before us; either in the Elegance of our Gardens, or in the number of our Plants; and I believe none equals us in the Variety of Fruits, which may be justly called good ; and from the earliest Cherry and Strawberry, to the last Apples and Pears, may furnish every Day of the circling Year. For the Taste and Perfection of what we esteem the best, I may truly say, that the French, who have eaten my Peaches and Grapes at Shene, in no very Ill year, have generally concluded, that the best are as good as any they have eaten in France, on this side Fountainbleau; and the first as good as any they have eat in Gascony; I mean those which came from the Stone, and are properly called Peaches, not those which are hard, and are termed Pavies; .... Italians have agreed, my White Figs to be as good as any of that sort in Italy, which is the earlier kind of White Fig there ; for in the latter [later] kind, and the Blue, we cannot come near the 


\section{Sir William Temple.}

warm Climates, no more than in the Frontignac or Muscat Grape.

"My Orange-Trees are as large as any I saw when I was young in France, except those of Fountainbleau, or what I have seen since in the Low Countries . . . . When I was at Cosezuelt with that Bishop of Minnster, that macle so much Noise in his time, I observed no other Trees but Cherries in a great Garden he had made. He told me the Reason was, because he found no other Fruit would ripen well in that Climate, or upon that Soil ; and therefore instead of being curious in others, he had only been so in the Sorts of that, whereof he had so many, as never to be without them from May to the end of September."

He goes on to discuss the size and shape of gardens, the best descriptions of grapes, plums, and other fruit, the careful appropriation of walls, and the choice of soil. $\mathrm{He}$ seems to have contributed personally to extend the resources of English gardens and greenhouses. He particularly informs us that he imported from various parts of France four new sorts of grape: the Arboyse, the Burgundy, the Black Muscat, and the Grizzelin Frontignac. Of the three kinds of fig, he preferred the white, of which there were two varieties. The Tawny, he tells 
I 86 Gleanings in Old Garden Literature.

us, " is very small, bears ill, and I think but a Bawble."

Of the gardens of his contemporaries he has not anything to say, except (and the exception is worth a good deal) that of the Countess of Bedford at Moor Park, in Hertfordshire, on which he dilates, from early and affectionate recollection, with evident zest.

"The perfectest Figure of a Garden I ever saw, either at Home or Abroad, was that of Moor-Park in Hertfordshire, when I knew it about Thirty Years ago. It was made by the Countess of Bedford, esteemed among the greatest Wits of her time, and celebrated by Doctor Donne."

A minute picture of Moor Park follows; and Temple takes occasion to remark that, as regards gardens in general, the form to be preferred is, in his opinion, an oblong on a slope.

Separated from the great philosopher of the age of Elizabeth and James I. by an interval of about a century and a half, HORACE WALPOLE, better known to the generality of 


\section{Horace Walpole.}

readers as a writer of Memoirs and Letters, presents himself to our notice as an authority on the present subject, but as an authority not less different in value from Bacon than the characters and intellects of the two men differed. In fact, when we look at the lapse of time between them, it dwindles into secondary consequence before the immense disparity and contrast between Elizabeth's "young Lord Keeper" and the master of Strawberry Hill. Both were men of genius ; but their gifts were of a totally different order. Bacon could not have written Walpole's Letters, nor could Walpole have given us the Novum Organum. Nay, he could not have produced the Sylva Sylvarum.

Walpole's Essay on Modern Gardening was finished in I770, but was not printed till I 785 , when it came from the Strawberry Hill press with a French translation by the Duc de Nivernois. We have only to turn over the pages of this production to arrive at the conclusion that the author, if we had happened to possess no independent or collateral knowledge of him, was a member 
of the fashionable world and a gentleman of fortune. He tells us, after a brief proem about the garden of Eden, the Homeric legend of Alcinous, and the mural records of Herculaneum, all about his rich and distinguished relatives and friends, and tells us as delightfully as he does elsewhere in his inimitable correspondence.

But Bacon was also nobly born, and had also high and powerful connections. $\mathrm{He}$ was Lord Chancellor of England under James I., and his father had kept the seals under Elizabeth. If Walpole had Strawberry Hill and Arlington Street, his predecessor had Gorhambury and Bacon House. The author of Sylva Sylvarum at least equalled the Earl of Orford in social influence and surroundings, and when one recollects that Bacon divided with Shakespeare the literary glory of the Elizabethan era, and that no such two had before, or have since, appeared in England or in the world, it is a piece of supererogation to say that in intellectual force Bacon and Walpole were not for an instant comparable. 
These pages have to do with a very fractional portion of the labours of either. But one has only to turn from the Section where I afforded some select specimens of the Sylva Sylvarum, to the present, where I deal with Walpole, to see at a glance how differently the earlier and later writer set about their work. The whole thought of Bacon was of his subject and of the best mode of rendering his experiments serviceable and his meaning clear. In the book of which I am now going to give a short account, there seems throughout to be an anxiety to crowd into his canvas (as it were) glimpses of the country seats of all the great ladies and gentlemen who had the good fortune to be known by him. It almost sounds in our ears like a concession, where he places a person of quality like Sir William Temple below Milton; but it is hard to resist a smile where he tells us that-

"the description of Eden [by Milton] is a warmer or more just picture of the present style than Claud Lorrain could have painted from Hagley or Stour- 
head. The first lines ... exhibit Stourhead on a more magnificent scale."

Of course, it is obvious enough that the poet, in depicting Eden, borrowed his notion of it from the gardens of England in his own age; but I merely adduced this comparison as a trait which pervades the Strawberry Hill essay. Walpole never wrote many lines without letting everybody know that he was a man of birth and fashion, and, to boot, of genius.

Walpole's essay is, nevertheless, very readable, very intelligent, and very instructive. By way of variety, no one can be displeased to have a better notion of it than there is, I somehow fancy, at present. With the introductory sketch we can dispense. Its chief value and interest centre in the remarks which the writer has left upon the gardens and gardening of his own day. In the opinions and ideas which prevailed in Bacon's time on horticulture, the management of flowers, and the arrangement of ornamental grounds, the intervening years had wrought momentous changes. The 


\section{Horace Walpole.}

Dutch and Italian influences had operated, and, on the whole, no doubt, beneficially, on English taste, and had enlarged the resources as well as the views of our countrymen.

Walpole very properly condemns, as Pope had already ridiculed in verse, the insipid geometrical style of laying out grounds, which prevailed, till a reform in such matters was accomplished by Bridgman, Kent, Capability Brown, and others, in the second half of the last century.

"The compass and square," says the Essay, "were of more use in plantation than the nursery-man. The measured walk, the quincunx, and the étoile imposed their unsatisfying sceneries on our royal and noble gardens. Trees were headed, and their sides pared away; many French groves seem green chests set upon poles. Seats of marble, arbours, and summer houses terminated every vista, and symmetry, even where the space was too large to permit its being remarked at one view, was an essential that, as Pope observed-

'... Each alley has a brother,

And half the garden just reflects the other.'

Knots of flowers were more defensibly subjected to 
the same regularity. 'Leisure,' as Milton expressed it,-

'... In trim gardens took his pleasure.'

In the garden of Marshal de Biron at Paris, consisting of fourteen acres, every walk is buttoned on each side by lines of flower-pots, which succeed in their seasons. When I saw it, there were nine thousand pots of Asters, or La Reine Margnerite."

Walpole pays a high tribute to the picture which Milton draws in the Paradise Lost of the Garden of Eden; but, as I have stated, he detects in it a resemblance to the gardens at Hagley and Stourhead, and even suspects that the blind bard had in his recollection the beauties of Theobalds and Nonsuch. Although, however, Walpole does justice to Milton, he was not sorry, I believe, to pass from him to Sir William Temple. It was a more congenial atmosphere. Temple was only, it is true, "an excellent man;" but he was a man nearer to Walpole's time, and nearer also to Walpole's heart. He quotes with enthusiasm his account of the garden at Moor Park, in Hertfordshire, designed under the eye of the Countess of Bedford, 


\section{Horace Walpole.}

who befriended Donne and some of his literary contemporaries.

It seems to the present writer that much of the improvement in the style of our gardens is to be found, in essence or suggestion, in the observations of Bacon, not in the Sylva, but in his essay on the subject, contained in the volume of I597. Of course, even when a few sensible men tried to supersede the stiff, tasteless manner introduced from the Low Countries, there was far from being a general rally round them; and. Walpole himself remarks that many foreigners had seen our gardens, and still preferred their own artificial ingenuity. $\mathrm{He}$ instances Le Nautre, the contriver of the groves and grottoes at Versailles, who came over to us, and planted St. James's and Greenwich parks - " no great monuments of his invention."

Temple, after speaking of the regular and irregular forms of gardens, pronounces in favour of the former, on the ground of the difficulty and risk attendant on success.

"I should hardly advise any of these attempts," he says, as cited by Walpole, "in the figure of gardens 
among us; they are adventures of too hard atchievement for any common hands; and, though there may be more honour if they succeed well, yet there is more dishonour if they fail, and it is twenty to one they will; whereas in regular figures it is hard to make any great and remarkable faults."

"Fortunately," proceeds Walpole, "Kent and a few others were not quite so timid, or we might still be going up and down stairs in the open air."

Referring to Temple's description of Moor Park, Herts, in Lady Bedford's time, he goes on to say :-

"But as no succeeding generation in an opulent and luxurious country contents itself with the perfection established by its ancestors, more perfect perfection was still sought; and improvements had gone on, till London and Wise had stocked our gardens with giants, animals, monsters, coats of arms, and mottoes, in yew, box, and holly. Absurdities could go no farther, and the tide turned. Bridgman, the next fashionable designer of gardens, was far more chaste ; and whether from good sense, or that the nation had been struck and reformed by the admirable paper in the Guardian, No. I73, he banished verdant sculpture, and did not even revert to the square precision of the foregoing age. He enlarged his plans, disdained to make every division tally to its opposite, and though he adhered much to strait walks with high clipped hedges, they 
were only his great lines: the rest he diversified by wilderness and with loose groves of oak, though still within surrounding hedges."

Here we have almost exactly what Bacon advises in 1597 . On revient toujours à ses premières anours!

Let us hear something more of Bridgman from Walpole :-

"I have observed in the garden at Gubbins, in Hertfordshire, many detached thoughts, that strongly indicate the dawn of modern taste. As his reformation gained footing, he ventured farther, and in the royal garden at Richmond dared to introduce cultivated fields, and even morsels of a forest appearance, by the sides of those endless and tiresome walks, that stretched out of one into another without intermission. But this was not till other innovators had broke loose too from rigid symmetry.

"But the capital stroke, the leading step to all that has followed, was [I believe the first thought was Bridgman's] the destruction of walls for boundaries, and the invention of fosses-an attempt then deemed so astonishing that the common people called them $H a ! H a$ ! to express their surprise at finding a sudden and unperceived check to their walks."

Walpole's etymology, or explanation, is 
doubtful enough, and part of the improved scheme, for which he claims credit on behalf of Bridgman, had been shadowed out, and even more, by Bacon.

"One of the first gardens planted in this simple, though still formal, style, was my father's, at Houghton," Walpole informs us. "It was laid out by Mr. Eyre, an imitator of Bridgman."

The latter artist was followed by Kent, a famous name in the annals of horticulture. Walpole characterises him as

"painter enough to taste the charms of landscape, bold and opinionative enough to dare and to dictate, and born with a genius to strike out a great system from the twilight of imperfect essays." "He leaped the fence," says our author, "and saw that all nature was a garden:"

From Walpole's account of Kent's peculiar bent of mind and cast of feeling, the conclusion comes to us that he, partly, doubtless, owing to the lessons and suggestions which he derived from Bridgman, was the real father of the modern school of gardening, breaking so much more completely away from the old 
prejudices, and approaching so much nearer to ourselves than his predecessors.

"The pencil of his imagination," writes his contemporary of him, "bestowed all the arts of landscape on the scenes he handled. The great principles on which he worked were perspective, and light and shade. Groups of trees broke too uniform, or too extensive a lawn, evergreens and woods were opposed to the glare of the champain; and where the view was less fortunate, or so exposed as to be beheld at once, he blotted out some parts by thick shades, to divide it into variety, or to make the richest scene more enchanting by reserving it to a farther advance of the spectator's steps. . . .

"But of all the beauties he added to the face of this beautiful country, none surpassed his management of water. . . . The gentle stream was taught to serpentine seemingly at its leisure; and where discontinued by different levels, its course appeared to be concealed by thickets, properly interspersed, and glittered again at a distance, where it might be supposed naturally to arrive. Its borders were smoothed, but preserved their waving irregularity. A few trees scattered here and there on its edges sprinkled the tame bank that accompanied its meanders; and when it disappeared among the hills, shades descending from the heights leaned towards its progress, and framed the distant point of light under which it was lost, as it turned aside to either hand of the blue horizon." 
He thus portrays the artistic mode of dealing with ground too thickly wooded for ornamental or picturesque purposes :-

"Where the united plumage of an ancient wood extended wide its undulating canopy, and stood venerable in its darkness, Kent thinned the foremost ranks, and left but so many detached and scattered trees as softened the approach of gloom, and blended a chequered light with the thus lengthened shadows of the remaining columns."

But Walpole, a little farther on, admits that Kent, on the one hand, had assistance, and, on the other, had faults.

"Mr. Pope undoubtedly contributed to form his taste. The design of the Prince of Wales' garden at Carlton House was evidently borrowed from the poet's at Twickenham. There was a little of affected modesty in the latter, when he said of all his works he was most proud of his garden. ... I do not know whether the disposition of the garden at Rousham, laid out for General Dormer, and, in my opinion, the most engaging of all Kent's works, was not planned on the model of Mr. Pope's, at least in the opening and retiring shades of Venus's vale."

He goes on to mention that he considered 


\section{Horace Walpole.}

the weak side of Kent's character his want of majesty, and his extravagant and undiscerning imitation of nature; but at the same time he says, "That Kent's ideas were but rarely great was in some measure owing to the novelty of his art;" and of course he was followed by other men, who introduced improvements on his plans as he had done on those of Bridgman, excellent as both were reckoned to be in their time and in relation to those who had gone before them. Referring to the advance of later men on his inventions and ideas, Walpole explains how that progress was partly due to causes beyond the control of Kent :-

"Succeeding artists have added new master-strokes to these touches perhaps. The introduction of foreign trees and plants, which we owe principally to Archibald, Duke of Argyle, contributed essentially to the richness of colouring so peculiar to our modern landscape. The mixture of various greens, the contrast of forms between our forest-trees and the northern and West-Indian firs and pines, are improvements more recent than Kent, or but little known to him. The weeping-willow and every florid shrub, each trace of delicate or bold leaf, are new tints in the composition 


\section{Gleanings in Old Garden Literature.}

of our gardens. The last century was certainly acquainted with many of those rare plants we now admire. The Weymouth pine has long been naturalised here; the patriarch plant still (I 770) exists at Longleat. The light and graceful acacia was known as early; witness those ancient stems in the court of Bedford House, in Bloomsbury Square; and in the Bishop of London's garden at Fulham are many exotics of very ancient date."

Walpole was of opinion that Kent improved as he proceeded; and he thought one of his latest works his best.

"Kent's last designs," he says, "were in a higher style, as his ideas opened on success. The north terras at Claremont was much superior to the rest of the garden."

Like other masters, Kent acquired a mannerism and a touch, which made his work easily recognisable by such as studied the subject.

"A return of some particular thought was common to him with other painters, and made his hand known. A small lake, edged by a winding bank with scattered trees, that led to a seat at the head of a pond, was common to Claremont, Esher, and cthers of his 
designs. At Esher, 'where Kent and Nature vied for Pelham's love,' the prospects more than aided the painter's genius."

"Sir Henry Englefield," he presently adds, "was one of the first improvers on the new style, and selected with singular taste that chief beauty of all gardens, prospect and fortunate points of view."

It may scarcely be requisite to explain that I have been the more copious in my extracts from Walpole's Essay, because he stands as nearly as possible midway between the old school of gardening and the new; and he was contemporary with Bridgman and Kent, two of the most eminent landscape gardeners of the eighteenth century; and nearly so with Pope, who, by Walpole's acknowledgment, did much to promote the development of a better taste and feeling, not exactly in horticulture, but in the arrangement of grounds. What Walpole says of Sir Henry Englefield may have been due to that gentleman's personal discernment and insight; but it was probably rather the outcome of his employment of some one who saw the possibility of carrying Kent's improvements still farther; 
and among such there was no man more conspicuous than Brown, or, as he was usually called, Capability Brown. This is what Walpole has to say about the latter :-

"It was foriunate for this country and Mr. Kent that he was succeeded by a very able master; and did living artists come within my plan, I should be glad to do justice to Mr. Brown; but he may be a genius by being reserved for some abler pen."

The original English was completed in I770; but Brown had been dead some years when it appeared with the French version, for the first time, in $\mathrm{I}_{7} 85$.

I hope that I have seemed to justify my long detention of the reader with the StrawberryHill volume. It was its worth and virtue as a link between two ages, which tempted me to accord to it a separate chapter, rather than any intrinsic merit, which I had been able to discern in its pages. For in its treatment it is flimsy enough, and in point of style it is disagreeably affected and artificial. 


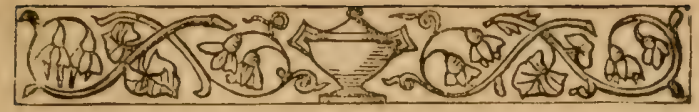

\section{XVI.}

Bibliography of Gardening Literature (I603-I800), AND OF Herbals aND Bee Culture-William and Samuel Curtis-James and George Sowerby -The Lindleys and LoudonsCryptogamic Flora of ScotlandSir William Jackson Hooker.

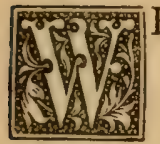

HILE, in this and the companion treatise on Cookery, it scarcely enters into my plan to describe the later literature, or take cognisance of all the modern improvements in these two favourite sciences, having rather set myself the task of tracing the early history of both arts, it may be useful to append a succinct catalogue of those publications on horticulture and the subjects immediately allied to it, which (as a rule) I have not treated in the text. 
204 Gleanings in Old Garden Literature.

There was not the same uninterrupted succession of books on this theme as on the less dispensable one of eating and drinking, dining and supping. I have, of course, inserted accounts of Worlidge and many others in the narrative; but down to the time of Pope and Pope's Bathurst there does not seem to have been very much published on the subject.

1. Profitable Instructions for the Manuring, Sowing, and Planting of Kitchen Gardens. By Richard Gardiner, of Shrewsbury. 4to. 1603.

2. The Fruiterer's Secrets. 4to. 1604.

3. Instructions for the Increasing and Planting of Mulberry Trees. 4to. 1609.

4. The English Husbandman. . . Together with the Art of Planting, Grafting, and Gardening. By Gervase Markham. 4to. 1613.

5. Country Contentments, or The Husbandman's Recreations. By the same. 4to. 1623 .

6. A New Orchard and Garden. By W. Lawson. 4to. 1623 .

7. A Garden of all sorts of pleasant Flowers, which our English air will permit to be mursed up. By John Parkinson, Apothecary of London. Folio. London, I629, I656. 
Bibliography of Garden Literature. 205

8. Rhodon and Iris. A Pastoral presented at the Florists' Feast at Norwich, May 3rd, 163I. By Ralph Knevett. 4to. 163x.

9. Mercurines Botanicus, sive Plantarum gratiâ suscepti Itineris, Anno MDCXXXIV., Descriptio, cum earum Nominibus Latinis et Anglicis, etc. Londini : 1634-4I. 8vo. Two parts. By Thomas Johnson, M.D., of Selby, and dedicated under the name of Socius Itinerans to Dr. Theodore Mayerne, Dr. Lister, etc.

[The copy before me has MSS. notes and matter added in a coeval hand, possibly the author's. It was sold at Sotheby's, August 29 th, 1877, No. 252. To part the first is attached a small folded plan of Bath, of which an account is comprised in the volume.*]

Io. A Theatre of Plants. By John Parkinson. Folio. London. 1640.

II. The Countryman's Recreation, or the Art of Planting, Grafting, and Gardening, in three Bookes. ... Whereunto is added, The Expert Gardener. By Gervase Markham. London : 1640. 4to.

[The Expert Gardener purports to be derived from French and Dutch sources.]

* Besides his published works, Johnson wrote an account of a botanical tour in Kent, with some companions, in the summer of 1629 , and of the flora of Hampstead in the following August. The MS. of these two narratives, consisting of nineteen leaves in 
206 Gleanings in Old Garden Literature.

12. The Garden of Eden. By Sir Hugh Platt. In two parts, I2mo. 1653-60.

13. The Art of Simpling. By W. Coles. r2mo. 1656.

14. Adam in Eden, or Nature's Paradise. By the same. Folio. 1657.

15. Adam out of Eden; or, An Abstract of certain excellent Experiments touching the Advancement of Husbandry. By Ad. Speed. 8vo. London, I659.

16. Flora, Ceres, Pomona. By John Rea. Folio. 1665, 1676, I702.

17. Poems on Divers Occasions. [By Jeremiah Wells.] London: 1667. 8vo. On eight leaves at the end, marked \%, is printed The Garden, by A. C., that is, Abraham Cowley.

18. The Complete Vineyard. By W. Hughes. 8vo. I670.

19. Plantarum Umbelliferarum Distributio Nova, Per Tabulas Cognationis et Affinitatis ex Libris Natura Observata et delecta. . . . Per Robertum Morison. Oxonii. I672. Folio.

[The author was a Professor of Botany.]

20. Rapin, of Gardens. In four books. Translated by John Evelyn. 8vo. I673.

[There are later editions, and it is included in Evelyn's Miscellaneous Works.]

octavo, was bound up with a copy of the Mercurizs, sold in 1883 . 


\section{Bibliography of Garden Literature. 207}

21. The Planter's Manual. By C. Cotton. Svo. 1675 .

22. The English Gardener; or, A Sure Guide to Young Planters and Gardeners, how to Order the Kitchen-Garden, Orchards, and Pleasure Garden, by Leonard Meager. 4to. I678. With plates.

23. Plain and Full Instructions to raise all sorts of Fruit-trees that prosper in England. By T. Langford. 8vo. I68I.

24. The Florist's Vade Mecum. By Samuel Gilbert, of Bewdley, Worcestershire. I2mo. 1682.

25. Aphorisms upon a new Way of improving Cyder, or making Cyder-Royal; to which are added certain expedients concerning the Raising and Planting of Apple-trees, Gooseberry-trees. . . . By Richard Haines. Folio. 1684.

26. The Gentleman's Recreation. In two parts. By Richard Blowe. Folio. I686-I710.

[The section on Agriculture and Husbandry contains a good deal of information on gardening and fruit-trees.]

27. The Book of Knoruledge. By Samuel Strangeboys. I2mo.

[To the later editions was attached a fourth part, containing the Complete Gardener.]

28. The Compleat Gard'ner; or, Directions for Cultivating and Right-ordering of Fruit-Gardens and Kitchen-Gardens. In six Books. By M. de la Quintinye, Chief Director of all the gardens of the French King. To which is added His Treatise of Orange-Trees, with the raising of Melons, 
208 Gleaningss in Old Garden Literature.

omitted in the French edition. Made English by John Evelyn, Esquire. Folio. London. 1693. Plates.

[In I699 an abridgment of this work by George London and Henry Wise appeared in 8 vo, "made of more use, with very considerable improvements."]

29. Curiosities of Nature and Art in Husbandry and Gardening, containing new experiments in the improvement of Land, Trees, Fruits, etc. 8vo. I707. Plates.

30. The Fruit-Gardener's Calendar. By John Lawrence. 8vo. I7I7.

31. A Philosophical Treatise of Husbandry and Gardening: By G. A. Agricola. Translated from the German by Richard Bradley, F.R.S. 4to. I72I. With cuts.

32. The Gardener's Calendar. By Philip Miller. 8vo. 1724. 2 vols.

33. The Gardener's and Florist's Dictionary. By the same. Svo. I724.

[A standard work in the last century. It was reprinted in $\mathbf{1 7 3} \mathbf{I}$, folio, and often subsequently. It is a mere compilation. Miller published other books of a professional nature.]

34. The Gardener's Universal Calendar. By Benedict Whitmill. 8vo. I726.

35. The Gentleman and Gardener's Calendar. By Richard Bradley, Professor of Botany, and F.R.S. 8vo. 1728 . 
Bibliograpliy of Garden Litcrature. 209

36. The Gentleman Gardener Instructed. By the Rev. David Stevenson. 8vo. 1746.

37. The Compleet Florist. 8vo. London. 1747. With 100 plates.

38. A Discription of the Gardens of Lord Cobham at Stows. Svo. I75I. With II plates.

39. The Scots Gardener's Director. By John Justice. Svo. 1755 .

40. The Gardener's New Calendar. By John Hill, M.D. 8vo. I 758 .

41. The Botanist's and Gardener's Dictionary and Calcudar. By James Wheeler, Nurseryman at Gloucester. 8vo. I763.

42. Every Man his own Gardener. By Thomas Mawe (John Abercrombie). 8vo. 1766.

[Abercrombie published other works in his own name.]

43. The Practical Gurdener and Gentleman's Directory for every month in the year. By James Garton. 8vo. 1769.

44. The Modem Gardener, or Universal Calendar. From the MSS. of Mr. Hin. By James Meader. 8vo. 1771. Borrowed from Mawe.

45. The Garden Companion. By the Rev. John Trusler. 8vo. I77I. Abridged from Hill.

46. The Gardener's and Planter's Calendar. By Richard Weston. Svo. I77I.

47. The Gardener's Pocket Calendar. By the same. 8vo. 1773 . 
2 Io Gleanings in Old Garden Literature.

48. The Gentleman and Lady's Gardener. By Mr. Eadmeades [a seedsman near London Bridge]. 8vo. 1774 .

49. The English Gardener's New and Complete Calendar. Svo. 1778.

50. The Gardener's Calendar. By John Ellis [gardener to the Bishop of Lincoln.] Svo. 1778.

5I. On the Progress of Gardening. In a Letter from the Hon. Daines Barrington to the Rev. Mr. Norris, Secretary. Read June I3th, I782. Archaologia, vii. II 3 , et seqq.

[This is a general survey, not confined to English gardening.]

52. Gibson's Acconnt of the Gardens in and round London in I69I. Read before the Society of Antiquaries in 1794. Archaologia, vol. xii.

[This forms an Appendix to the present work.]

53. A Treatise on the Culture of the Pine-Apple, and the Management of the Hot-House. By William Speechly. 8vo. York. 1795. Plates.

54. The Botanist's Calendar and Pocket English Flora. I2mo. 1797.

55. Introduction to the Knowledge and Practice of Gardening. By the Rev. Charles Marshall. With a Calendar. Third Edition. I2mo. 1800. 56. A Descriptive Account of White Knights, near Reading, a seat of the Duke of Marlborough, by 
Mr. and Mrs. Hofland. Folio, privately printed, N.D. [about 1820.]

[This volume contains an introductory account of gardening by Mrs. Hofland.]

57. Gleanings on Gardens, chiefly respecting those of the Ancient Style in Englind. By S. Felton. 8vo. London. 1829. Pp. $72+$ viii.

This list brings down the literature of gardening to the commencement of the new school of horticulture.

But I shall add the particulars of the principal writers or books on HERBS and Bee-Culture on a similar principle :-

\section{OLD ENGLISH HERBALS.}

I. The Great Herbal. Folio. 1516, 1526, 1529 , 1539, 1561. From the French.

2. The Little Herbal. 4to. I525, 1526. From the Latin.

3. A Book of the Properties of Herbs, which is called an Herbal. By Walter Cary. Svo. R. Redman (about I540).

[All the editions are undated.]

4. Macer's Herbal, practised by Dr. Linacre. I2mo. [about 1540]. Two editions.

5. A Little Herbal of the Properties of Herbes. By Anthony Ascham. 8vo. 1550.

6. Turner's Herbal. Folio. I55I. Part II., folio, 1562. Part III., folio, I568. With cuts. 
2 I 2 Gleanings in Old Garden Literature.

7. A New Herbal, or History of Plants. By Rembert Dodoens. Translated by Henry Lyte. Folio. 1578. With cuts.

S. An Herbal for the Bible. By Levinus Leminius.

Translated by Thomas Newton. 8vo. I58r.

9. The Herbal, or General History of Plants. By John Gerard, of London, Master in Chirurgery. Folio. 1597. Edited by Thomas Johnson, the Botanist. Folio. I633, 1636.

Io. Ram's Little Dodeon. By W. Ram. 4to. $\mathbf{1 6 0 6 .}$

\section{BEES.}

I. The Profitable Art of Gardening. By Thomas Hill. Third edition. 8vo. 1568. With a Treatise "Of the Miraculous Government of the Bees" annexed.

2. A Treatise Concerning the Right Use and Ordering of Bees. By Edmund Southern. 4to. 1593 .

3. The Ordering of Bees. By John Levett. 4to. 1634 .

4. A Discourse or History of Bees. By Richard Remnant. 4to. 1637 .

5. The Reformed Commonwealth of Bees. By S. Hartlib. 4to. 1655 .

[In this book is a copper-plate cut of a hive so constructed as to remove the honey without injuring or disturbing the inmates.]

6. Vinetum Britannicum. By John Worlidge. 
Second Edition. To which is added, "A

Discourse teaching the best way of improving Bees." Svo. I678.

7. A Further Discovery of Bees. By M. Rusden.

Svo. 1679. Plates.

8. The True Amason; or, The Monarchy of Bees.

By Jos. Warder. 8vo, I7I3.

9. The English Apiary; or, The Complete BeeMaster. By John Gedde. 8vo. I72I.

Io. The Antient Bee-Master's Farewell. By John Keys. 8vo. 1796.

II. A Treatise on Bees. By the same. I2mo. ISr4.

Of the modern school the foremost name is that of CuRTis, of whose nursery at Old Brompton we have already heard. Between I777 and I799 William Curtis produced his celebrated and still esteemed work, the Flora Londinensis, or Plates and Descriptions of such Plants as growi zeild in the Environs of London. 2 vols., folio. This great work was edited, with additions and corrections, by Graves and Hooker, in $\mathrm{I} 82 \mathrm{I}$.

In 1787 Curtis commenced his Botanical Magazine, which he carried down to 1826 , and which was continued by his son Samuel and Sir W. J. Hooker to I $85^{8}$. The author 
2 I 4 Gleanings in Old Garden Literature.

published a Companion to the Magazine in I788; it was a periodical which exercised a powerful influence on the advancement of botany and the diffusion of an interest in the subject.

The younger Curtis, besides editing his father's Flora, brought out in i822 a monograph on the Camellia.

Next to Curtis and his son comes SOWERBY, a family which during more than half a century (I790-1850) occupied a prominent and honourable position in this department as well as in those of conchology and mineralogy. The Englis/ Botany of James Sowerby appeared between I790 and r820 in numbers forming six-and-thirty octavo volumes; and it is still a favourite and useful set of books. A supplement was afterward added.

This is perhaps James Sowerby the Elder's best known work, and that on which his reputation chiefly depends. But both his son and himself and George Brettingham Sowerby continued to enrich our literature with erudite compilations on nearly every 
branch of this fascinating art, and on subjects cognate to it, down to a date within living memory, - - link between the old and modern schools, but with a clear leaning to a more enlightened and intelligible system of classification, and with a knowledge of the Genera amplified by the latest discoveries at that period.

The late Mr. Henry Bohn, in his recension of the Bibliographer's Manual, has afforded practical evidence of the strong personal interest which he felt in horticulture and botany by the carefully-prepared lists of the labours of the three Sowerbys, and of one or two other authors, whom I have presently to mention. Mr. Bohn himself printed for private circulation a descriptive catalogue of his own extensive collection of Roses.

George and John Lindley presented a third example of a family which, during successive generations, did its part in spreading a correct knowledge of all the branches of tree, plant, and vegetable culture, and in improving the management of the orchard 
and kitchen garden. But the latter originally made his name as a writer, not only on the British but on the exotic flora, by the publication, in $\mathrm{I} 82 \mathrm{I}$, of his Collectanea Botanica and other works. The exertions of John Lindley were most indefatigable, and covered the whole ground. There was no section of botany and horticulture which he did not treat with ability and public advantage. In 1829 he delivered his introductory lecture before the University of London. His printed contributions to the branch of letters of which he had made a special study, extended over a quarter of a century, and occupy nearly two columns of the small type of the Bibliographer's Manual.

At the same time, in Scotland, Robert Kaye Greville offered a splendid contribution to botanical learning in his Scottish Cryptogamic Flora, which came out in six large volumes between ${ }_{1} \delta_{22}$ and $\mathrm{I} \delta 2 \delta$, and which seems entitled to the distinction of being considered the earliest specific work on that subject in our literature. Mr. Greville is also known as the author of the Flora Edinensis (8vo, 1824) 
and of a monograph on British Algæ (8vo, I830).

In r 829 Mr. Loudon commenced the publication of his Magazine of Natural History, and Journal of Zoology, Botany, etc., which formed a very valuable series, and ran to 1840 , making thirteen octavo volumes. Mr. Loudon had the assistance of several of the most distinguished specialists of the day -Audubon, Bell, Vigors, Forbes, Waterton, and others; and it was to the pages of this periodical that Ruskin, then a youth, contributed in $1834-6$ his earliest efforts in print. In his Instructions in the Use of Rudimentary Series he says :-

"Mr. Loudon was the first literary patron who sent words of mine to be actually set in print, in his Magasine of Natural History, when I was sixteen."

In I 83 I Robert Sweet completed his Hothouse and Greenhouse Manual, which I apprehend to have been the parent production on that specific and vital part of the subject, and which a reference to Lowndes will shew to 
have been only one of a series of labours in the field ; and Loudon's Hortus Britannicus followed in 1832 .

The group of distinguished men, to whom we are permanently indebted for placing our country in respect to this province of science in as high a rank as a relatively ungenial climate will ever permit, was reinforced at this time by Joseph Paxton, principal gardener to the Duke of Devonshire at Chatsworth. Paxton's name is still favourably recollected in connection with his professional labours, especially the Exhibition of $185 \mathrm{I}$ and the Crystal Palace, as well as with his literary achievements, of which the chief are the Horticultural Register, commencing in I83I, and carried down to 1836 , and the Magazine of Botany and Register of Flowering Plants, which he edited from $\mathrm{r} 834$ to 1849 . He published a monograph on the Dahlia in 1838, and other books, including the Flower Garden (1850-3), 3 vols., royal 8 vo, in which he was assisted by Dr. James Lindley.

In 1838 appeared Loudon's Suburban 


\section{Loudon.}

Gardener and his most important work, the Arboretum et Fruticetum Britannicum, * the latter in eight octavo volumes. It was, perhaps, next to the Magazine just noticed, and the Encyclopicedia of the same author, the most capable and successful attempt to diffuse a general knowiedge of all the new species and varieties of forest and fruit trees, plants, and shrubs, imported from foreign countries both by professional growers and by private enterprise. The magazine had doubtless proved of the greatest utility to the author in the way of preparation and learning.

Loudon pays an appropriate tribute to the warm and steady encouragement afforded by the Northumberland family to this interesting cause, and he mentions, as his main object in undertaking the labour, on the one hand, the slow progress made by this country in availing itself of new discoveries, and, on the other, the tendency of existing kinds to disappear from neglect.

* Published in I822, reprinted in I824, rewritten in I83I, and republished, edited by Mrs. Loudon, in 1850 . 
Loudon was not an antiquary, nor did he, I believe, profess to be one; and he committed many errors in regard to the original introduction of trees, herbs, and flowers into Britain. But his books, and his wife's too, mark a distinct epoch in the literary as well as the technical history of arboriculture and gardening, just as the publication of Miller's Dictionary, and the exertions of several of Miller's contemporaries,-Abercrombie, Weston, Forsyth, and others, - -had done in the eighteenth century.

Besides the valuable labours of $\mathrm{Mr}$. Loudon in flower and tree culture, his wife, who informs us that she owed all her acquaintance with the subject to his instructions and encouragement, wrote those very useful and still favourite manuals, Gardening for Ladies and The Ladies' Companion to the Flower Garden. Both were frequently reprinted. I have the sixth edition of the former (1843), and the seventh of the latter (I858). It seems to have been about 1830 that this accomplished lady first entered on her experiences. 
Mr. and Mrs. Loudon, etc. $22 \mathrm{I}$

The Flower, Fruit, and Kitchen Garden, by James Main, A.L.S., came out in three parts in $1840-1$, $12 \mathrm{mo}$, with a few pages of Introductory Remarks. There is a great deal of information in this handy little book, which is still as applicable as when it was written; and it possesses the advantage of being succinct and intelligible. It bears the same sort of relation to the larger productions of the Sowerbys, Lindleys, and Loudons that Miss Acton's cookery-book bears to those of Ude, Soyer, and Francatelli.

But before I quit the Loudons and my present subject, I shall extract from Gardening for Ladies, sixth edition ( 1843 ), a portion of the introduction, because this and the companion book formed nearly the earliest endeavour to bring the treatment of flowers within the comprehension of the possessors of small private gardens :-

"When I married Mr. Loudon," his wife frankly and gracefully says, "it is scarcely possible to imagine any person more completely ignorant than I was of everything relating to plants and gardening; and, as may be easily conceived, I found every one about me 
so well acquainted with the subject, that I was soon ashamed of my ignorance. My husband, of course, was quite as anxious to teach me as I was to learn, and it is the result of his instructions that I now (after more than twelve years' experience of their efficacy) wish to make public for the benefit of others.

"I do this, because I think that books intended for professional gardeners are seldom suitable to the wants of amateurs. .... As the rapid sale of the previous editions of this work affords the surest proof that it has met the wants of those for whose use it was designed, it may be asked why I have made so many alterations and additions. My answer is, that I have done so in order that my book may keep pace with the improving spirit of the times. For this reason I have written the chapter on manures, in order to give my readers an idea of the new theories of Liebig on that subject; and I have also given them a sketch of M. De Chevreul's new doctrine of colours, as applied to flower gardens."

It is gratifying to meet with genuine workers. In her other publication, The Ladies' Companion to the Flower Garden, seventh edition ( 1858$)$, Mrs. Loudon was more directly indebted to her husband, who wrote several of the articles which it comprises, and read and revised the whole in the first and second impressions. The Appendix 


\section{Mr. and Mrs. Loudon, etc. 223}

was suggested by Lord Murray, to whom Mrs. Loudon owns her weighty obligations.

But the preface to the Ladies' Companion has a concluding paragraph, which I fervently wish that publishers and authors would alike take to heart :-

"Notwithstanding the large sale of the work (which has exceeded twenty-five thousand copies), it has now been stereotyped; but every new edition has been carefully revised, and descriptions of new plants and of new discoveries in floriculture have been added, so as to bring the whole down completely to the present day."

Perhaps it was the refusal to perpetuate errors and imperfect information which made it necessary for the writer to seek a new publisher, for the Ladies' Companion has not the name of Mr. Murray at the foot of the title-page.

Mr. Bohn, in his edition of the Bibliographer's Manual of Lowndes, furnishes an elaborate list of the publications, from $\mathrm{I} 8 \mathrm{I} 3$ to 1854 , of the late Sir William Jackson Hooker, who, in his way, as the Loudons in theirs, so largely contributed to the 
224 Gleanings in Old Garden Literature.

development and progress of the science which he above all others loved and understood.

Besides the well-known works of Lindley, it is proper to mention the large folio volume of Nature-Printed Ferns, issued under the care of Henry Bradbury, and re-produced some years later in four octavo volumes uniform with the Alga published by the same process. 


\section{APPENDIX.}

A Short account of Several Gardens NEAR LONDON, WITH REMARKS ON SOME PARTICULARS WHEREIN THEY EXCEL OR ARE DEFICIENT, UPON A VIEW OF THEM IN DECEMber, I69I.*

I. THE AMPTON COURT Garden is a large plat, environed with an iron palisade round about next the park, laid all in walks, grass plats, and borders. Next to the house, some flat and broad beds are set with narrow rows of dwarf box, in figures like lace-patterns. In one of the lesser gardens is a large green house divided into several rooms, and all of them with stoves under them, and fire to keep

* Communicated to the Society of Antiquaries by the Reverend Dr. Hamilton, Vice-President, from an original manuscript in his possession. Read July $3^{\text {rd, }}$ 1794. [This is the narrative by Gibson, to which I have referred more than once in the text.] 
a continual heat. In these there are no orange or lemon trees, or myrtles, or any greens, but such tender foreign ones that need continual warmth.

2. Kensington Gardens are not great nor abounding with fine plants. The orange, lemon, myrtles, and what other trees they had there in summer, were all removed to Mr. London's and Mr. Wise's greenhouse at Brompton Park, a little mile from them. But the walks and grass laid very fine, and they were digging up a flat of four or five acres to enlarge their garden.

3. The Queen Dowager's Garden, at Hammersmith, has a good greenhouse, with a high erected front to the South, whence the roof falls backward. The house is well stored with greens of common kinds; but the Queen not being for curious plants or flowers, they want of the most curious sorts of greens, and in the garden there is little of value but wall trees; though the gardener there, Monsieur Hermon Van Guine, is a man of great skill and industry, having raised great numbers of orange and lemon trees by inoculation, with myrtles, Roman bayes, and other greens of pretty shapes, which he has to dispose of.

4. Beddington Garden, at present in the 
hands of the duke of Norfolk, but belonging to the family of Carew, has in it the best orangery in England. The orange and lemon trees there grow in the ground, and have done so near one hundred years, as the gardener, an aged man, said he believed. There are a great number of them, the house wherein they are being above two hundred feet long; they are most of them thirteen feet high, and very full of fruit, the gardener not having taken off so many flowers this last summer as usually others do. He said, he gathered off them at least ten thousand oranges this last year. The heir of the family being but about five years of age, the trustees take care of the orangery, and this year they built a new house over them. There are some myrtles growing among them, but they look not well for want of trimming. The rest of the garden is all out of order, the orangery being the gardener's chief care; but it is capable of being made one of the best gardens in England, the soil being very agreeable, and a clear silver stream running through it.

5. Chelsea Physick Garden has great variety of plants, both in and out of greenhouses. Their perennial green hedges and rows of different coloured herbs are very pretty, and 
so are their banks set with shades of herbs in the Irish stitch-way, but many plants of the garden were not in so good order as might be expected, and as would have been answerable to other things in it. After I had been there, I heard that Mr. Watts, the keeper of it, was blamed for his neglect, and that he would be removed.

6. My Lord Ranelagh's Garden being but lately made, the plants are but small, but the plats, borders, and walks, are curiously kept, and elegantly designed, having the advantage of opening into Chelsea college walks. The kitchen garden there lies very fine, with walks and seats, one of which, being large and covered, was then under the hands of a curious painter. The house there is very fine within, all the rooms being wainscoted with Norway oak, and all the chimneys adorned with carving, as in the council-chamber in Chelsea college.

7. Arlington Garden, being now in the hands of my lord of Devonshire, is a fair plat, with good walks, both airy and shady. There are six of the greatest earthen pots that are any where else, being at least two feet over within the edge; but they stand abroad, and have nothing in them but the tree holy-oke, an 
indifferent plant, which grows well enough in the ground. Their greenhouse is very well, and their greenyard excels; but their greens were not so bright and clean as farther off in the country, as if they suffered something from the smutty air of the town.

8. My Lord Fauconbergh's Garden, at Sutton Court, has several pleasant walks and apartments in it; but the upper garden next the house is too irregular, and the bowling green too little to be commended. The greenhouse is very well made, but ill set. It is divided into three rooms, and very well furnished with good greens; but it is so placed, that the sun shines not on the plants in winter, where they most need its beams, the dwellinghouse standing betwixt the sun and it. The maze or wilderness there is very pretty, being set all with greens, with a cypress arbour in the middle, supported with a well-wrought timber frame; of late it grows thin at the bottom, by their letting the fir trees grow without their reach unclipped. The enclosure wired-in for white pheasants and partridges is a fine apartment, especially in summer, when the boxes of Italian bayes are set out, and the timber walk with vines on the side is very fine when the blew pots are on the 
pedestals on the top of it, and so is the fishpond with the greens at the head of it.

9. Sir William Temple, being lately gone to live at his house in Farneham, his garden and greenhouse at West Shecne, where he has lived of late years, are not so well kept as they have been, many of his orange trees, and other greens, being given to Sir John Temple, his brother, at East Sheene, and other gentlemen; but his greens that are remaining (being as good a stock as most greenhouses have) are very fresh and thriving, the room they stand in suiting well with them and being well contrived, if it be no defect in it that the floor is a foot at least within the ground, as is also the floor of the dwelling-house. He had attempted to have orange trees to grow in the ground (as at Beddington), and for that purpose had enclosed a square of ten feet wide, with a low brick wall, and sheltered them with wood, but they would not do. His orange trees in summer stand not in any particular square or enclosure, under some shelter, as most others do, but are disposed on pedestals of Portland stone, at equal distance, on a board over against a South wall, where is his best fruit, and fairest walk.

10. Sir Henry Capell's garden at Kew has 
as curious greens, and is as well kept as any about London. His two lentiscus trees (for which he paid forty pounds to Vesprit) are said to be the best in England, not only of their kind, but of greens. He has four white striped hollies, about four feet above their cases, kept round and regular, which cost him five pounds a tree this last year, and six laurustinuses he has, with large round equal heads, which are very flowery and make a fine show. His orange trees and other choicer greens stand out in summer in two walks about fourteen feet wide, enclosed with a timber frame about seven feet high, and set with silver firs hedge-wise, which are as high as the frame, and this to secure them from wind and tempest, and sometimes from the scorching sun. His terrace walk, bare in the middle, and grass on either side, with a hedge of rue on one side next a low wall, and a row of dwarf trees on the other, shews very fine, and so do from thence his yew hedges with trees of the same at equal distance, kept in pretty shapes with tonsure. His flowers and fruits are of the best, for the advantage of which two parallel walls, about fourteen feet high, were now raised and almost finished. If the ground were not a little irregular, it 
would excel in other points, as well as in furniture.

II. Sir Stephen Fox's garden at Chiswick being but of five years' standing, is brought to great perfection for the time. It excells for a fair gravel walk betwixt two yew hedges, with rounds and spires of the same, all under smooth tonsure. At the far end of this garden are two myrtle hedges that cross the garden; they are about three feet high, and covered in winter with painted board cases. The other gardens are full of flowers and salleting, and the walls well clad. The greenhouse is well built, well set, and well furnished.

I2. Sir Thomas Cooke's garden at Hackney is very large, and not so fine at present, because of his intending to be at three thousand pounds' charge with it this next summer, as his gardener said. There are two greenhouses in it, but the greens are not extraordinary, for one of the roofs being made a receptacle for water, overcharged with weight, fell down last year upon the greens, and made a great destruction among the trees and pots. In one part of it is a warren, containing about two acres, very full of coneys, though there was but a couple put in a few years since. There is a pond or a mote round about them, and on 
the outside of that a brick wall four feet high, both which I think will not keep them within their compass. There is a large fish-pond lying on the South to a brick wall, which is finely clad with philaria. Water brought from far in pipes furnishes his several ponds as they want it.

13. Sir Fosiah Child's plantations of walnut and other trees at Wansted are much more worth seeing than his gardens, which are but indifferent. Besides the great number of fruit trees he has planted in his enclosures with great regularity, he has vast number of elms, ashes, limes, \&c., planted in rows on Epping forest. Before his outgate, which is above twelve score [yards] distance from his house, are two large fish-ponds on the forest, in the way from his house, with trees on either side lying betwixt them; in the middle of either pond is an island betwixt twenty and thirty yards over, and in the middle of each a house, the one like the other. They are said to be well stocked with fish, and so they had need to be if they cost him five thousand pounds, as it is said they did; as also that his plantations cost twice as much.

14. Sir Robert Clayton has great plantations at Marden in Surrey, in a soil not very benign 


\section{Gleanings in Old Garden Literature.}

to plants, but with great charge he forces Nature to obey him. His gardens are big enough, but strangely irregular, his chief walk not being level, but rising in the middle and falling much more at one end than the other; neither is the wall carried by a line either on the top or sides, but runs like an ordinary park wall, built as the ground goes. He built a good greenhouse, but set it so that the hills in winter keep the sun from it, so that they place their greens in a house on higher ground not built for that purpose. His dwelling-house stands very low, surrounded with great hills; and yet they have no water but what is forced from a deep well into a waterhouse, whence they are furnished by pipes at pleasure.

15. The Archbishop of Canter-bury's garden at Lambeth has little in it but walks, the late archbishop not delighting in one, but they are now making them better; and they have already made a greenhouse, one of the finest and costliest about the town. It is of three rooms, the middle having a stove under it; the foresides of the rooms are almost all glass, the roof covered with lead, the whole part (to adorn the building) rising gravel-wise higher than the rest; but it is placed so near Lambeth church, that the sun shines most on it in 
winter after eleven o'clock; a fault owned by the gardener, but not thought on by the contrivers. Most of the greens are oranges and lemons, which have very large ripe fruit on them.

16. Dr. Uvedale of Enfield is a great lover of plants, and having an extraordinary art in managing them, is become master of the greatest and choicest collection of exotic greens that is perhaps any where in this land. His greens take up six or seven houses or roomsteads. His orange trees and largest myrtles fill up his biggest house, and another house is filled with myrtles of a less size, and these more nice and curious plants, that need closer keeping, are in warmer rooms, and some of them stoved when he thinks fit. His flowers. are choice, his stock numerous, and his culture of them very methodical and curious; but, to. speak of the garden in the whole, it does not lie fine to please the eye, his delight and care lying more in the ordering particular plants, than in the pleasing view and form of his garden.

17. Dr. Tillotson's garden near Endfield is a pleasureable place for walks, and some good walls there are too; but the tall aspin trees, and the many ponds in the heart of it, are not 
so agreeable. He has two houses for greens, but had few in them, all the best being removed to Lambeth. The house is moated about.

I8. Mr. Evelyn has a pleasant villa at Deptford, a fine garden for walks and hedges (especially his holly one, which he writes of in his Sylva), and a pretty little greenhouse, with an indifferent stock in it. In his garden he has four large round philareas, smooth clipped, raised on a single stalk from the ground, a fashion now much used. Part of his garden is very woody and shady for walking; but his garden, not being walled, has little of the best fruits.

19. Mr. Watt's house and garden made near Endfield are new; but the garden for the time is very fine, and large and regularly laid out, with a fair fish-pond in the middle. He built a greenhouse this summer with three rooms (somewhat like the archbishop of Canterbury's), the middle with a stove under it, and a sky-light above, and both of them of glass on the foreside, with shutters within, and the roof finely covered with Irish slate. But this fine house is under the same great fault with three before (Numbers 8, 14, 15): they built it in summer, and thought not of winter; the dwelling house on the South side interpos- 
ing betwixt the sun and it now when its beams should refresh plants.

20. Brompton Park garden, belonging to Mr. London and Mr. Wise, has a large long greenhouse, the front all glass and board, the North side brick. Here the King's greens, which were in summer at Kensington, are placed, but they take but little room in comparison of their own. Their garden is chiefly a nursery for all sorts of plants, of which they are very full.

21. Mr. Raynton's garden at Endfield is observable for nothing but his greenhouse, which he has had for many years. His orange, lemon, and myrtle trees, are as full and furnished as any in cases. He has a myrtle cut in shape of a chaire, that is at least six feet high from the case, but the lower part is thin of leaves. The rest of the garden is very ordinary, and on the outside of his garden he has a warren, which makes the ground about his seat lye rudely, and sometimes the coneys work under the walli into the garden.

22. Mr. Richardson at East Barnet has a pretty garden, with fine walks and good flowers; but the garden not being walled about they have less summer fruit, yet are, therefore, the more industrious in managing 
the peach and apricot dwarf standards, which, they say, supply them plentifully with very good fruit. There is a very good fish-pond in the middle of it, from which a broad gravel walk leads to the highway, where a fair pair of broad gates, with a narrower on either side, open at the top to look through small bars, well wrought and well painted, are a great ornament to the garden. They have orange and lemon trees; but the wife and son being the managers of the garden (the husband being gouty and not minding it), they cannot prevail for a house for them other than a barn end.

23. Captain Foster's garden at Lambeth has many curiosities in it. His greenhouse is full of fresh and flourishing plants, and before it is the finest striped holly hedge that perhaps is in England. He has many myrtles, not the greatest, but of the most fanciful shapes that are any where else. $\mathrm{He}$ has a framed walk of timber covered with vines, which, with others, running on most of his walls without prejudice to his lower trees, yield him a deal of wine. Of flowers he has good choice, and his Virginia and other birds in a great variety, with his glass hive, add much to the pleasure of his garden. 
24. Monsieur Anthony Vesprit has a little garden of very choice things. His greenhouse has no very great number of plants, but what he has are of the best sort, and very well ordered. His oranges and lemons (fruit and tree) are extraordinary fair, and for lentiscus's and Roman bayes he has choice above others.

25. Ricketts, at Hoxton, has a large ground, and abundantly stocked with all manner of flowers, fruit-trees, and other garden plants, with lime trees, which are now much planted; and, for a sale garden, he has a very good greenhouse, and well filled with fresh greens, besides which he has another room very full of greens in pots. He has a greater stock of Assyrian thyme than any body else; for, besides many pots of it, he has beds abroad, with plenty of roots, which they cover with mats and straw in winter. He sells his things with the dearest, and, not taking due care to have his plants prove well, he is supposed to have lost much of his custom.

26. Pearson has not near so large a ground as Ricketts (on whom he almost joins), and therefore he has not so many trees, but of flowers he has great choice, and of anemonies he avers he has the best about London, and sells them only to gentlemen. $\mathrm{He}$ has no 
greenhouse, yet has abundance of myrtles and striped philareas, with oranges and other greens, which he keeps safe enough under sheds, sunk a foot within ground, and covered with straw. He has abundance of cypresses, which, at three feet high, he sells for four pence apiece to those that take any number. $\mathrm{He}$ is moderate in his prices, and accounted very honest in his dealing, which gets him much chapmanry.

27. Darby, at Hoxton, has but a little garden, but is master of several curious greens that other sale-gardeners want, and which he saves from cold and winter weather in greenhouses of his own making. His Fritalaria Crassa (a green) had a flower on it of the breadth of a half crown, like an embroidered star, of several colours; I saw not the like any where, no, not at Dr. Uvedale's, though he has the same plant. He raises many striped hollies by inoculation, though Captain Foster grafts them as we do apple trees. He is very curious in propagating greens, but is dear with them. He has a folio paper book in which he has pasted the leaves and flowers of almost all manner of plants, which make a pretty show, and are more instructive than any cuts in herbals. 
28. Clements, at Mile-end, has no bigger a garden than Darby, but has more greens, yet not of such curious sorts. He keeps them in a greenhouse made with a light charge. $\mathrm{He}$ has vines in many places about old trees, which they wind about. He made wine this year of his white Muscadine, and white Frontinac, better I thought than any French white wine. He keeps a shop of seeds and plants in pots next the street.

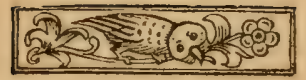





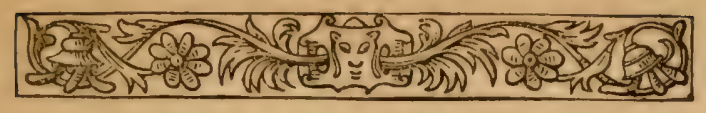

\section{N DEX.}

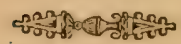

Abercrombie (John), 167, I68.

Africa, I33.

Alcinous, 188 .

Ale (alla), I36.

Alexander, a romance, 76 .

Alleȳn (Edward), I20.

America, 122, 123, 147, 168, 238.

Anglo-Saxon culture of the vine, I3I.

Anne (Queen), I7 I.

Antiquities of gardening, literary, II et seqq.

Apothecaries' Company, 5o.

A pothecaries, ignorance of early, 47,48 .

Apple-garth, 56 .

— tart, I44.

- wine $=$ cyder, 56 .

Apples, 86.

- seliers of, I 16 .

Aprons, blue, 9.

Arable and pasture, I78.

Arboretum at Paddington, I 76 . 
Arbours, 72-5.

Arboyse grape, the, 185 .

Argyll (Archibald, Duke of), 199.

Arlington Garden, 228.

Arrack, I33.

Artichokes, 36, I 18.

Ash-yard for hop-poles, 55 .

Asparagus, 36, I 23, 124, 169, I70, 177 .

- wild, I23,.124.

Astrology, 11, 12.

Athens, 5 .

Auricula, 9.

Austen (Ralph), 29, 30.

Australia, South, 94 .

Babylon, 5 .

Bacon (Francis), 3, 25-9, 45, 60, 83, 90-Ir4, I37,

I39, 147, I48, 182, 186-9.

Barnes, Surrey, 23, I8r.

Barnet, East, 237.

Barrels, plants transported in, 40.

Battersea, 177, I78, 18r.

Beaumont and Fletcher, I4r.

Beddington, 67, 68, 226, 227, 230.

Bedford (John Russell, Duke of), 69-7r.

Bedford (Lucy, Countess of), 186, I92-4,

Bedford House, Bloomsbury, 200.

Bee-culture, 53, I30.

Beer, 36, 135-7.

Bees, list of works on, 212, 213. 


\section{Index.}

Bekker's Charicles and Gallus, 6.

Berries (gooseberries, etc.), 123.

Berry tribe prosperous northward, 43 .

Bethnal Green, 177.

Bible, 3 .

Bibliography of Gardening Literature, $203 \cdots$ I I.

Billingsgate, 133 .

Birch, 159.

Blackwell (Mr. and Mrs.), 5 I.

Bohn (H. G.), 2 I 5, 223.

Bradbury (IIenry), 224.

Bradshaw (Jeffrey), of Bradford, I28.

Brailsford (Mr.), his paper on Ancient Trees, I59.

Bramshill, 49.

Brathwaite (Richard), 30.

Breton (Nicholas), 86-8 et passim.

Brewing, 135-7.

Bridgman, Kent, and Capability Brown, I9I, I94202.

Brigs (Mr. S.), I 50.

Bristol, 123.

Britons, 4, 5 .

Brompton Park, I71, 237.

Brompton, Old, 19, 132, I75-7.

Broom, Spanish, 165.

Brown (Capability), rgr.

Browne (William), A.M., 50.

Browne's Shepherd's Pipe, 49.

Buckingham Palace, 148.

Bulbs, importation of, 44,45 . 
Bunyan (John), 8.

Burgundy grape, 185 .

Burleigh, Lord Exeter's seat, 24, 127, 128.

Busino, Orazio, 24, 127, I28.

Cabbages, 177 .

Cæsar, 5.

Campden House, Kensington, I 32.

Capell (Sir Henry), 230, 23 I.

Caper tree, $\mathbf{1 3 2 .}$

Carews, 67, 68, 227.

Carrot, i 12, I 13 .

Catalogues of gardens, early, 68.

Camberwell, i\&o.

Cameron (Commander), I33.

Canker, the, 157 .

Castelvetri (Giacomo), I69.

Caus (Isaac de), 16, I56.

Cedars at Chelsea, 50.

Celsa (mulberries?), 59.

Charles I., 35.

Charles II., I29.

Chatsworth, 218 .

Chelsea, 24, 50, 84, I49.

- Physic Garden at, 24, 50, 51, 227, 22 S.

Cherries, 64, 137, 143, 185 .

Cherry, double flowering, I65.

Cherry-fairs, I43.

Chestnut, horse, 158 . 


\section{Index.}

Chestnut, sweet, 158 .

Cheyne Walk, Chelsea, 149.

Child (Sir Josiah), 233.

Chiswick, 181, 229, 232.

Citrons, I5I, 152 .

Claremont, 200.

Clay used in grafting, 83 .

Clements of Mile-End, 24I.

Coaches, hackney and stage, 180.

Cobham, gardens at, $\mathbf{} 6$.

Coleridge (S. T.), I.

Colour changed by grafting and other processes, 83 ,

IOg.

of fruit, 137 .

Columella, 14.

Coney-garth, 55 .

Conservatories; $51,83,84$.

Cooke (Sir Thomas), 232.

Cookery, 8.

Cottage-gardens, 8r, 82.

Cowdray Park, Midhurst, 158.

Cromwell House, Old Brompton, I76.

Cromwell (Oliver), 3, I 76.

Cryptogamic flora of Scotland, 216.

Crystal Palace, 218.

Culloden sword-blades, 19.

Curiosities or subtleties, $82,88,89$, 108-10.

Curtis (Samuel and William), 213, 214.

Curtis's Botanical Garden at Brompton, 175 .

Cyder, 56, 130, 133, 134. 
Deptford, I $8 \mathbf{r}$.

Dethicke (Henry), 15.

Devonshire (Duke of), 2 I8.

Diamond (Dr.), I7.

Distillation, $132-7$.

Dixon (Hepworth), 18.

Dodoens (Rembert), 47.

Donne (Dr.), 186.

Dormer (General), 198.

Dulwich College, I20.

Dunmow, Prior of, I40.

Durham (Joseph), I8.

Dutch asparagus, 123.

- gardens in England, 44.

- school, I9-21, 44, 45, I 73, 174 .

Eagle, 60.

Eden, garden of, 3, r88, I8g.

Edward I., 58.

Elder, embroidered, 89 .

Eleanor of Castile, 58.

Elizabeth (Queen), 45, 47.

Ely House, I38.

Enclosures and parterres, 153.

Enfield, 234, 236, 237.

Englefield (Sir Henry), 20 I.

Esher, 200.

Espaliers, I55.

Essex, 131, I52.

Essex House, I29. 


\section{Index.}

Evelyn (John), 2, 7-9, 24: 25, 30-3, 37-40, 50, $51,60,67,68,82$, I 16, I 1 7, 124, 129, 130, 146, 165, 171, 236.

Fauconbergh's (Lord) garden at Sutton Court, 229

Felton (Samuel), 16, I7.

Figs, 184 .

Finkel, 133 .

Fontainebleau, I84.

Foote (Samuel), 35, 36.

Forbes (James), 69-7 I.

Forest-trees, 159 .

Forster (John), of Hanlop, I22.

Forsyth (W.), 157 .

Foster (Captain), 238, 240.

Fox (Sir Stephen), 232.

French Gardener, The, 30-37.

- grapes, 185 .

- horticulture, I9, 59 .

- wines, 129.

Fritalaria Crassa, 240.

Frontignac grapes, 185 .

Fruits, 57, I16, I6I.

— lists of, in 1658 .

- - in Scotland, 43.

Fruit-trees, 127 et seqq.

Fulham, 19, 149, 177, 180, 200.

Fuller (Thomas), I77, $\mathbf{7} 78$.

Garden, 55 . 
Garden houses, 75 .

- life, $72-7$.

- the ancient English, 5.

Gardeners, eminent, 65 .

_- farming, 180 .

Gardens near London in r6gr, 6i -8, 225-4r.

- public and royal, 60 et seqq.

Gardiner (Richard, of Shrewsbury), I I I-I4.

Garth, 55.

Gascony, I84.

Genoa, I2r.

George III., 157 .

Gelder-rose, I66.

Gerard (John), 68, I I8, I20, I39.

Gibson's Account of the Gardens near London in I69I, 66-8, 225-4I.

Gillyflower, 2, 56, 79 .

Glamorganshire, 88 .

Glasse (Mrs.), 8, 9.

Gloucester (Duke of), 138.

Goffe (Nicholas), I47.

Goldsmith's Vicar of Wakefield, 58.

Gorse, I63.

Gower (John), I43.

Grafting, 12, 19, 82, 83, 102, 103.

Grafts, 6 r.

Grapes, 24, I27, I28, 132, I 84 .

- branch of, $\mathbf{I} 32$.

Gray and Wear, nurserymen, I7I.

Gray's Inn, I Io. 


\section{Index.}

Greek horticulture, 6 .

Greenhouses, 5I, 83, 84 .

Greenwich, 6r.

Gresham (Sir Thomas), 58.

Greville (P. K.), 210-17.

Grizzelin Frontignac grape, the, I85.

Grottoes, 76.

Gubbins, IIerts, 195 .

$H a, H a$ hedge, 195 .

Hackney, 49, 232.

IIagecius or Hajck (T.), 36, I35-7.

Hagley, I89, 192.

Hammersmith, Queen Dowager's garden at, 226.

Hampton Court, I4, I3I, 225, 226.

Harris (Walter), 44 .

Harrison's Description of England, 22.

Hawkins (Sir John), 17.

Hazlitt (William), 8r, 82.

Heat, artificial, $26,35,83-5,236$.

Heating apparatus, $83-5$.

Henrietta Maria, 62.

Henry VI. I52.

- VII., 6I, I 37, I45, I55.

- VIII., 6I, I40.

Henshaw (Thomas), 30.

Herbals, 46-8, 51, 52 .

- list of, $211,212$.

Herbarists at Norwich, Society of, 150. 
Herbert (Philip), Earl of Pembroke and Montgomery, I6.

Herbs, kitchen, I 5: I I 5 .

- medicinal, 52 .

- price of, $6 \mathbf{I}$.

Herculaneum, 188.

Herefordshire, orchards of, 135 .

Hertfordshire, 186 , $192-5$.

Hesiod, 6.

Hill (Thomas), 13-5, I30.

Hindberry, or wild raspberry, 137 .

Holborn, 68, I20, I38, I43.

Holland, 44, 123, 124, 178.

Holly, variegated, 88 .

Honey, 53.

Hooke's Micrographia, 160.

Hookers, the, 65, 7 I, 223.

Hop-poles, 22, 23.

Hop-yards, 22, 23.

Hops, 22, 23.

Hortus siccus, 240.

Hot-beds, 83 .

Hoxton, 239, 240.

Hughes (W.), I29, I30.

Hyacinth, the, 45 .

Ilford, Essex, 131 .

India, $\mathbf{1} 46$.

Ingestry House, Old Brompton, I 76.

Ingleby (Dr.), I 3 I. 


\section{Index.}

Ireland, 121, I22.

Italian figs, I84.

Jam, 37.

James I., I 47 .

Jardin, 55,

Jargonelles, 2.

Jeaffreson, Cordy, I8.

Jessamine, I65.

Johannes de Garlandia, 59, 60, 68, 161 .

John the Gardener, $\mathbf{I I .}$

Johnson (Dr.), 8, 60.

Johnson, Thomas, the botanist, 205.

Jucca or Yucca, 165.

Jugglers in London, 106-8.

Kennett's Parochial Antiquities, 49, I 56.

Kensington, 19, I74, I75.

- Gardens, 226, 237 .

Kent, I79.

Kent the gardener, I9I, I94-202.

Kew, 230, 231.

Gardens, 65 .

Kirke's Nursery, I32, I 75, 176.

Kitchen-garden, the, 54 et seqq.

Lamb (Charles), I, 2, 42.

Lambert (General), 2, 3 .

Lambeth, 238. 
Lambeth Palace garden, 234.

La Serre (Olivier de), 147.

Lee (John), nurseryman, I74.

Leek, 55,56 .

Lemon, 26.

_ juice used for scurvy, 125 .

Lemons, preserved, $\mathbf{5} \mathbf{5}$.

Le Nautre, I93.

Leprosy, $\mathbf{1 2 5}$.

Lincoln (Earl of), I38, I43.

Lincolnshire, I24.

Lindley (George and John), 215, 216.

Lindley (Dr. James), I28.

Lisle (Lord), I 3 I.

L'Obel (Matthieu de), 49.

London (George), I7r.

London (William), $\mathbf{I} 72$.

London and Wise, nurserymen, $17 \mathrm{I}-3, \mathrm{1} 94,208,237$.

London, Bishop of, his garden at Fulham, 200.

- environs, of, celebrated for vegetables, 24, II9, 169.

- street-life of, in Bacon's time, 106-8.

- window-gardening in early, 79, 80.

Longleat, 200.

Loudon (J. C.), 217-24. (Mrs.), 7, 220-3.

Low Countries, 185, 193.

Lucas (Joseph), 55, I 59.

Lysons, I 77-81.

Lyte (Henry), 47. 


\section{Index.}

Macer's Herbal, 46.

Main (James), 221.

Manure, Bacon's experiments with, $9 \mathbf{I}-5$.

- various kinds of, $9 I-5$.

Marden, Surrey, 233.

Market-gardens, I69 et seqq.

Mascall (Leonard), I9-2I.

Matthews (Mrs.), I.

Mazes, 14.

Mead or metheglin, I33.

Medlar, 145.

Melons, 34-6.

Middlemist's Cape Nursery, 176.

Midhurst, Sussex, 158.

Mile End, 24 I.

Miller's Dictionary, 220.

Milton (John), 189, 192.

Mint or aigre-douce, $\mathbf{1 6 2 .}$

Mitcham, 52 .

Montpelier Tea-gardens at Walworth, 81-2.

Moor Park, I86, 192-4.

More (Sir Thomas), 100.

Mortlake, I8I.

Mosses, 160.

Mowing, 85 .

Mulberry, 59, 147 .

Mulberry Garden, 148 .

Munster (Bishop of), his cherry orchard, I 85 .

Murray (Lord), 223.

Muscadine, $24 \mathrm{I}$. 
Muscat, black, 185 .

- or Frontignac grapes, 184 .

Mustard, 59.

Myrtle, 26, 227.

Names of flowers, etc., Saxon and Norman, 56.

Nature-printed Ferns and Sea-weeds, 224.

Nash's Mansions of the Olden Time, 49.

Neckam (Alexander), 56—8, 79.

Newbery's Dives Fragmaticus, 34.

Nidderdale, 159.

Nivernois (Duc de), 187 .

Nonsuch, 192.

Norway, 133.

Norwich, 150.

Nottingham, 172.

Nurserymen at Old Brompton, I75, I 76.

Occupations, gardening, 85-8.

Onion, I I 5, I16, 144 .

— seller, II6.

- Spanish, $\mathbf{r} \mathbf{1 6 .}$

Orange, 26, 57, 58, 230, 231.

Orange trees at Sheen, $185,230$.

at Kew, $23 \mathrm{I}$.

Orangery at Beddington, 67, 68, 227, 230.

Orchard, 54.

Oxford, 50.

Oxfordshire, 156. 


\section{Indcx.}

Paddington, 176.

Paris, 32, 59, 6 .

Passe (Crespin de) the eller and younger, 45 .

Pasture converted into plough-land, 178.

Paxton (Sir Joseph), 218.

Peach, 94, II6, I38, I42, I43, IS4.

flowering, 165 .

October, 142.

Pears, 2, .3I-3, I42, I 43 .

Warden, I40, I4I.

Pearson, a nurseryman at ILoxton, 239.

Peas, II 7, II8, I78, I79.

- buttered, 179 .

Parkinson (John), II 8 .

Parks, public, 63 .

Peppermint, 52.

Pepys (S.), 40.

Percy family, encouragement of gardening by, 219 .

Perry, I35.

Persica (peach ?), I43.

Petrus de Crescentiis, 7 .

Phønix, 60.

Physic gardens, 24, 48-52.

Pine apple, I44, I 45 .

Pines, kernels of, used instead of olives, 152.

Platt (Sir Hugh), 49.

Pollard's school at Old Brompton, 176 .

Pombe, I33.

Pome de orange, 58.

Pomegranate, 146. 
Pope (A.), 68, 198.

Porkington MS., 12.

Potato, the, $121-3, \mathbf{I} 33$.

- liquor distilled from, $\mathbf{r} 33$.

Pottle of strawberries, 62, 63, 139, 140.

Prejudices and errors of gardeners, 104, I05.

Promptuarium Parvulorum, 9.

Pruning, 43.

Quinby, I40, I4I.

Quince, 121, 143--5.

Raleigh (Sir Walter), I20, I28.

Randolph (Thomas), 62.

Ranelagh's (Lord) garden, 228.

Raspberry, 137, 138.

Raynton (Mr.), 237.

Reformation, I4I.

Rei Rustice Scriptores, 6, 7 .

Reid (John), 42, 43.

Removal of trees, 49.

Rhubarb, I50, I5I.

Ribston pippin, $\mathbf{1 5 7}$.

Rice, distillations from, 133 .

Richardson (Mr.), 237.

Ricketts of Hoxton, 239.

Rose (John), 129, I30.

Roses, I6 I, I66, 167.

Rousham, I9S. 
Saffron, 152.

Saffron-Walden, 152.

St. James's Palace, 129, I48.

St. Regle, pear of, $\mathrm{I}_{42}$.

St. Vincent, Abbey of, I9.

Sandwich (Earl of), letter of Evvelyn to, II6, II7, $124,146$.

Sandwich, Kent, I 79 .

Scotish cryptogamic flora, 216, 217 .

- horticulture, 42,43 .

Scurvy, 125.

Seeds and plants brought from America and the IV'st Indies, 24.

Seedsmen, fraudulent, in $1603,113$.

Shakespeare (W.), $\mathbf{I}_{3} 8-4 \mathbf{I}, \mathbf{1 6 6}, \mathbf{1} 88$.

Sheen, royal garden at, $6 \mathrm{I}$.

- Sir W. Temple's garden at, 64, I3 I, IS2-6.

Shepherd's Bush, I76.

Shropshire, I I I $-\mathbf{I}_{3}$.

Silk, manufacture of, 147 .

Silkworm, cultivation of the, 147 .

Simpson's at Billingsgate, 133 .

Sion House, 177.

Sir Cleges, a romance, 77.

Sloane (Sir Hans), 50.

Somerset, Duchess of, r29.

- House garden, 62, 63 . the Protector, 63 .

Southwell (Sir Robert), I22.

Sowerbys, the, 2I4, 215. 
Spanish influence, $5^{8}$.

- potato, 123 .

Squire of Low Degree, 72.

Stanley (James, Earl of Derby), 50.

Stephens (Philip), 50.

Stourhead, 190, 192.

Stoves, 51, 83, 84 .

Strand Inn, 63.

Strawberries, 29, 61, 62, I37-40, I70, I84, 185 .

Street life of London, early, I06-8.

Sugar, 53 .

Summer-houses, 75,76 .

Surrey, I7-19, 23, 81, S2, 144, 177, 178, 181, 233.

Sutton Court, Chiswick, 229.

Sweet (Robert), 2 r 7 .

Swift (Jonathan), 65, I83.

Sylva Sylvaram, Bacon's extracts from, 9I-III.

Tallard (Count), I72.

Tea-gardens at Walworth, 81, 82 .

Telephone, the, $\mathbf{r} 60$.

Temple (Sir John), 230.

- (Sir William), 2, 6, 64, 131, I82-6, IS9, 192-4, 230.

Tennyson's Talking Oak, I59.

Thames Street, Upper, I49.

Thatch or matting used for protecting plants, 83 .

Theobalds, 192.

Thornes (Edward), III, II2.

Thyme, Assyrian, 239. 


\section{Index.}

Tillotson (Archbishop), 235.

Tobacco, 49.

Tools, gardening, 153,154 .

Training of trees, $153, \mathbf{1} 55$.

Trees, ancient, $\mathbf{I} 59$.

- lists of, 140 et passim.

Tulips, 2, I6 I, 164 .

Turf, ancient, $\mathbf{1 8 .}$

Turner (William), 46-8, 53 .

Twickenham, 198.

- House, I7-ig.

Uvedale (Dr.), 235, 240.

Valentines, Ilford, I3I.

Variegation of foliage, 88, 89.

Varro, 6, I4.

Vauxhall, 133 .

Vegetable marrow, I76, I 77 .

Vegetables, 22, 34, 54 et seqq., I 77-8I.

- high prices of, in $1619,119,120$.

- salted, I 24.

- sanitary value of, 125 .

Venice, 49 note.

Venner (Dr.), I22.

Versailles, 193.

Verulam Buildings, I IO, II 1 .

Vesprit (M.), 239.

Vin ordinaire, $12 S$.

Vine, the, ral et seq?. 
Vines, 129-32.

Vintners' Hall, I49.

Virgil, 6.

Virginia, 122, $123,148$.

— birds of, 238 .

Wales, 56, 88, 122.

Walnut-trees at Wanstead, 233 .

Walpole (Horace), 2, 182, I86-202.

Walter de Biblesworth, 86, 163.

Walworth, 81, 82 .

Wandle river, I44.

Wanstead, 233.

Warden pear, 140, 141.

- pie, I40, 141 .

Water lily, 164.

Water pipes, 234.

Water pot, I 54 .

Watts (Mr.), 51, 236.

West Indian trees, 199.

West of England, I39.

Westminster, royal garden at, $1_{3} 8,1_{43}$.

Weston (Richard), 25.

Weymouth pine, the, 200.

Wheatley (H. B.), 63 .

White (Gilbert), I25.

William III., 65, I 7 I, I 83 .

Willow, 158 .

Wilton Garden, 16, 156.

Wimbledon, 2. 


$$
\text { Index. } \quad 263
$$

Window-gardening, 78-So.

Windsor pears, 2.

Wine, 127, 128, 131, 132.

Wines, French, 129.

- home-made, 127, I28, I 76, 24 I.

- prices of in 1524 and $1584,128,129$.

- sweet, 129.

Wise (Henry), I 7 I.

Withy, 158.

Woburn Abbey, 69-71.

Woodall (John), I25, 126.

Woolner (Richard, R.A.), I8.

Worlidge (John), 40-2, 80, 8r, 83, 88, 89, 122, I23, 130, $133-5,158,164,165$.

Yard $=$ garth, 55 .

Yorkshire, I24, I28.

Zouch (Lord), 48, 49. 



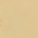






\section{LIBRARY OF CONGRESS}

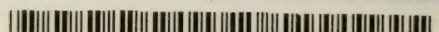

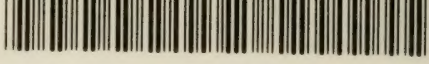

0000913489A 